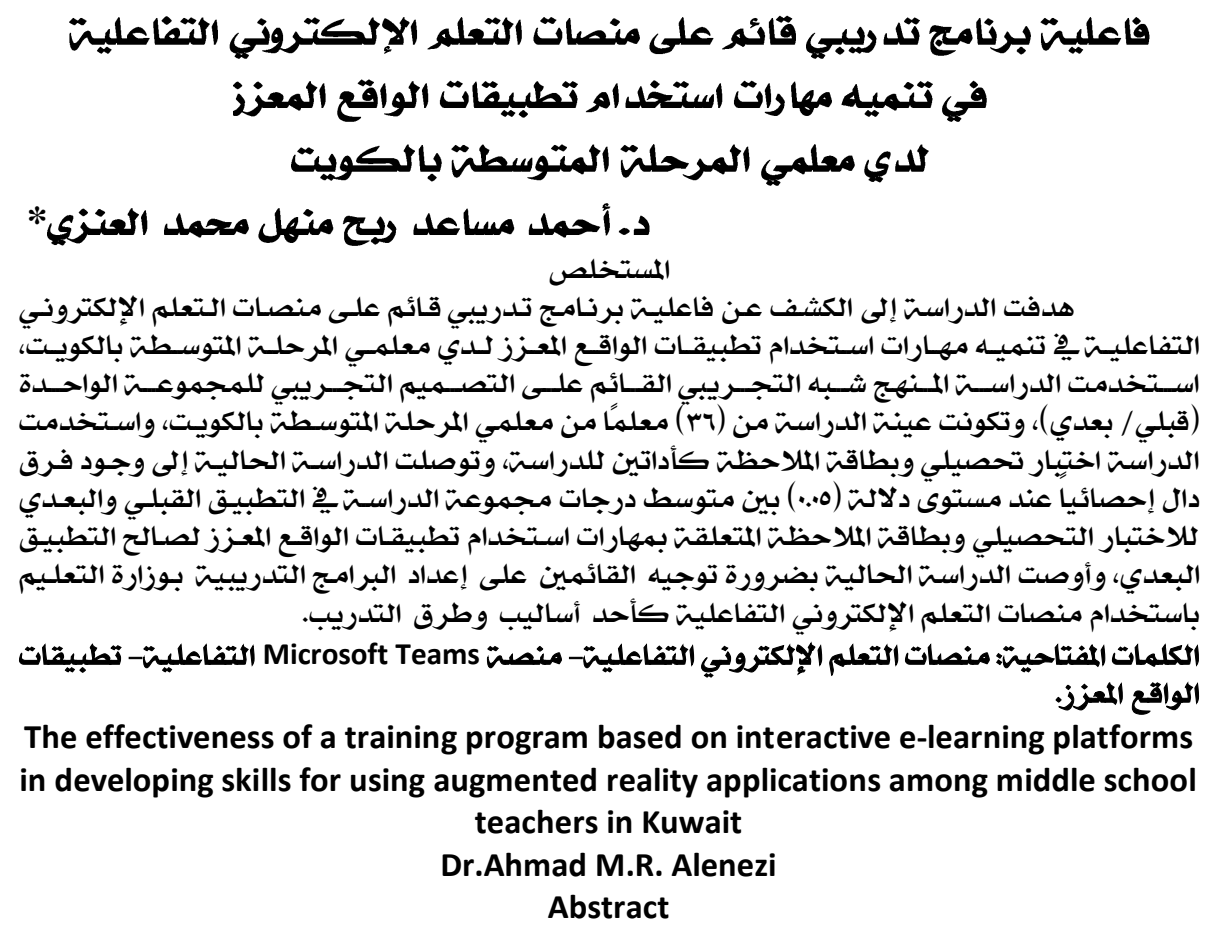

The effectiveness of a training program based on interactive e-learning platforms in developing skills for using augmented reality applications among middle school teachers in Kuwait

Dr.Ahmad M.R. Alenezi

Abstract

The study aimed to reveal the effectiveness of a training program based on interactive e-learning platforms in developing skills for using augmented reality applications among middle school teachers in Kuwait, The study used the semiexperimental approach based on the experimental design of one group (pre / post), The study sample consisted of (36) middle school teachers in Kuwait, The study used an achievement test and the observation card as two tools of the study, The current study found a statistically significant difference at a level of significance (0.05) between the average scores of the study group in the pre and post application of the achievement test and the observation card related to the skills of using augmented reality applications in favor of the post application, The current study recommended that those in charge of preparing training programs in the Ministry of Education should be directed to use interactive e-learning platforms as one of the training methods and methods.

Keywords: interactive e-learning platforms, Microsoft Teams interactive platform, augmented reality applications. 


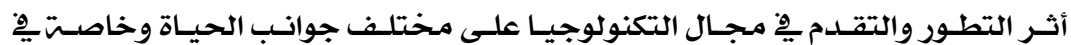

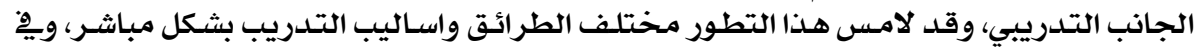

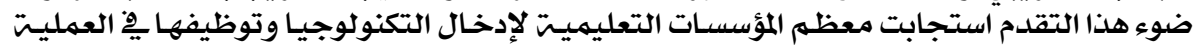

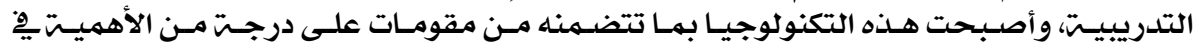

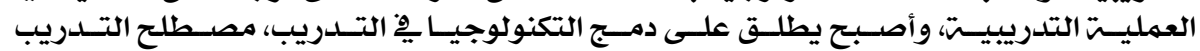

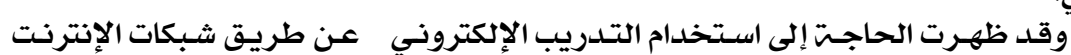
الإلكتروني.

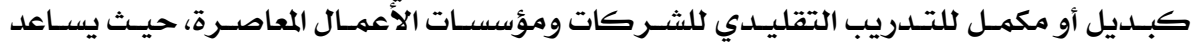

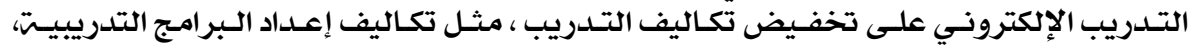

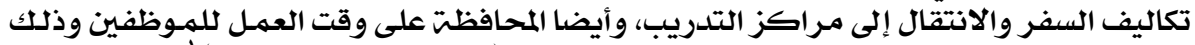

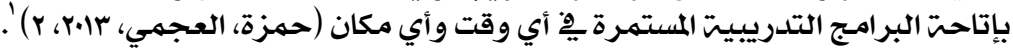

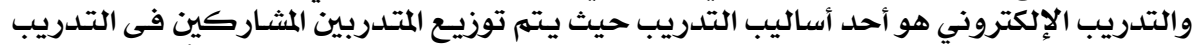

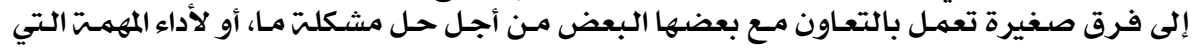

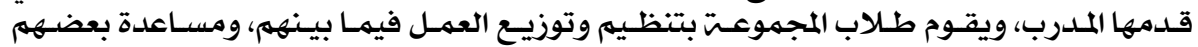

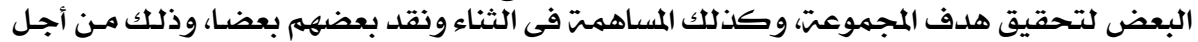

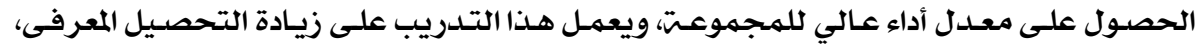
وتنميت المهارات الاجتماعيت وبناء فريق العمل (Khan, 2016).

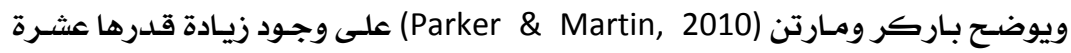

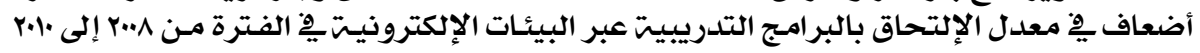

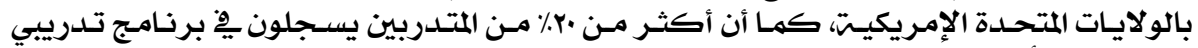

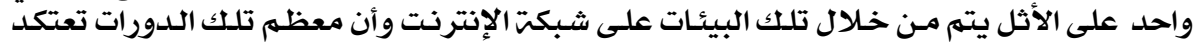

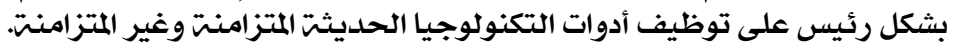

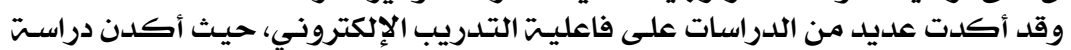

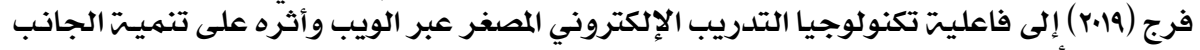

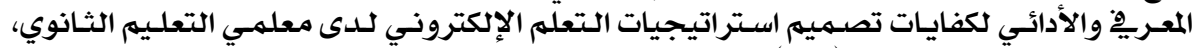

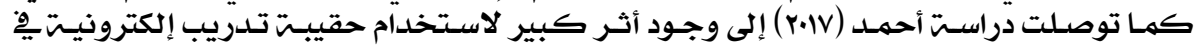

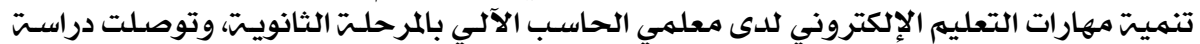

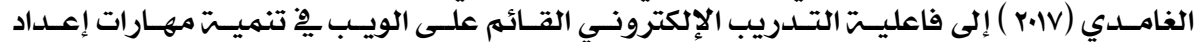

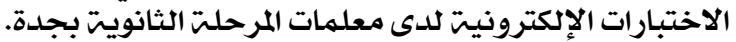

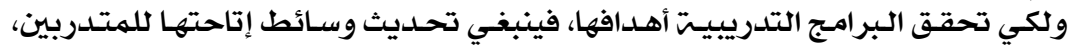

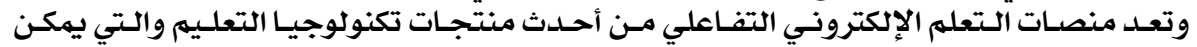

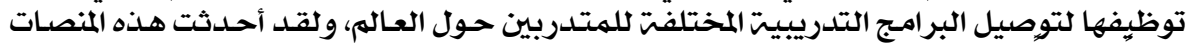

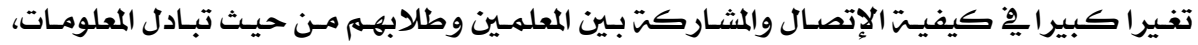

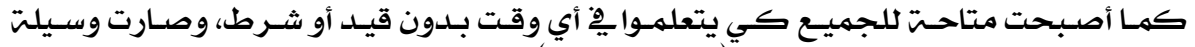

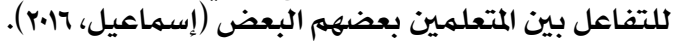

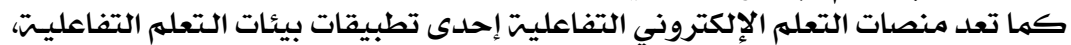

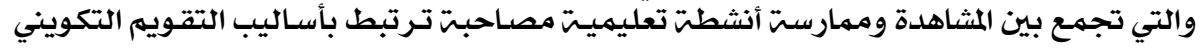

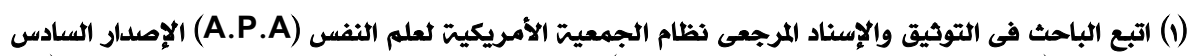

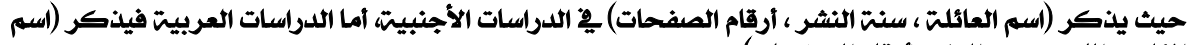
المؤلف وأللقب، سنت النشر، أرقام الصفحات). 


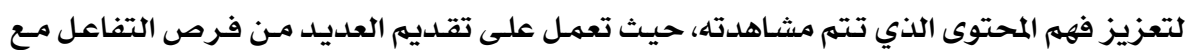
المحتوى عبر مهارست الأنشطت القائمت على الفعل (Stonebraker, Robertshaw \& Moss, 2016).

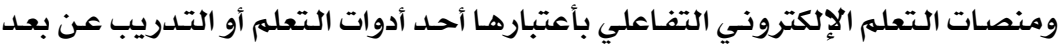

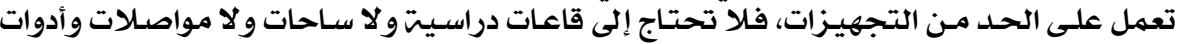

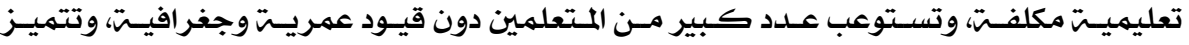

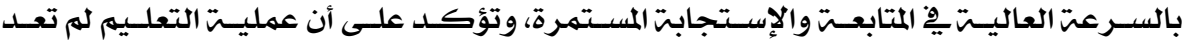

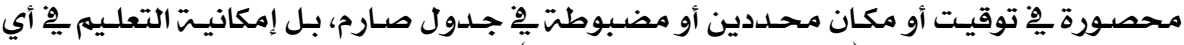

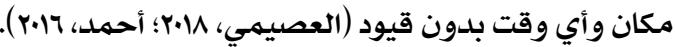

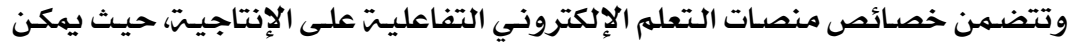

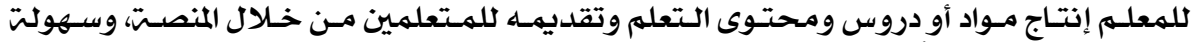

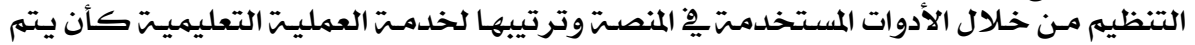

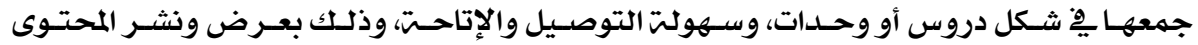

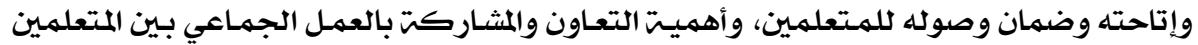

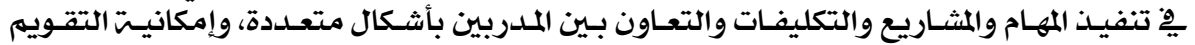

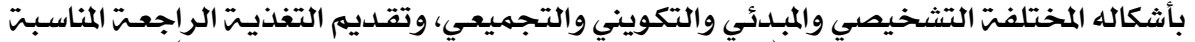

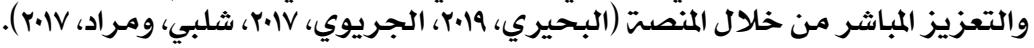

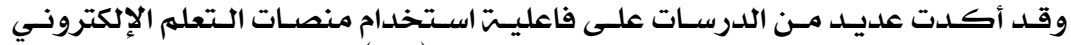

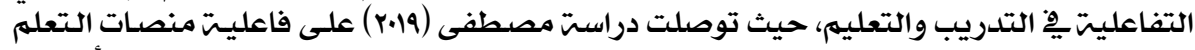

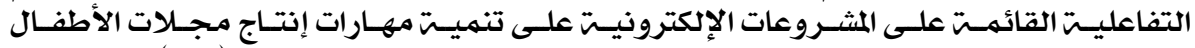

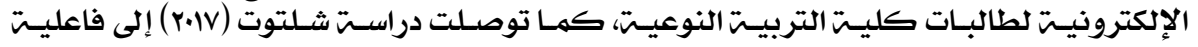

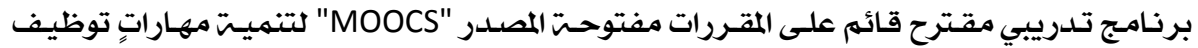

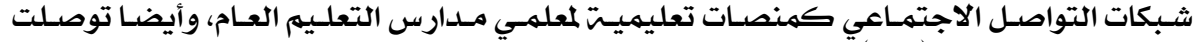

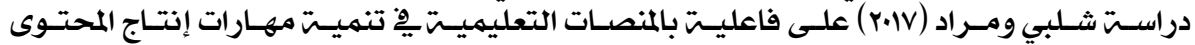

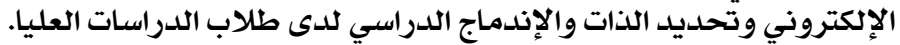

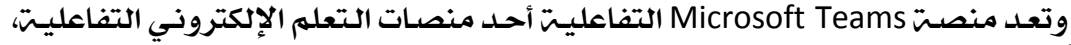

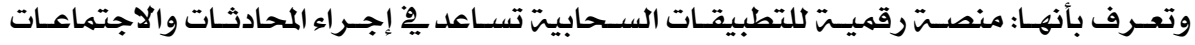

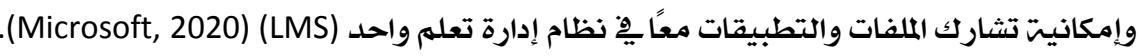

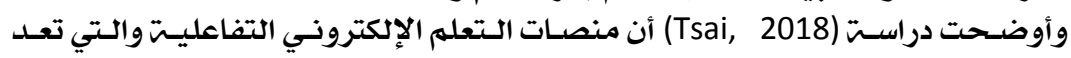

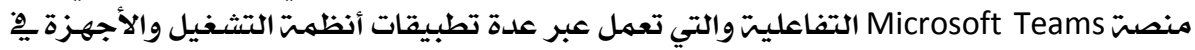

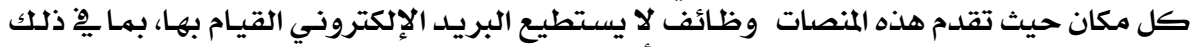

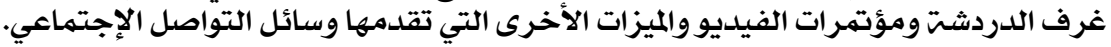

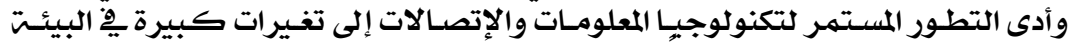

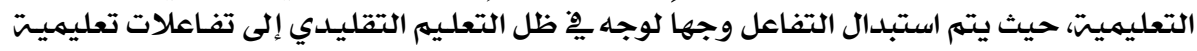

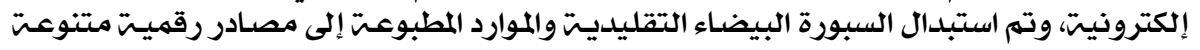

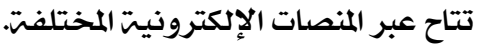

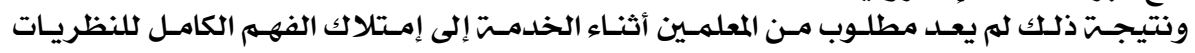

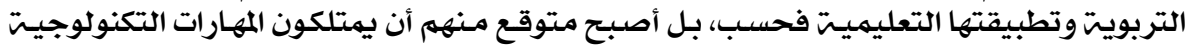

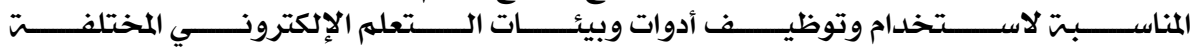

.(Tschida, Hodge\& Schmidt, 2016)

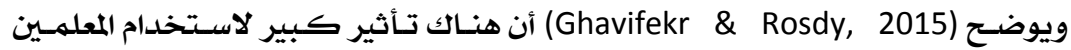

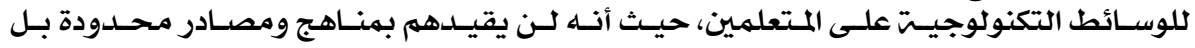




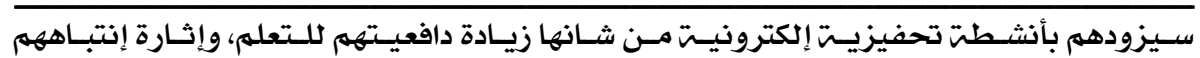

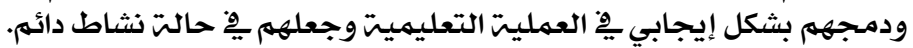

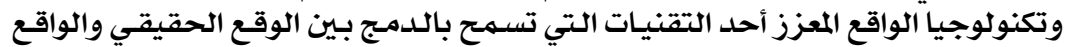

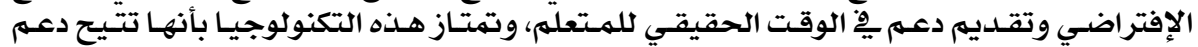

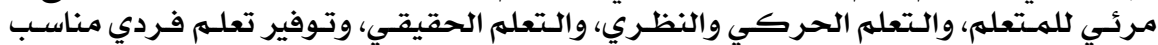

(Matcha \& Rambli, 2013)

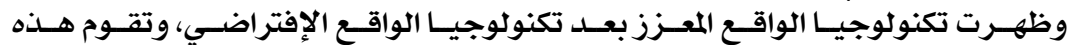

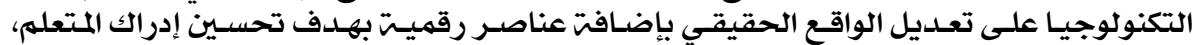

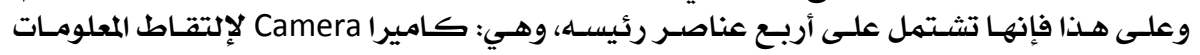

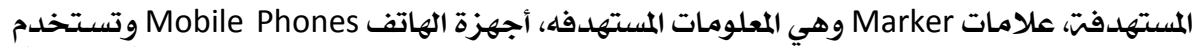

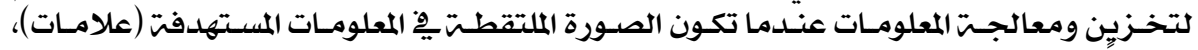

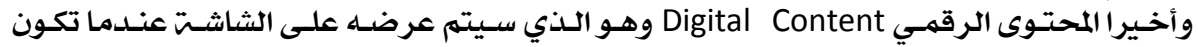

كاميرا الهاتف قادرة على تتبع العلامات (Abd Majid, Mohammed \& Sulaiman, 2015).

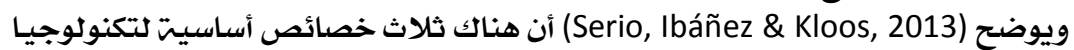

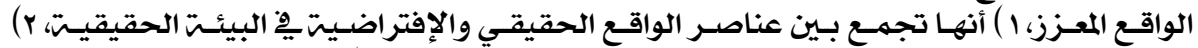

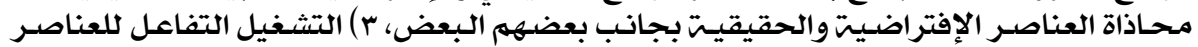

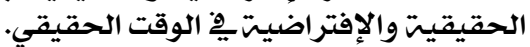

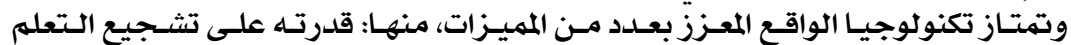

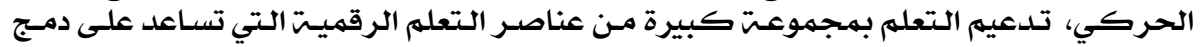

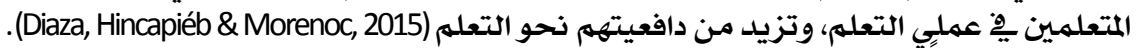

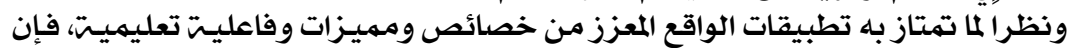

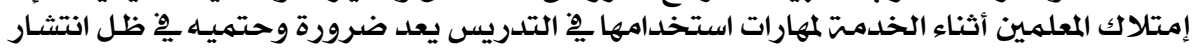

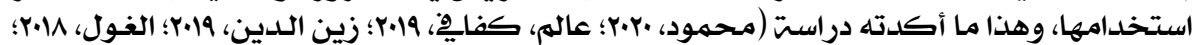

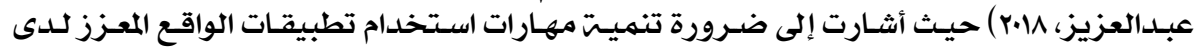

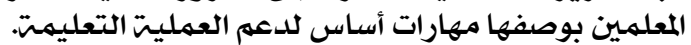

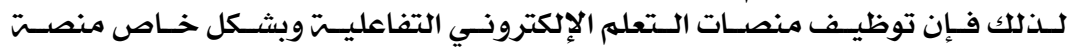

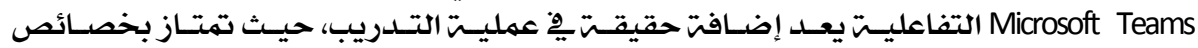

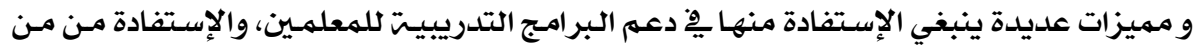

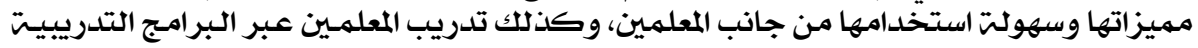

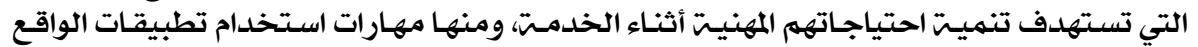

المعزز.

\section{مشكلثة اللدراست}

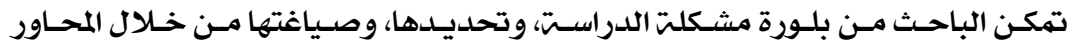
والإبعاد الآتيت: تصني:

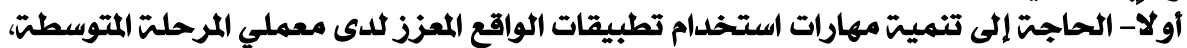

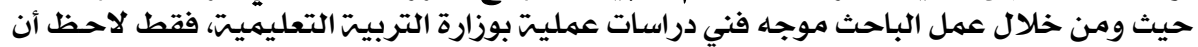

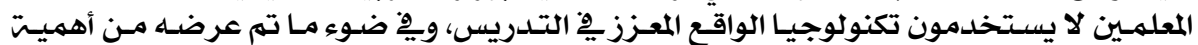

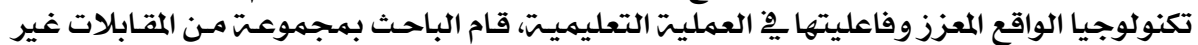

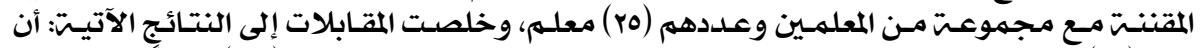

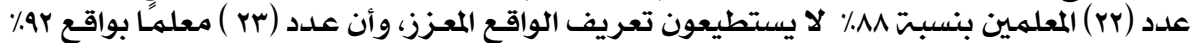

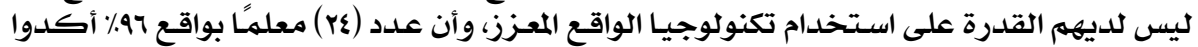

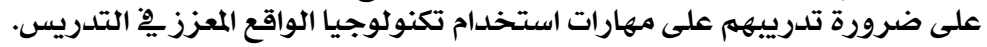




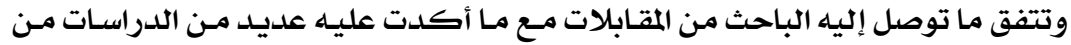

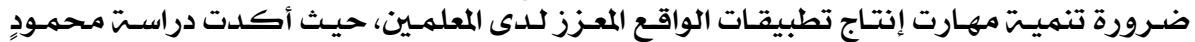

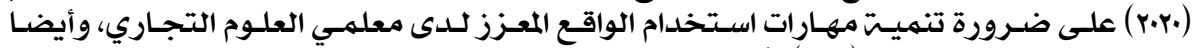

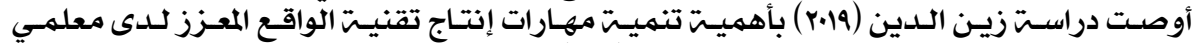

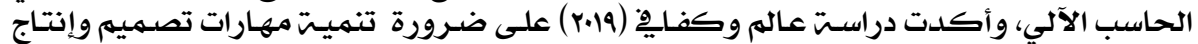

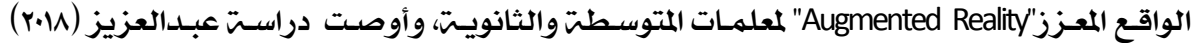

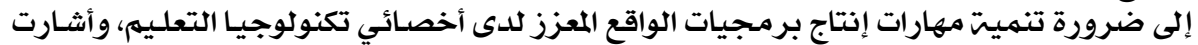

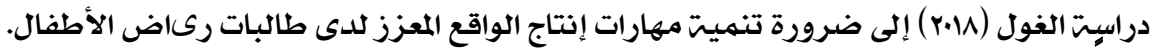

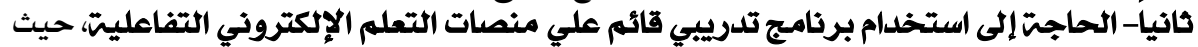

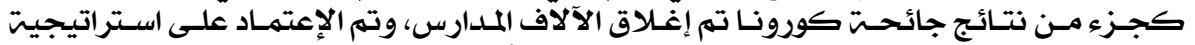

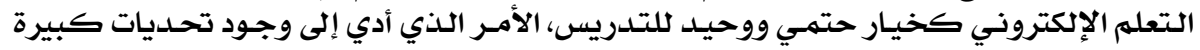

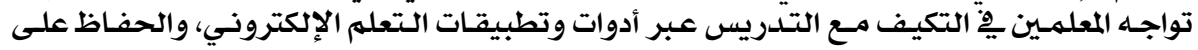

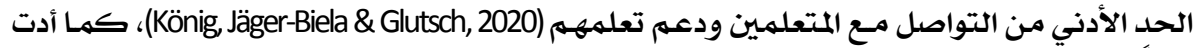

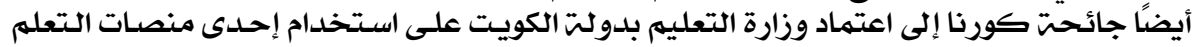

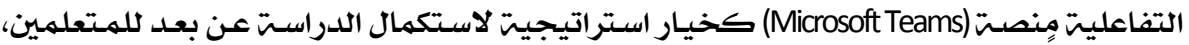

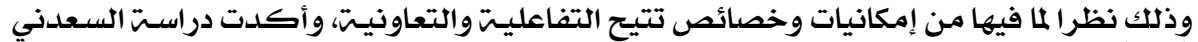

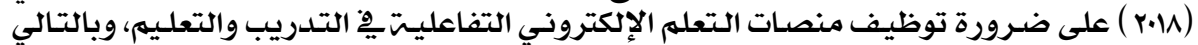

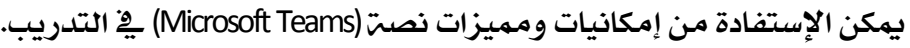

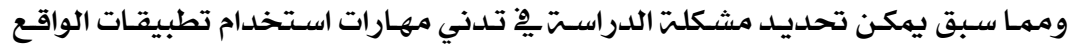

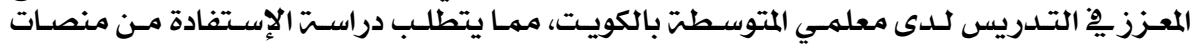

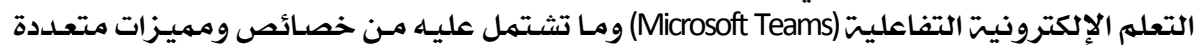

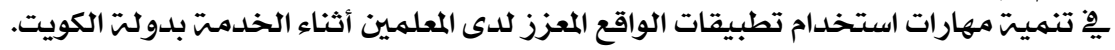

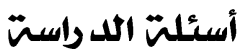

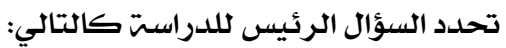

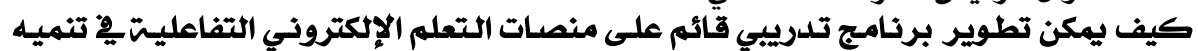

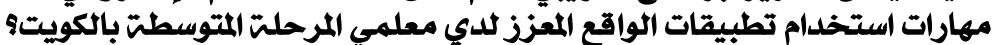

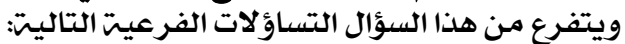

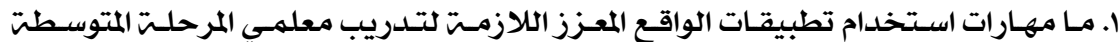
بالكويت عليهاء مارئخان

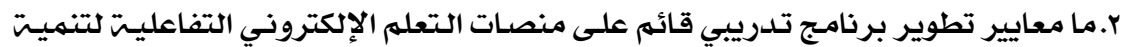

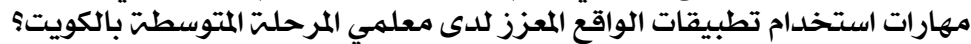

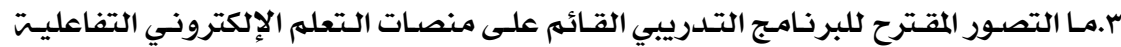

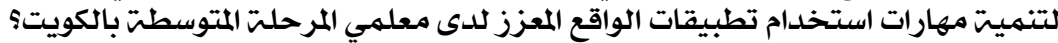

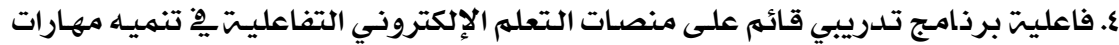

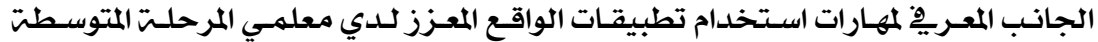
بالكويت؟ الجاني المعري

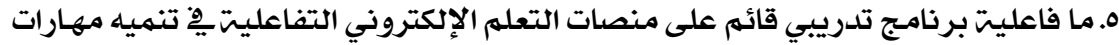

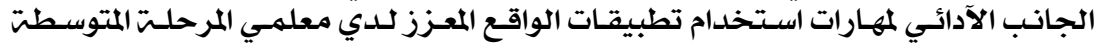

بالكويت؟ 
أهد اف الد راستَ

هدفت الدراست الحاليت إلى:

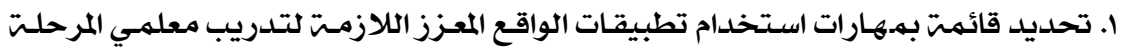

المتوسطت بالكويت عليها.

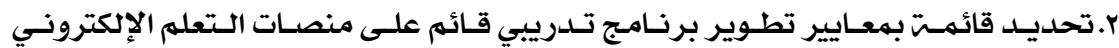

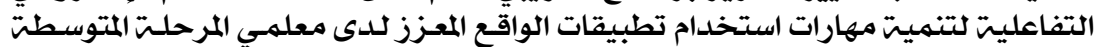
بالكويت.

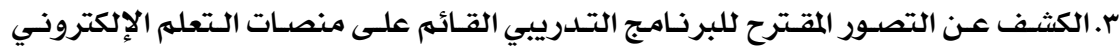

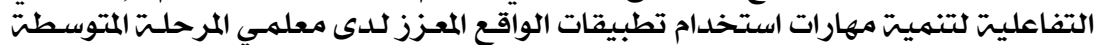

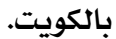

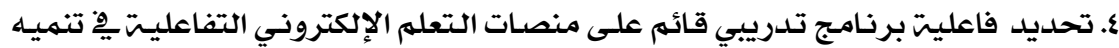

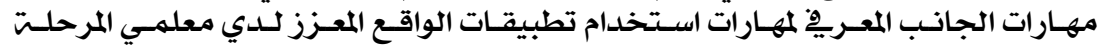

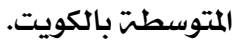

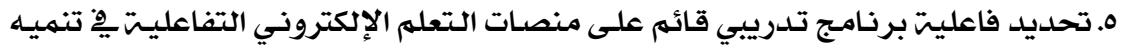

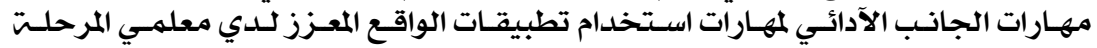

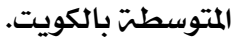

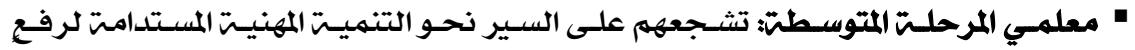

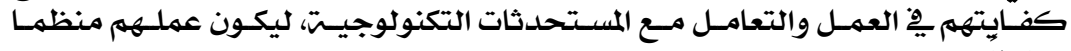
وهادفا.

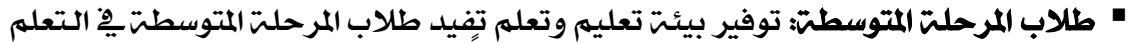

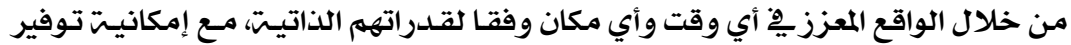
تغذيت فوريت لهم.

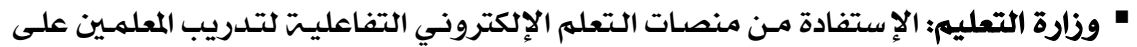

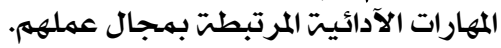

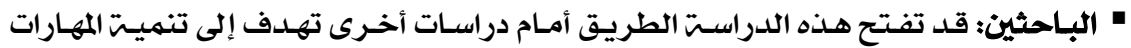

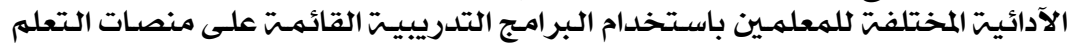
الإلكتروني التفاعليت. حلدود الد راست الحتر

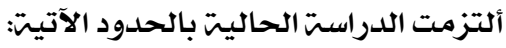

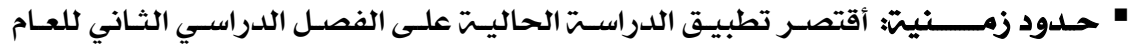

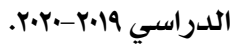

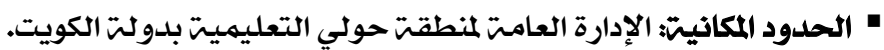

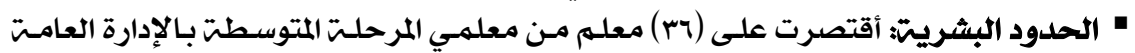

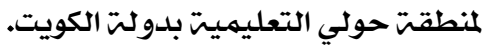
• الحدود الموضوعيتّ: مهارات استخدام برنامج (Ar) للواقع المعزز. 


\section{منهج الد راست ومتغيراتها:}

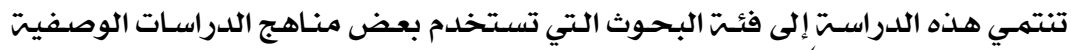

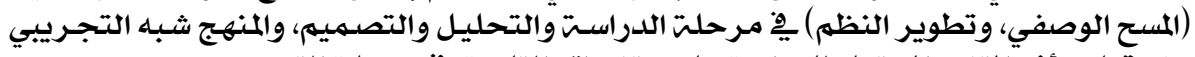

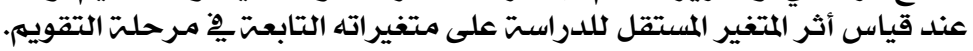

وتكونت متغيرات الدراست من:

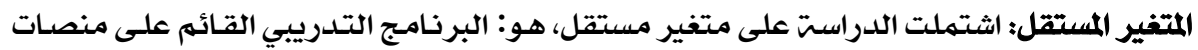

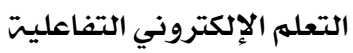

المتغيرات التابعت: اشتملت الدراست الحاليت على متغيران تابعان التهان هما:

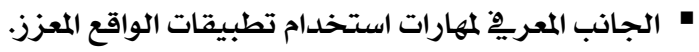

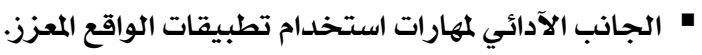

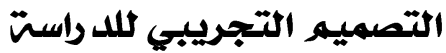

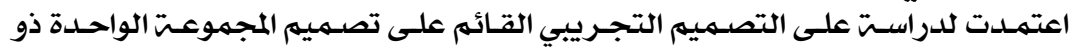

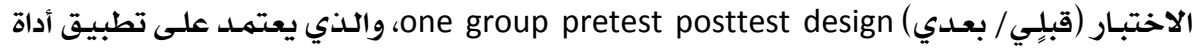

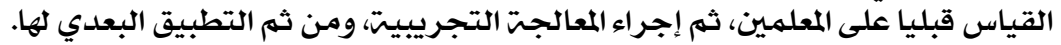

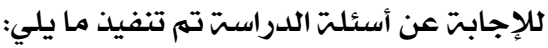

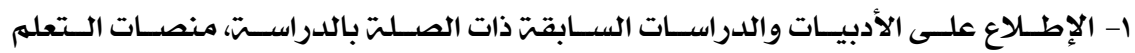

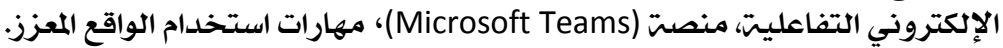

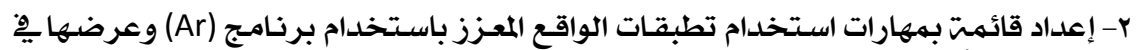

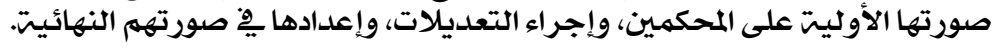

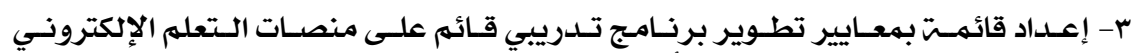

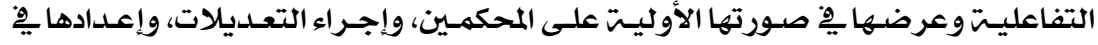
صورتهم النهائيت.

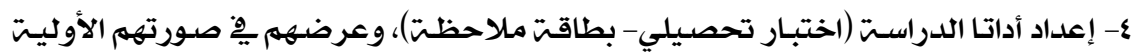

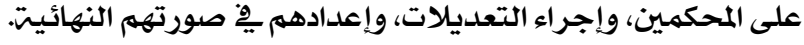
ه- إعـداد المحتـوى التـدريبي لعرضـه على منصست (Microsoft Teams)، واستـمارة التقـويم الخخاصده به. - المجتوى

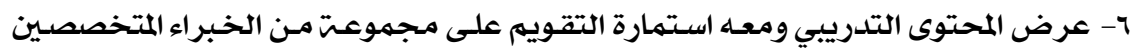

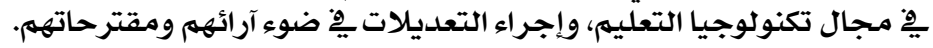

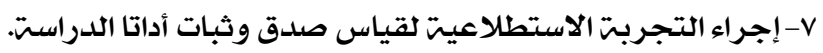
^- اختيار عينت الدراستة.

ه- تطبيق أداتا الدراستة قبلياً على مجموعت الدراستة الدراستة.

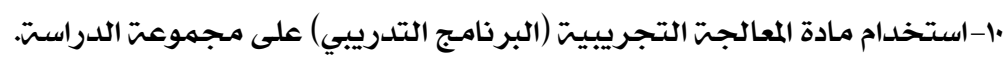


11-تطبيق أداتا الدراستة بعديًا على مجموعت الدراستة.

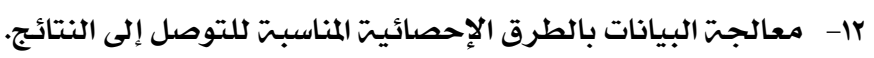
rا- تقديم التوصيات والمقترحات يْ ضوء ما أسفرت عنه نتائج الدراستة.

مصطلحات الد راست

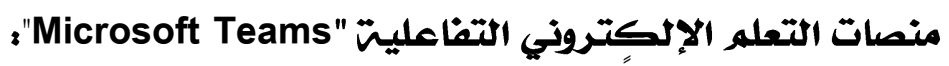

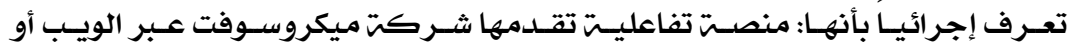

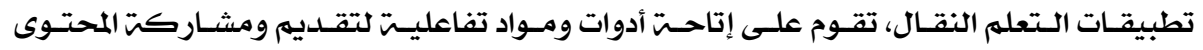

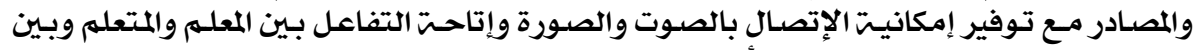

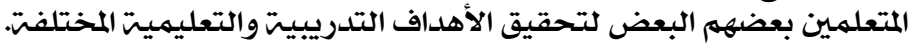

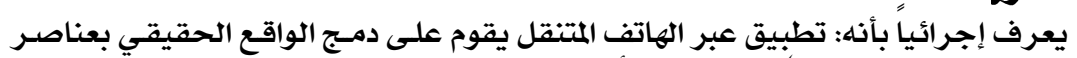

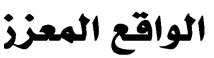

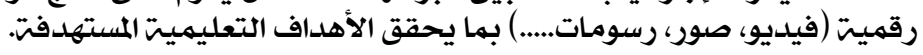

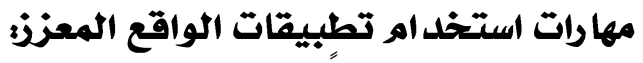

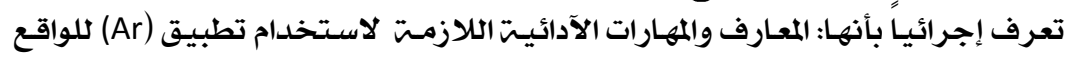

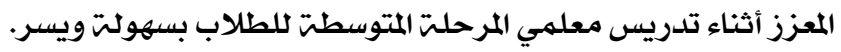

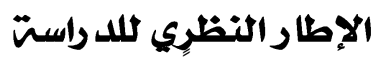

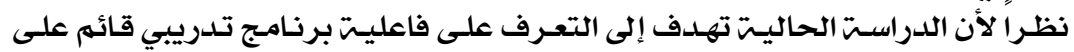

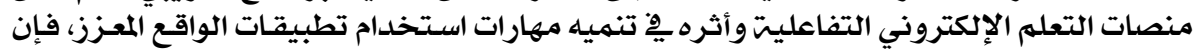

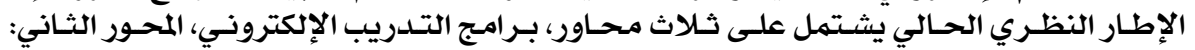

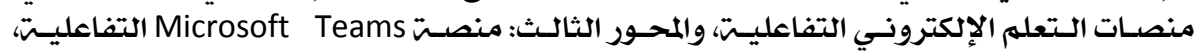

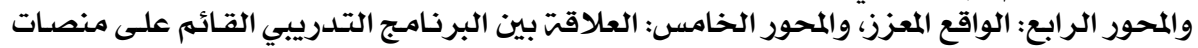

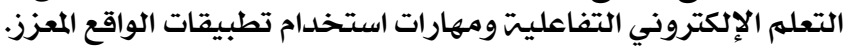

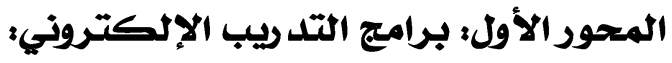

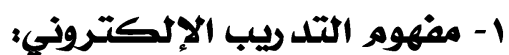

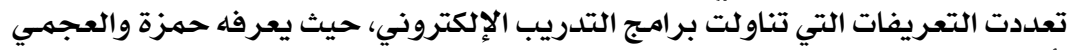

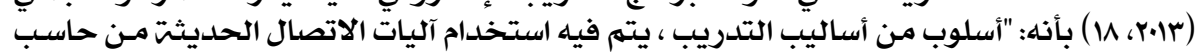

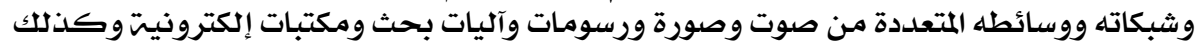

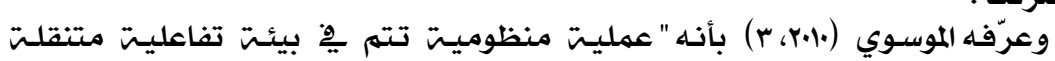

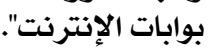

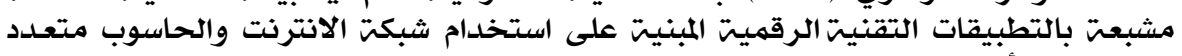

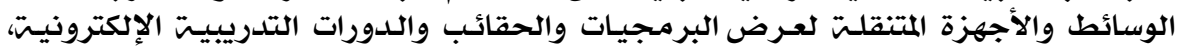

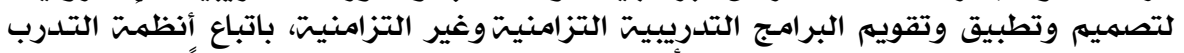

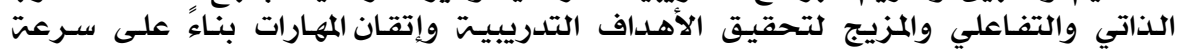

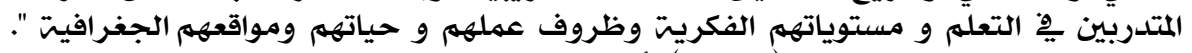

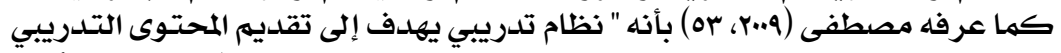

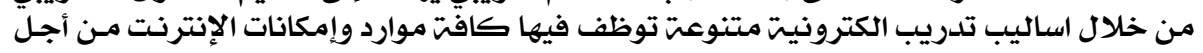

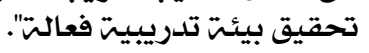




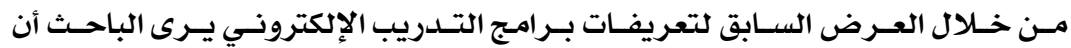

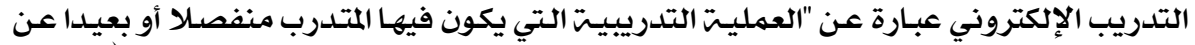

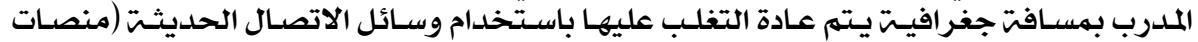
التعلم الإنكتروني التفاعليتً".

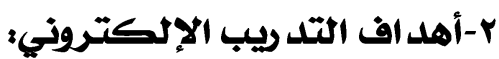

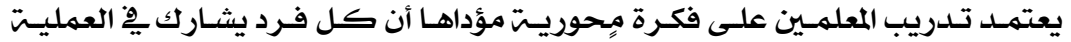

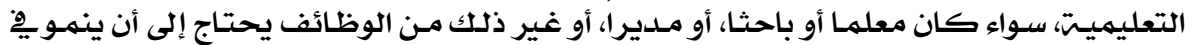

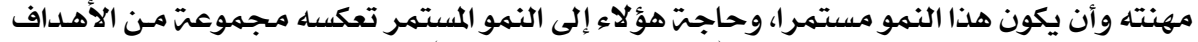

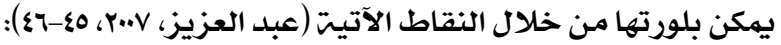

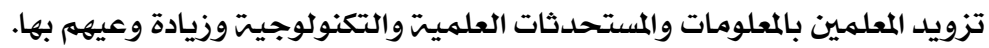

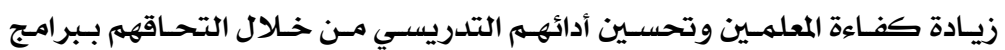

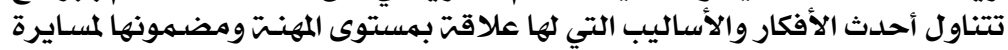

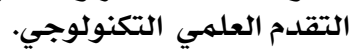

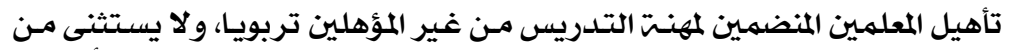

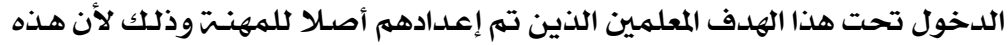

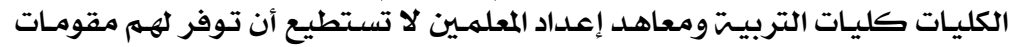

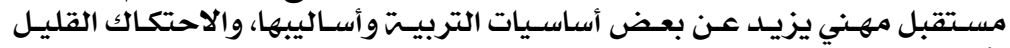

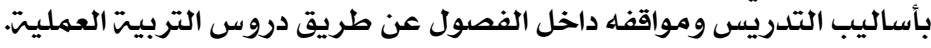

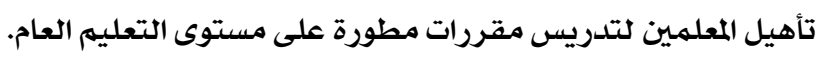

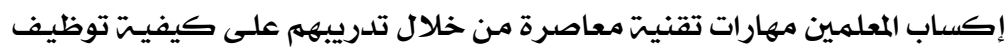

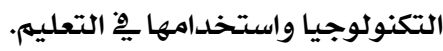

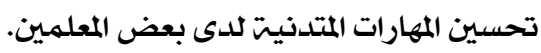

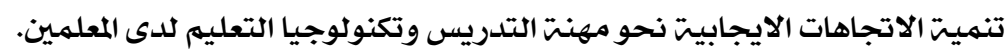

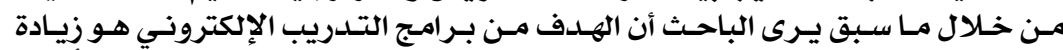

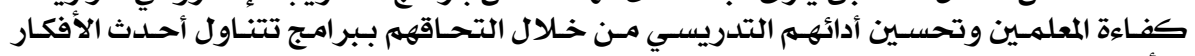

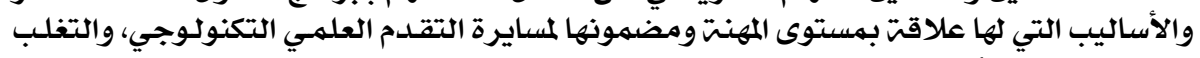

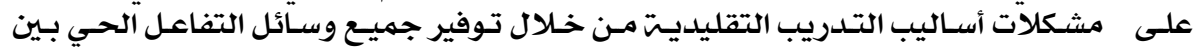

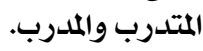

\section{r- خصائص برامج التلد ويب الإلكتروبروني:}

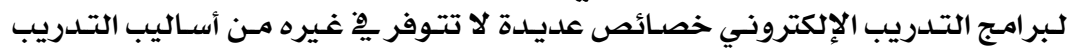

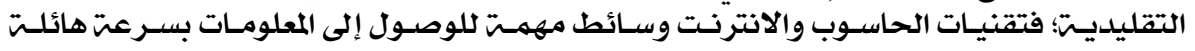

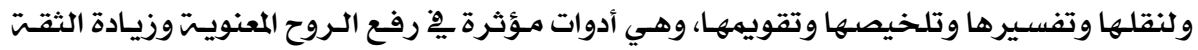

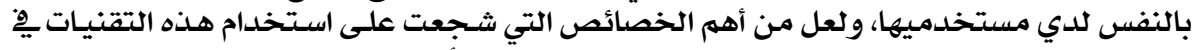

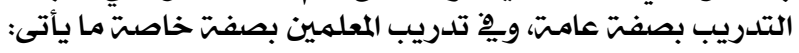

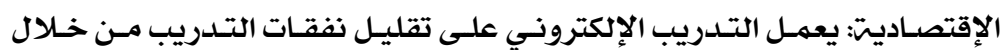

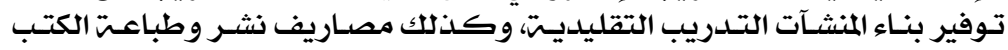

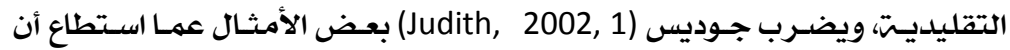

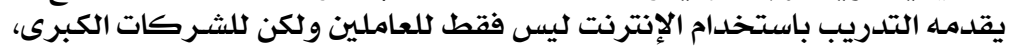

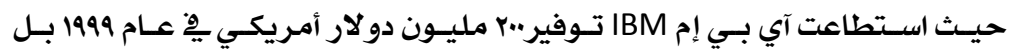




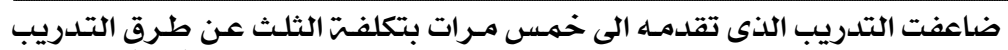

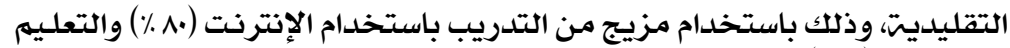

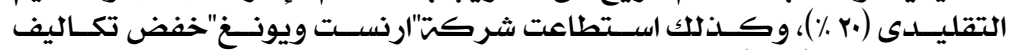

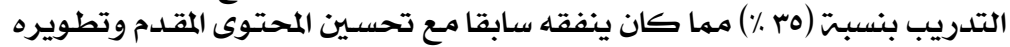

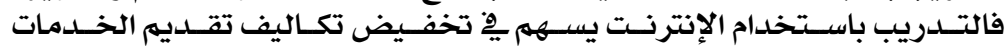

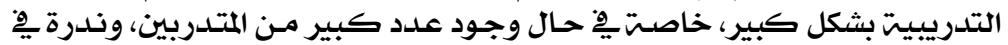

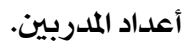

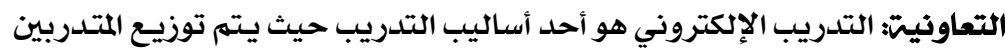

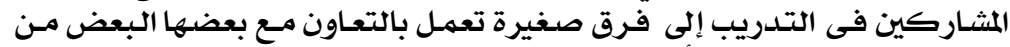

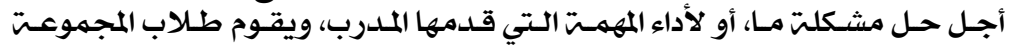

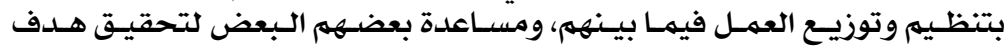

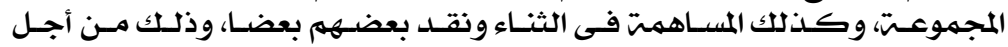

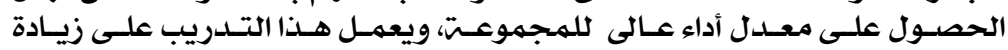
التحصيل المعرفى، وتنميت المهارات الاجتماعيت وبناء فريق العهل (Mai, 2004, 2).

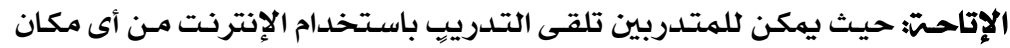

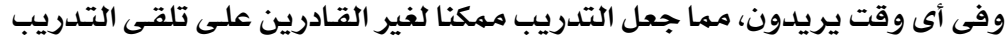

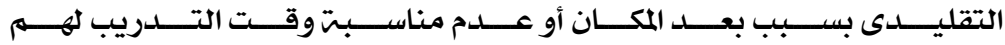

(William, 2005,10)

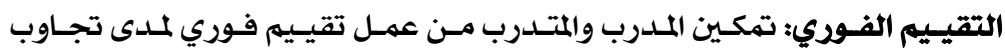

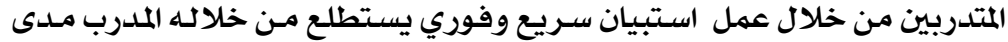

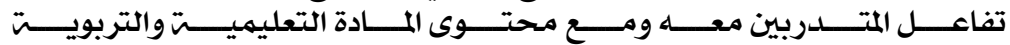
(Roger\& Dianne ,2006, 32)

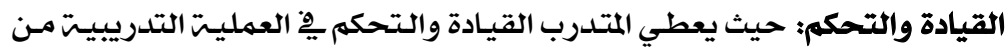

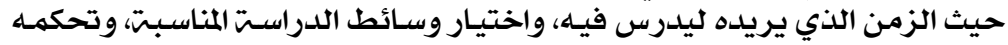

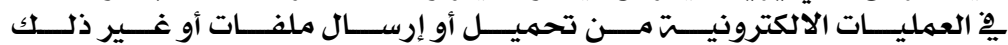

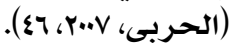

ويتصف التدريب الالكتروني بجملت من السمات منها (القادري، جبיץ، ب-ع):

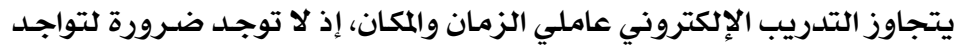

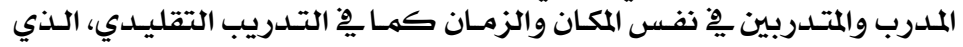

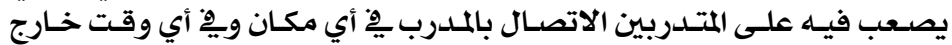

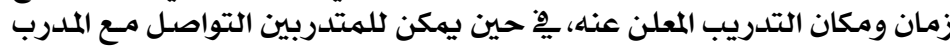

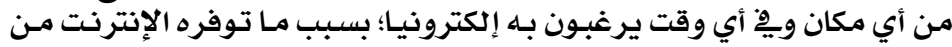

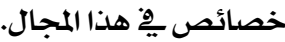

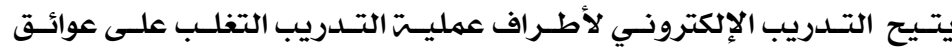

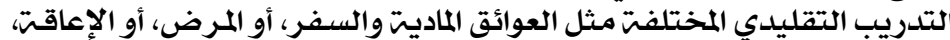

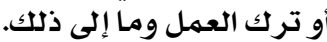

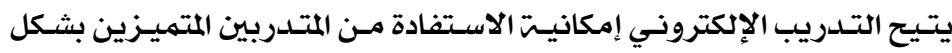
أكبر وفعال.

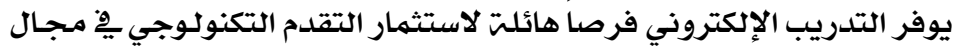

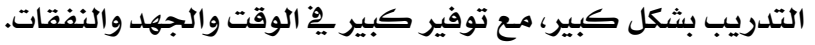




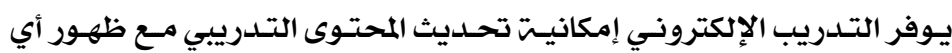

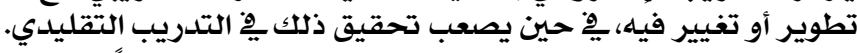

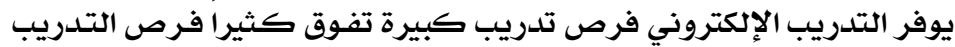

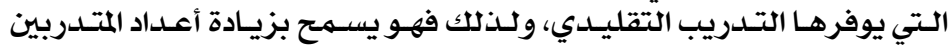
بشكل كبير.

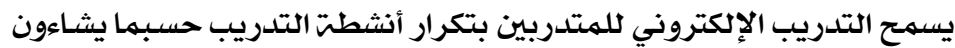

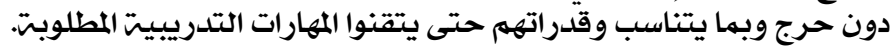

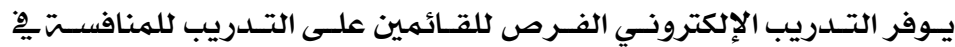

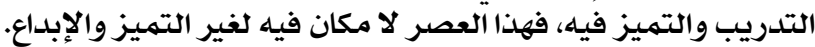

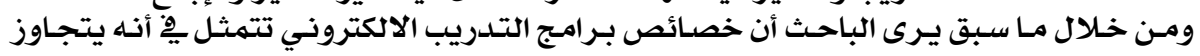

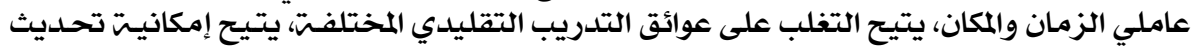

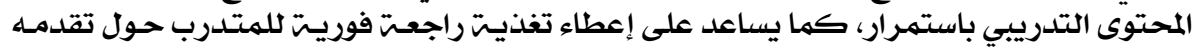

\section{ع - مميزات التدل ريب الإلكترونيء}

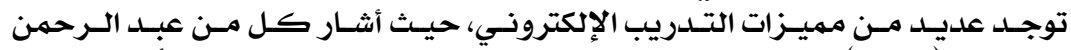

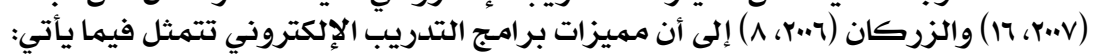

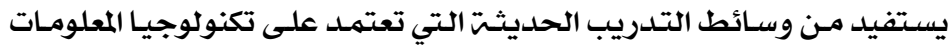

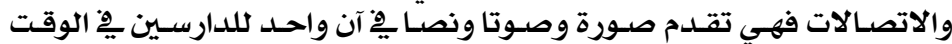

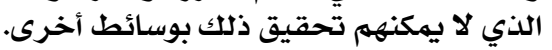

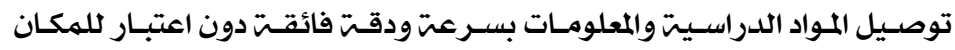

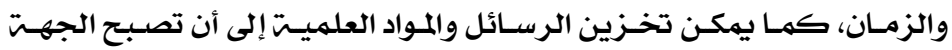

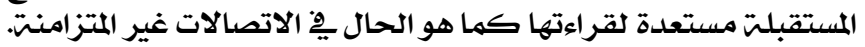

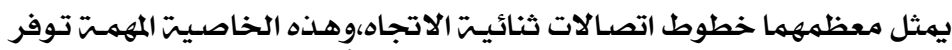

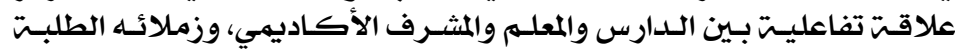

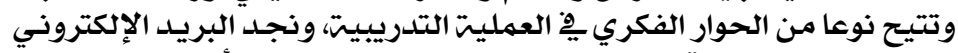

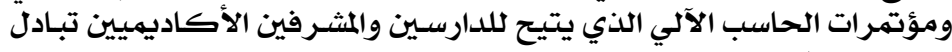
المعلومات والاستفسارات فيما بينهم.

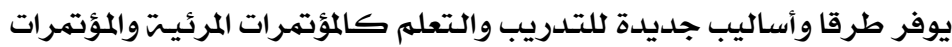

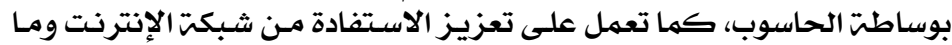

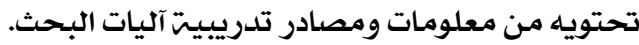

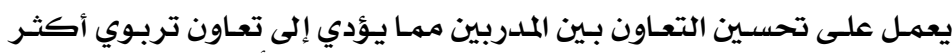

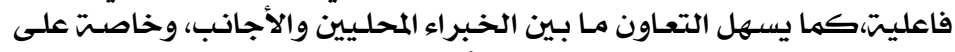

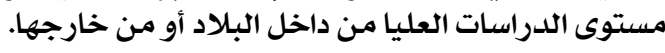

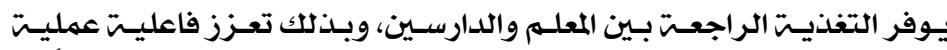

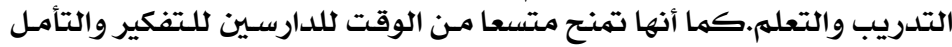
قبل الإجابت أو إعطاء رأي.

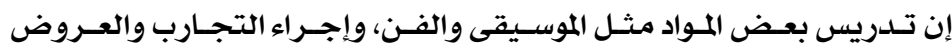

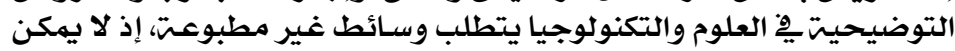

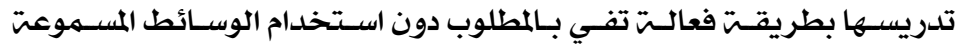

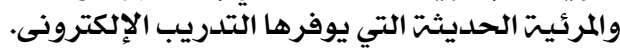


يشجع على التدريب التعاوني والعمل الجماعي وعلى ربط جماعماعات الدارسـين

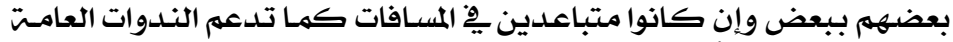

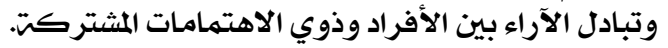

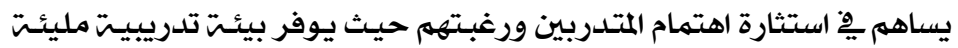

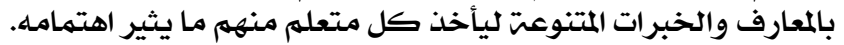

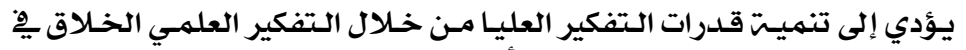

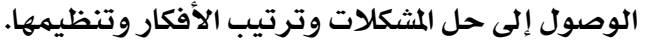

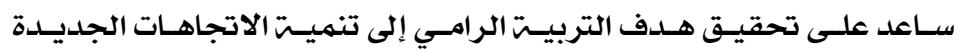
وتعديل السلوك.

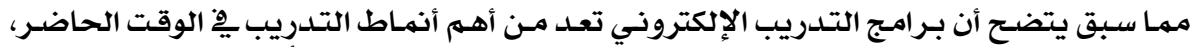

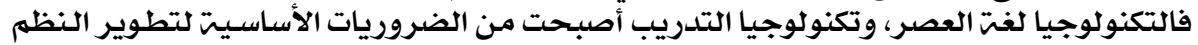

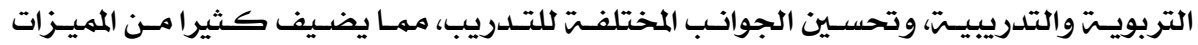
للتدريب.

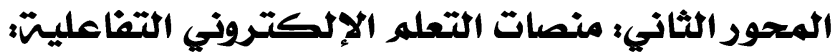

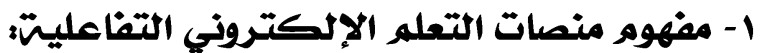

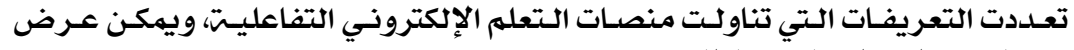

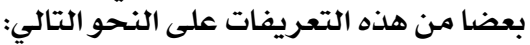

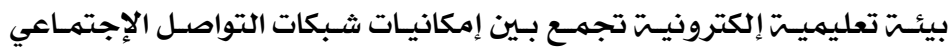

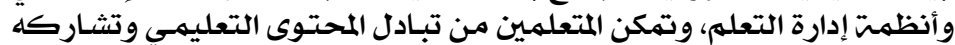

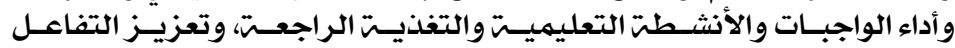

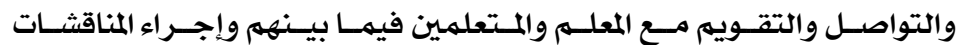

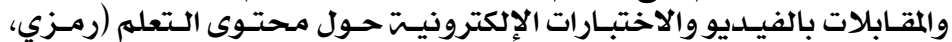
. (r.19

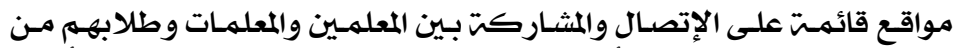

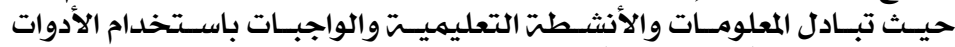

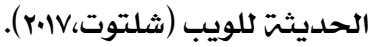

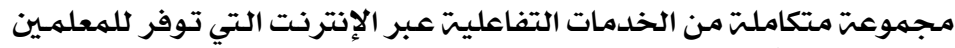

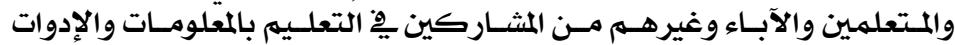

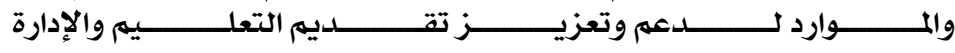
.(homanova \& prextova, 2017)

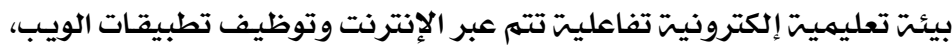

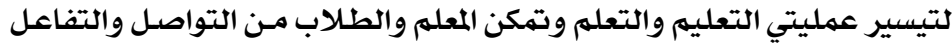

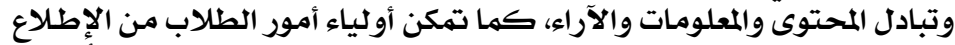

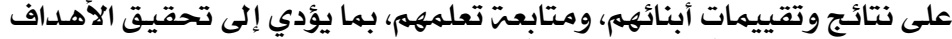

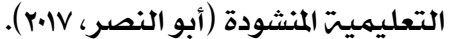

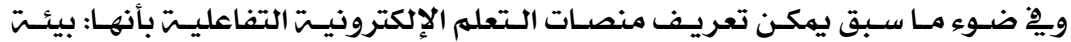

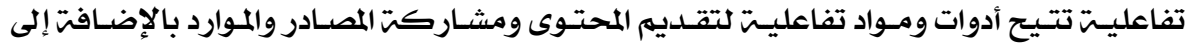

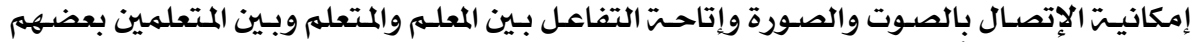

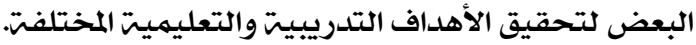




\section{r- خصائص منصات التعلم الإلكتروني التفاعليتهات}

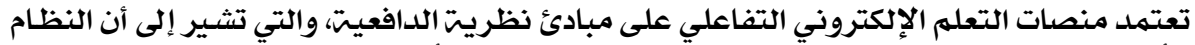

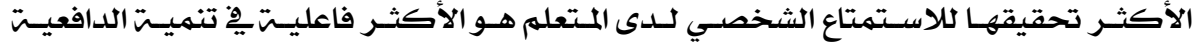

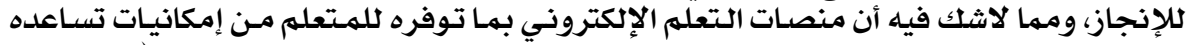

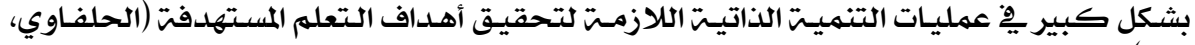

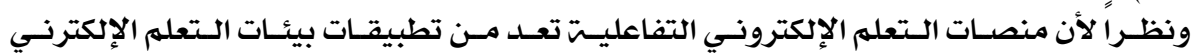

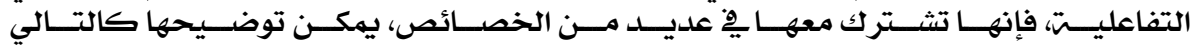

:(Sandybayev, 2020; Oproiu, 2015; Ch \& Popuri, 2013)

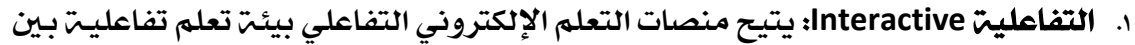

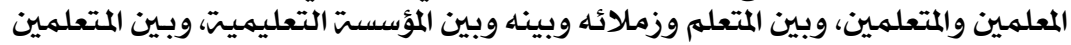

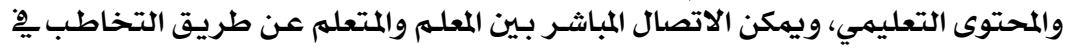

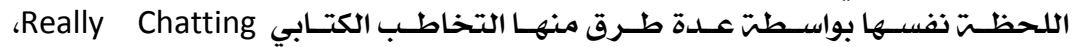

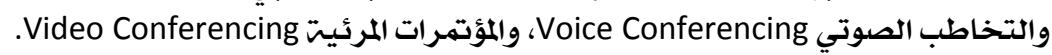

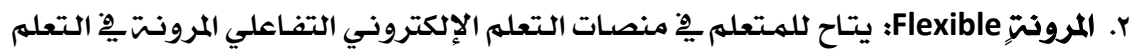

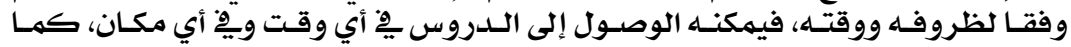

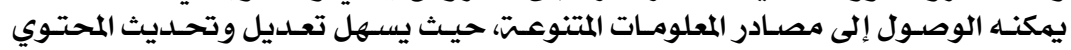

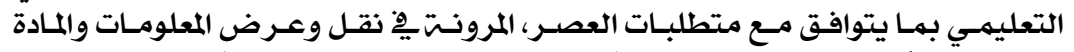

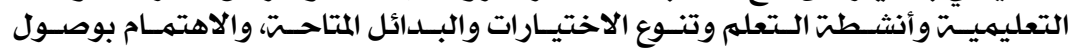

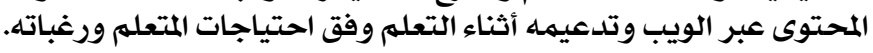

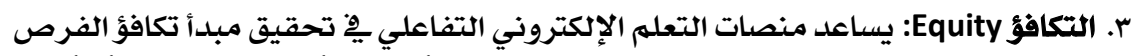

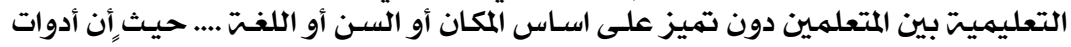

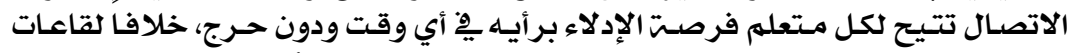

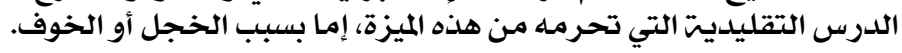

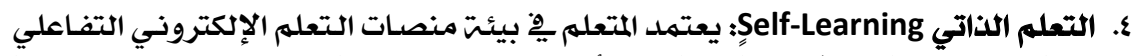

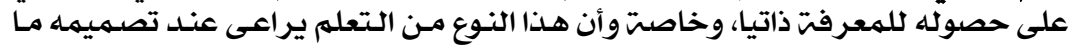

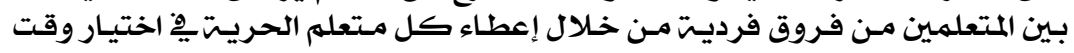

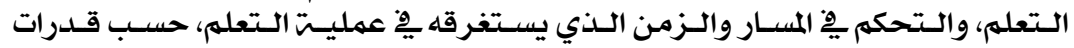

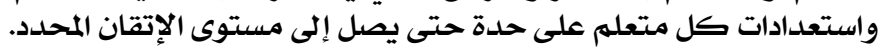

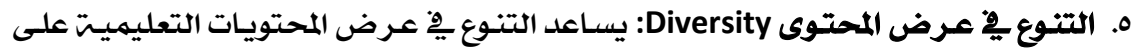

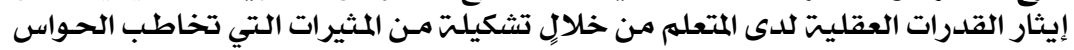

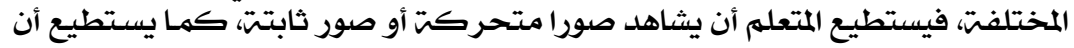

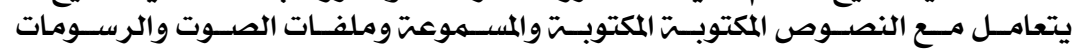
والتكوينات الخطيت بكافت أشكالها.

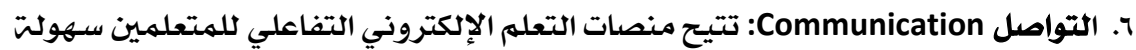

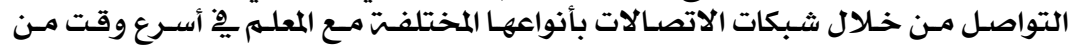

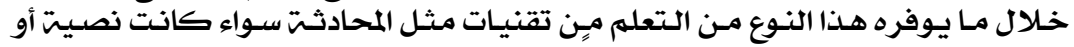

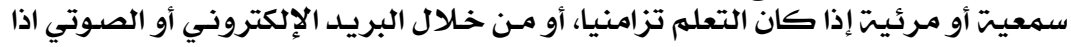

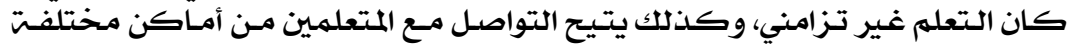




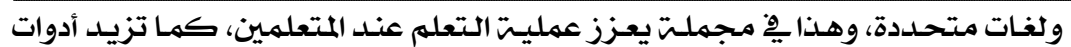

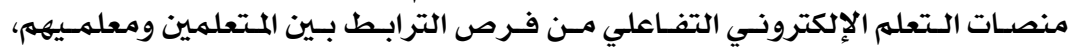

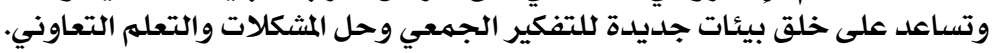

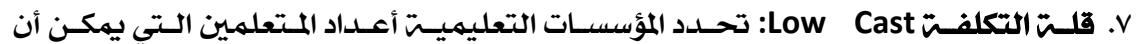

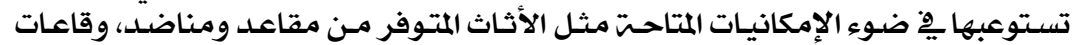

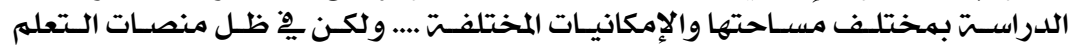

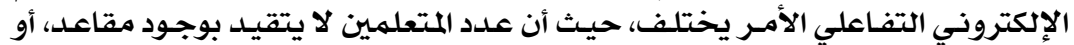

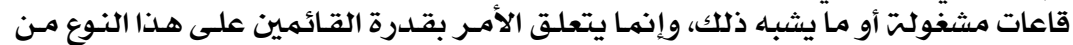

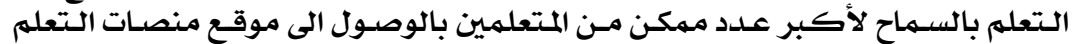

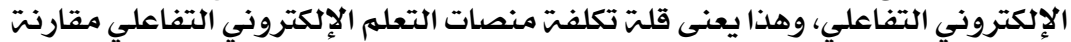
بالتعله التقليدي.

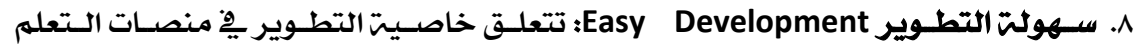

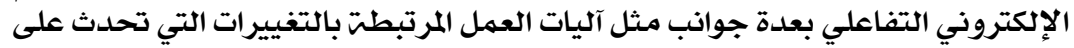

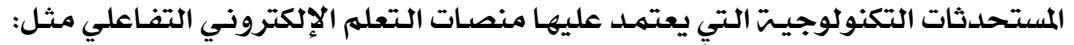

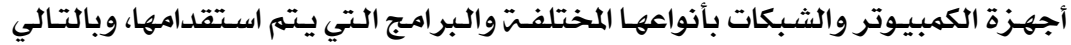

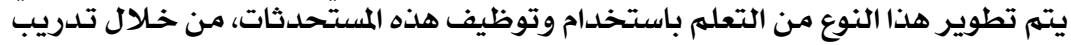

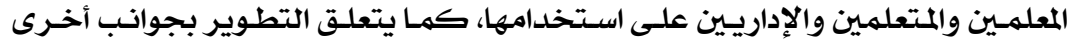

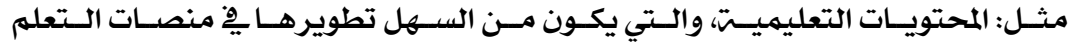

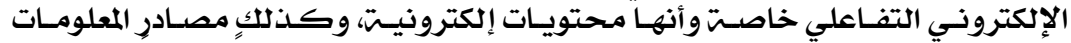

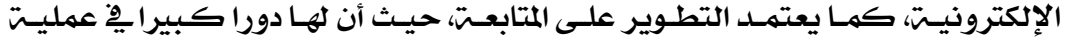

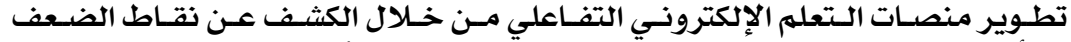

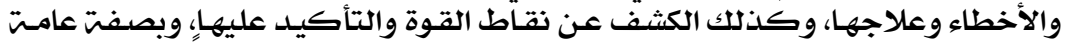

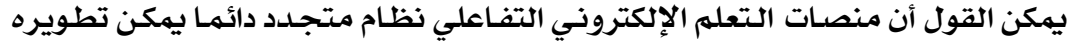
بسهولتة، ومن ثم تزداد فاعليته.

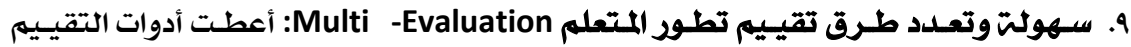

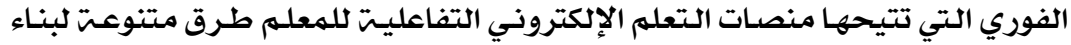

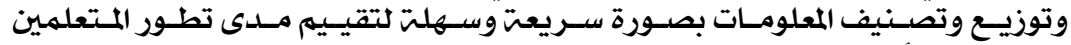

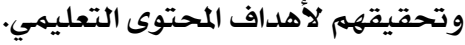

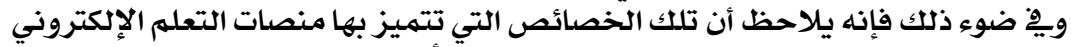

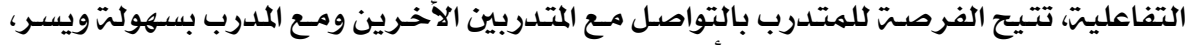

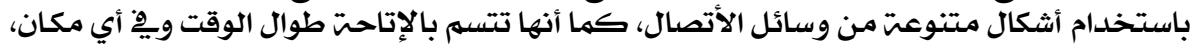

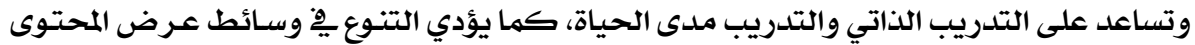

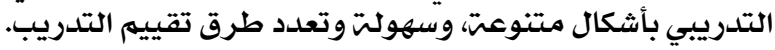
r- مميزات منصات التعله الإلكتروني التهات التفاعليتئ

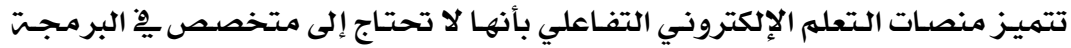

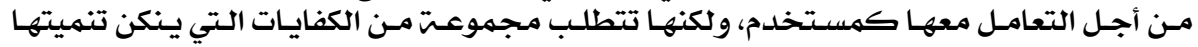

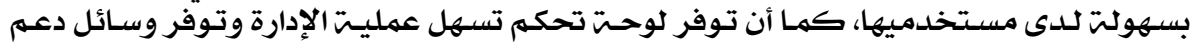

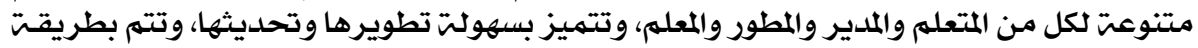

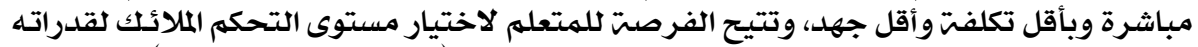

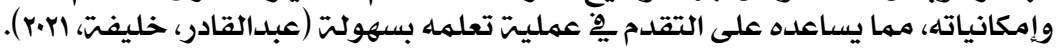




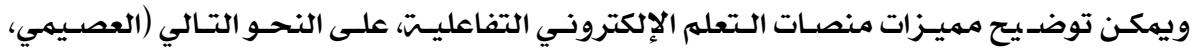

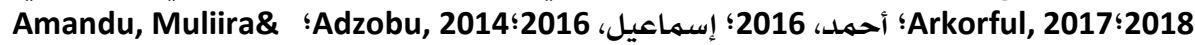

:(Fronda, 2013

$$
\begin{aligned}
& \text { • تجمح بين شبكات التواصل الإجتماعي لتساعدهم على تبادل الآراء والأفكار. }
\end{aligned}
$$

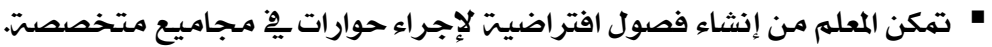

$$
\begin{aligned}
& \text { • توفر مكتبت رقهيت تحتوى على مصادر المعاء التعله. } \\
& \text { • ت تساعد على إعداد بنولك أسئلتة. }
\end{aligned}
$$

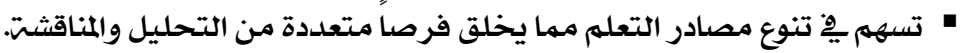

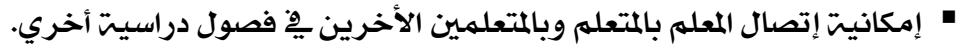

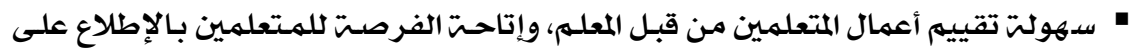

درجاتهم.

$$
\begin{aligned}
& \text { - تشجيع المتعلمـين على تبادل ومشاركت الملفات. } \\
& \text { • تساعد على التعلم التشاركي. }
\end{aligned}
$$

• تساعد على تحقيق الجو النفسي والإجتهاعي الآمن بين المعلمـين والمتعلمـين.

$$
\text { • تتمتع هذه البر امـج بسهولت التحميل على الهواتف الذهيت. }
$$

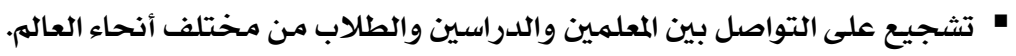

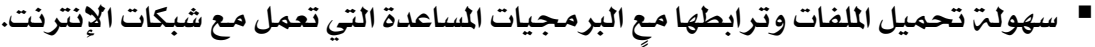

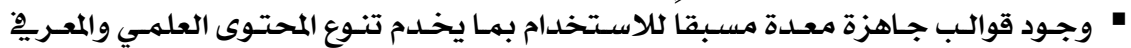
المقدم.

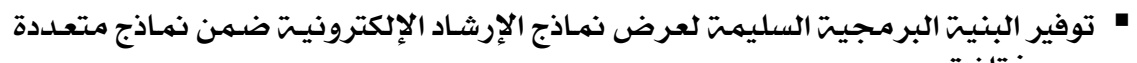
ومختلفت.

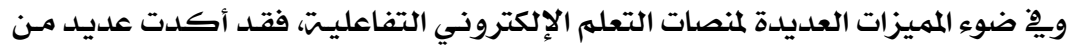

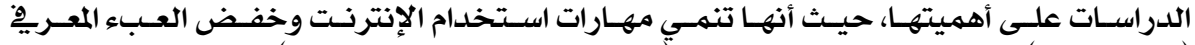

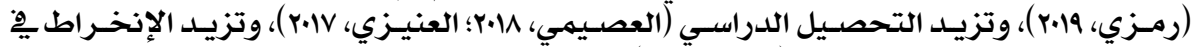

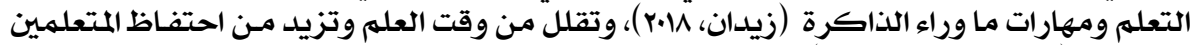

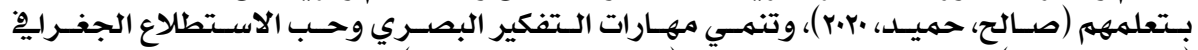

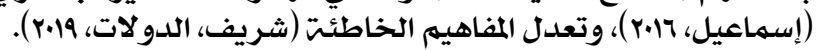

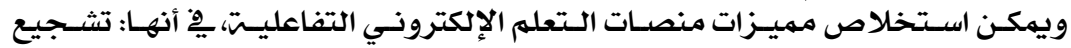

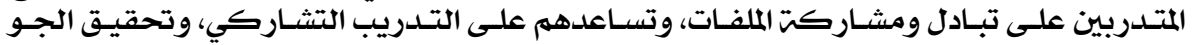

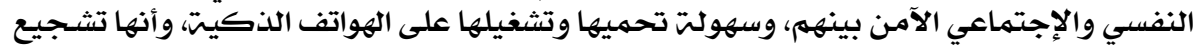

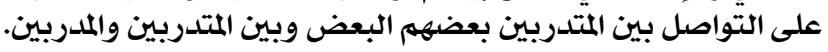

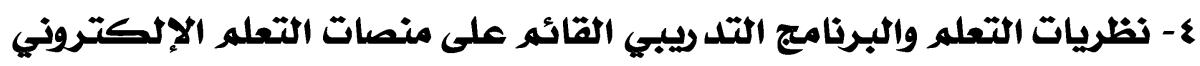

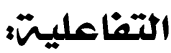

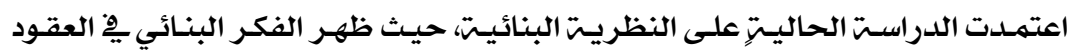

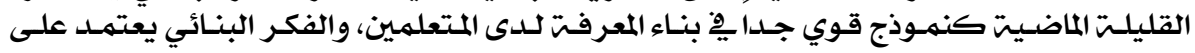

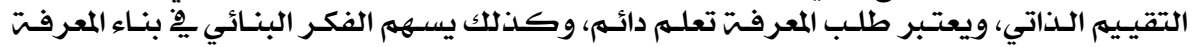

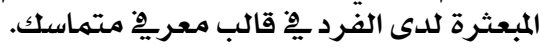




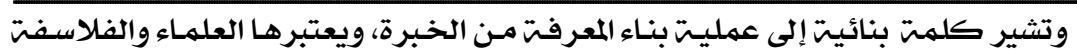

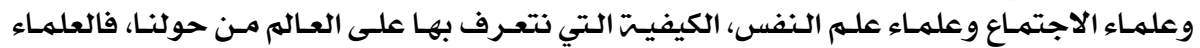

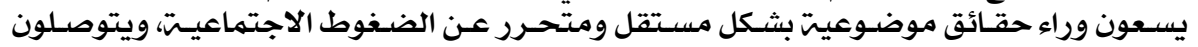

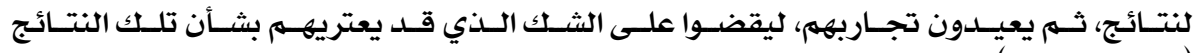

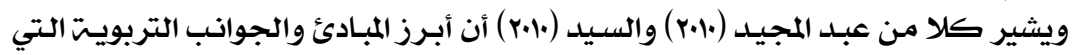

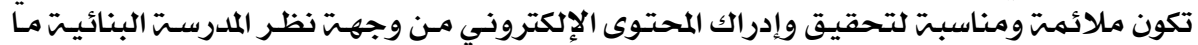

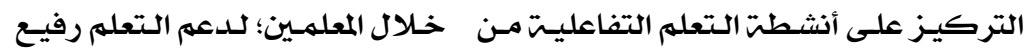

المستوى والحضور الاجتماعي للمساعدة على تنميت المعنى الشخصي.

جعل المتعلمـين نشيطين يؤدون أنشطت رفيعتة المستوى وذلكت مـن خـلال مطالبتهمه

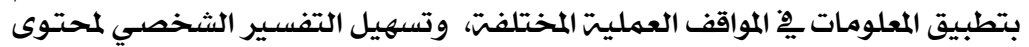

التعله، ومناقشت الموضوعات داخل الجماعت.

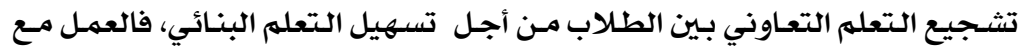

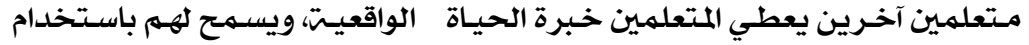

$$
\text { وتحسين مهارات ما وراء المعرفيت. }
$$

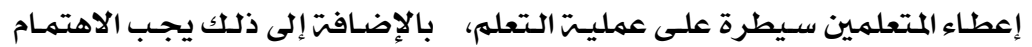

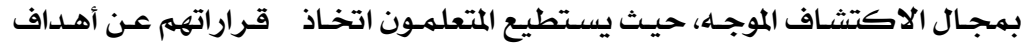
التعلهم من خلال توجيه المعله.

التركيز على نشاطات التعله التفاعليت لتشجيع مستويات التفكير التهليع العليا مـع توفير

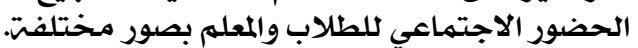

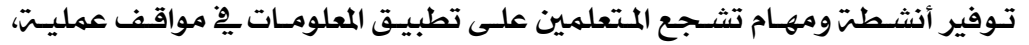

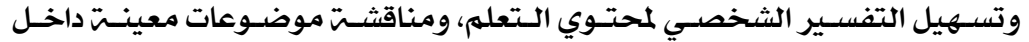
المجموعات.

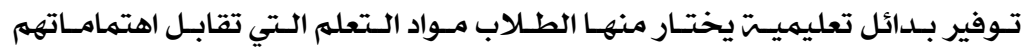

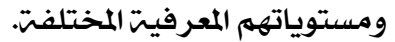

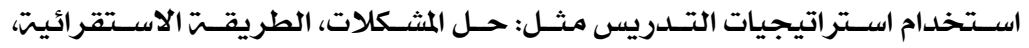

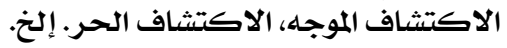

أن تكون استراتيجيات تقييم الطالب مححددة وواضحت ومفهومت من قبل الطلاب. استخدام أسـاليب مختلفـت مـن التقـويم، مثل: التقويم الـذاتي للمـتعله كelf-Assessment

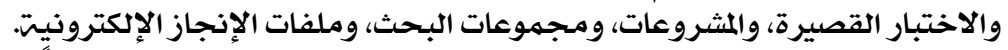

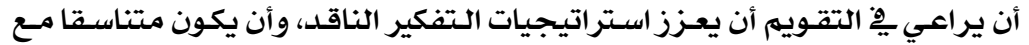
أهداف التعلهم.

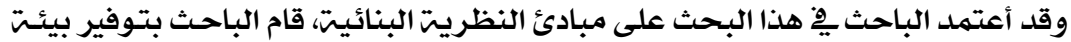

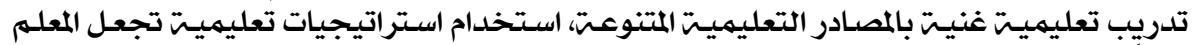

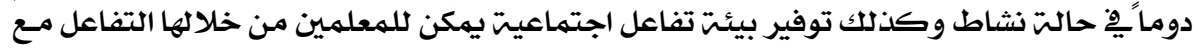




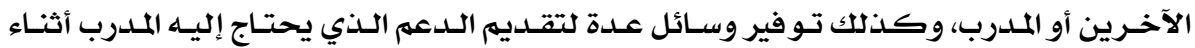

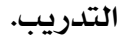

\section{المحور الثااثث: منصت Microsoft Teams التقاعليت:}

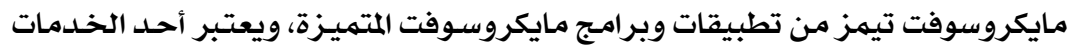

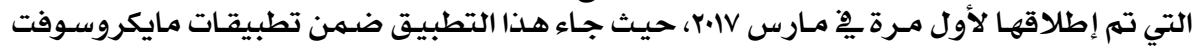

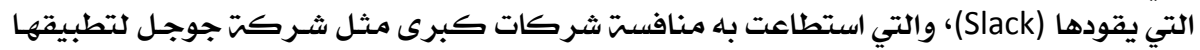

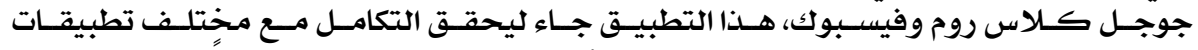

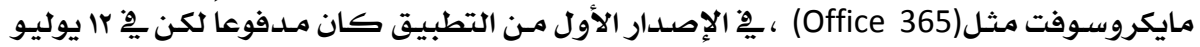

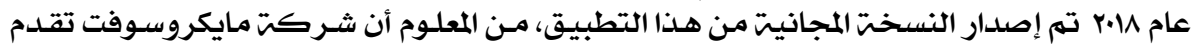
مختلف الخدمات للشركات والمؤسسات منها (Office 365) و و(Skype for Business).

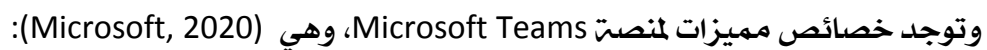

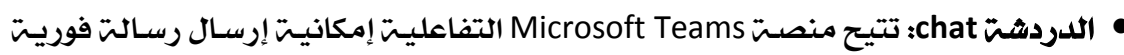

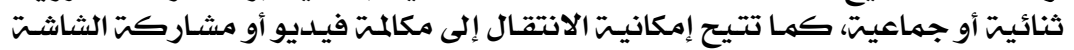

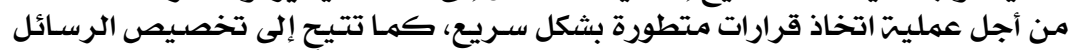

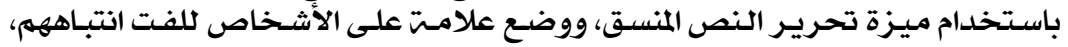

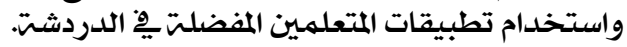

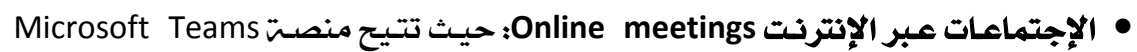

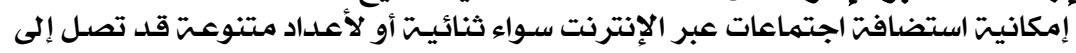

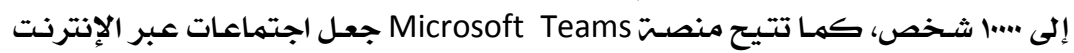

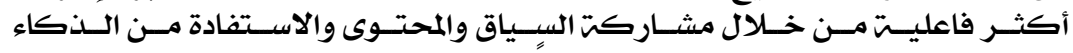

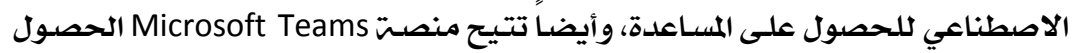

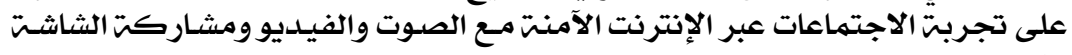
عاليت الجودة.

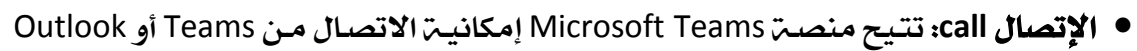

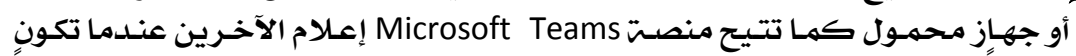

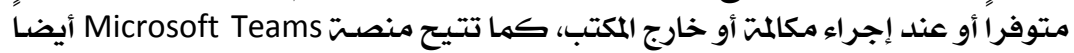

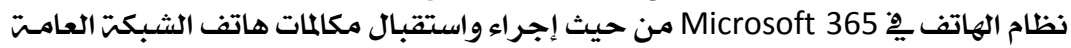

$$
\text { للهاتفيت المحولت (PSTN). }
$$

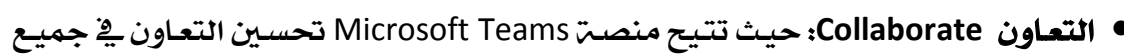

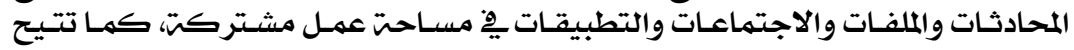

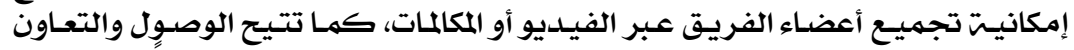

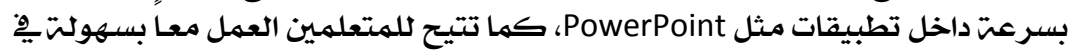
التوقيت الحقيقي عبر المستندات والتقويمات التمات والملفات المشتركت.

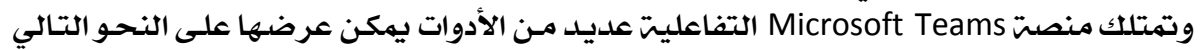

:(Microsoft, 2020)

- أداة مؤتمرات الفيديو Video conferencing: وهي أداة تجعل عقد الاجتماعات أكثر

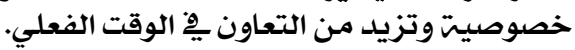

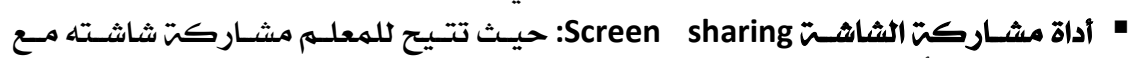
المتعلمين الأخرين بحيث يستطيعون رؤيتها وهو يكتب عليها. 
فاعليت برنامج تدريبي قائم على منصات التعلم الإلكتروني التفاعليتّ فِّ تنميه مهارات د. أحمد مساعد ربح منهل

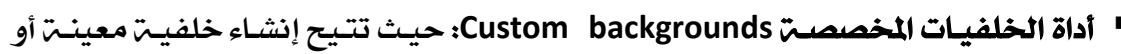

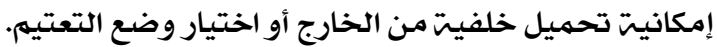

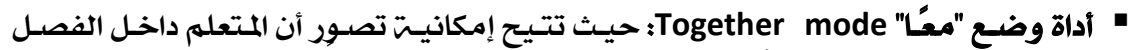

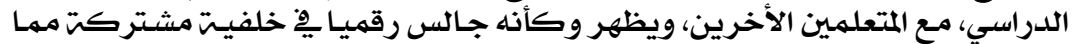
يشعره بالإنتماء والألفتئ.

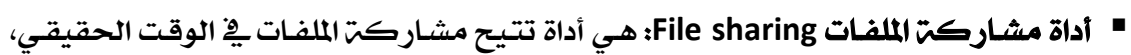

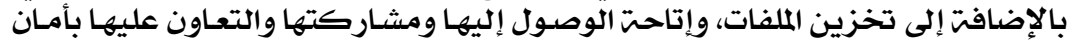
من أبي مكان.

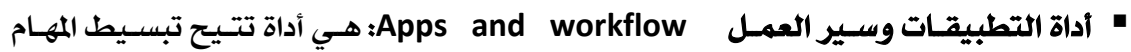

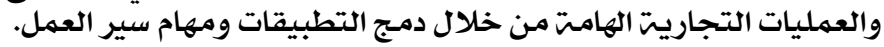

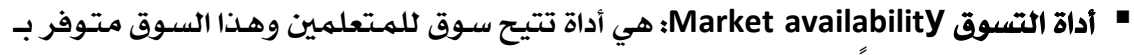

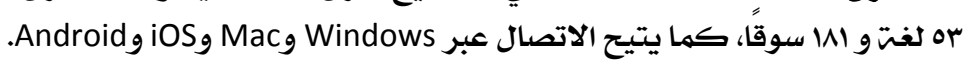
• أداة الخصوصيت والأمان Privacy and security: هي أداة تتيح تلبيت الاحتياجـات الإن

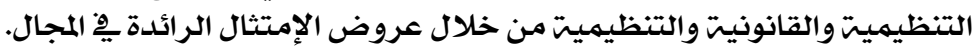

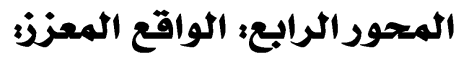

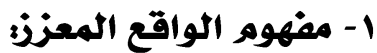

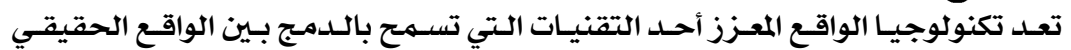

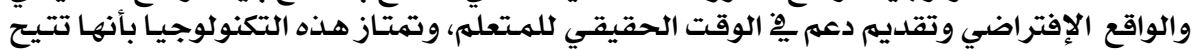

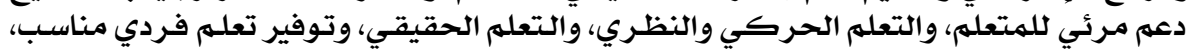

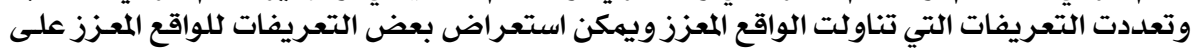

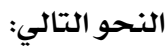

- تطبيق يته من خلال أجهزة الموبيل ويقوم على تفاعل المستخلدم مـن شاشت الهاتف النقال من خلال حاست اللمس (Diaza, Hincapiéb \& Morenoc, 2015).

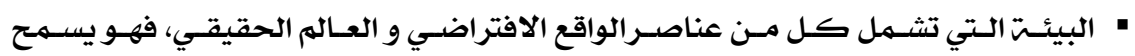

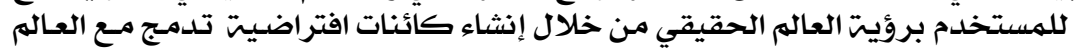

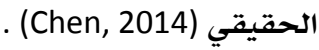

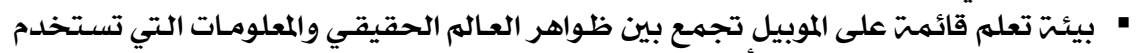

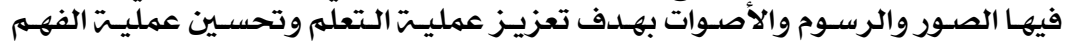
وزيادة دافعيت المتعلم نحو عمليت التعلم (Salmi, Kaasinen\& Kallunki, 2012).

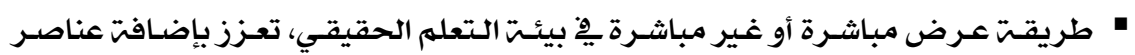
رقميت مولدة بالكمبيوتر (Carmigniani \& Furht, 2011).

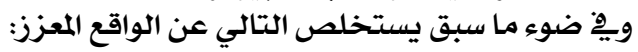

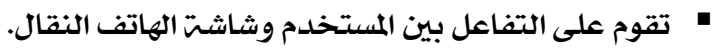

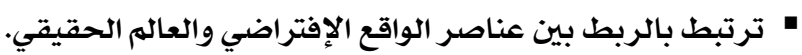

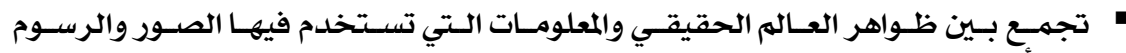

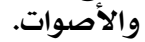
• تعزز بإضافت عناصر رقميت مولدة بالكمبيوتر. 
r- خصائص الواقع المعززة

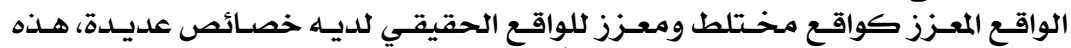

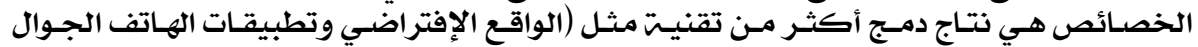

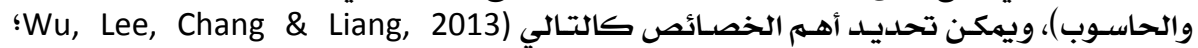

الحلفاوي، (1) الحاسوب):

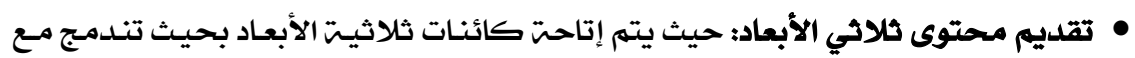

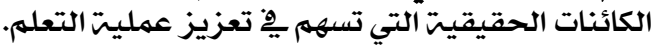

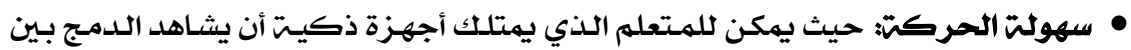

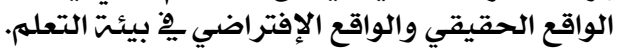

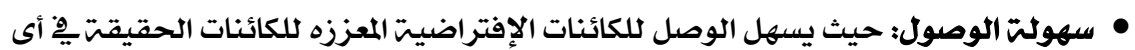

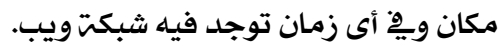

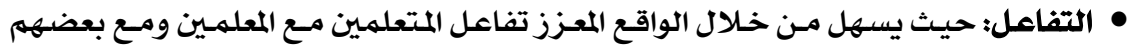
البعض بفاعليت وسهولتئ.

• المرونت: حيث يهكن للطلاب والمعلمـين الحصول علي (الخدمتة) من أي مكان.

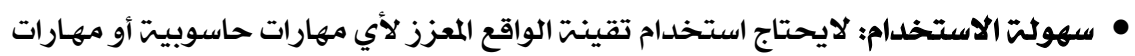

خاصتة.

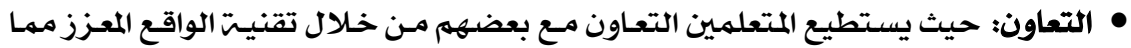

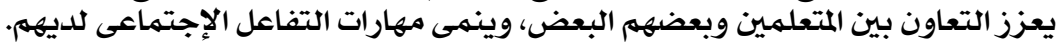

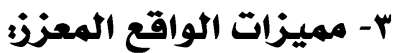

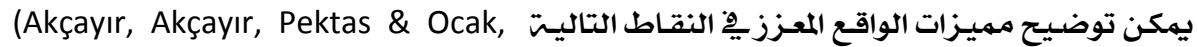
:2016; Radu, 2012; Yuen, Yaoyuneyong \& Johnson, 2011)

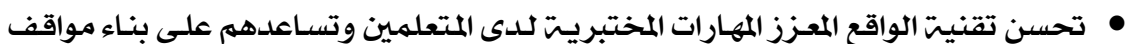

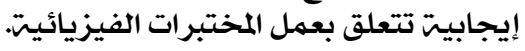

• زياده فِ فهم المحتوي العلهي.

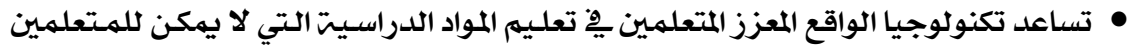

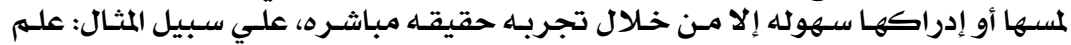
الفلك والجغر آنمافيا.

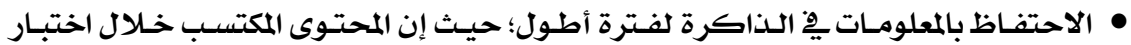

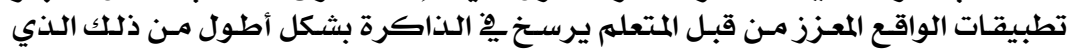

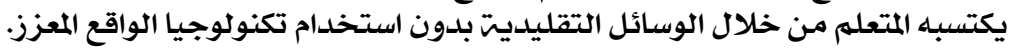

• المشاركتة، وتحفيز المتعلمـين على اكتشاف معلومات المواد التعليميتت من زوايا مختلفت.

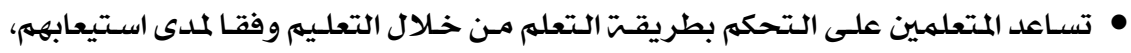
وطريقتهم المفضلت.

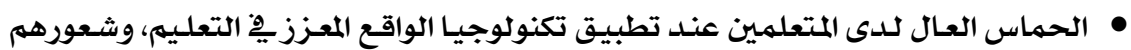

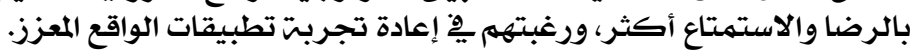




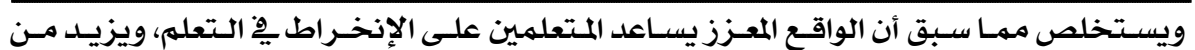

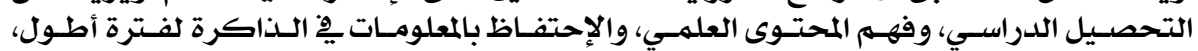

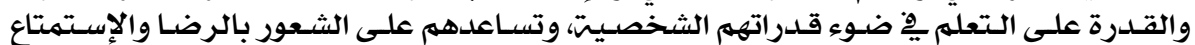

بالتعلم.

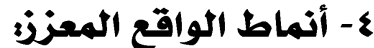

تعددت أنماط الواقع المعزز، حيث تنقسم تكنولوجيا الواقع المعزز إلى شكلين، هما (DunleaW, 2014):

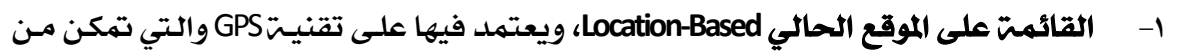

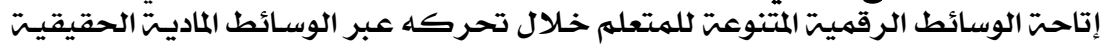
المختلفة.

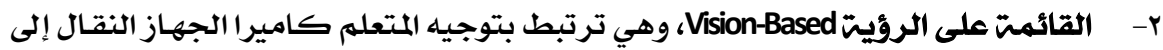

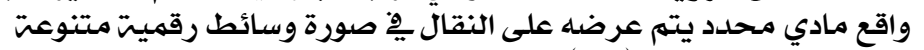

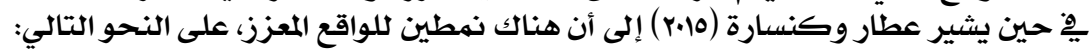

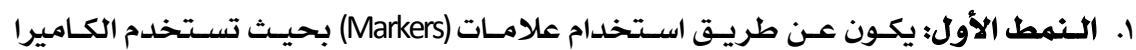
إلتقاطها وتميزها؛ لعرض المعلون طعات المعات المرتبطت به.

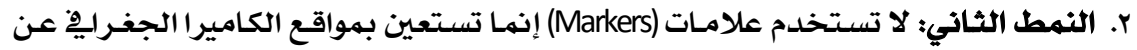

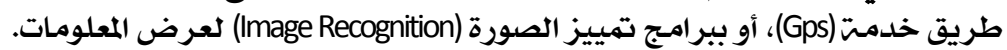

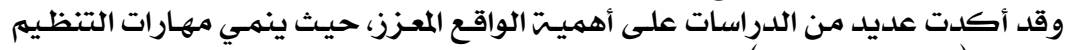

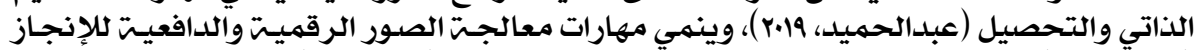

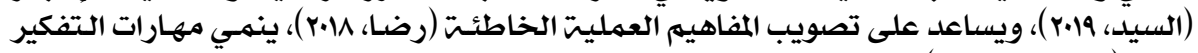

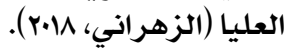

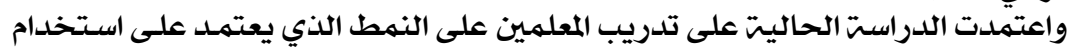

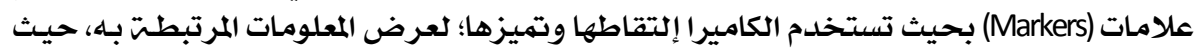

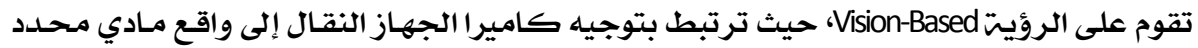

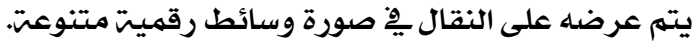

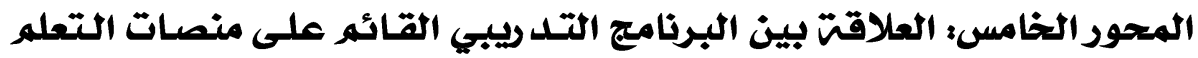

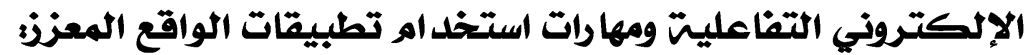

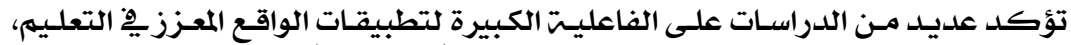

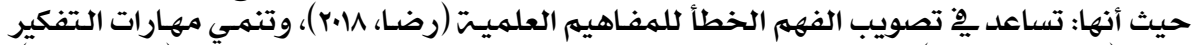

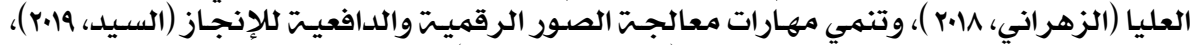

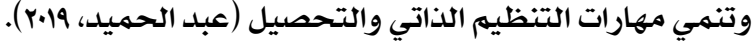

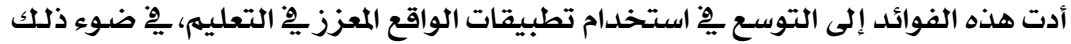

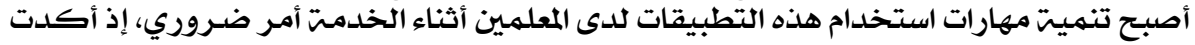

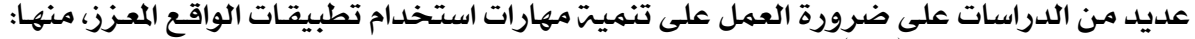

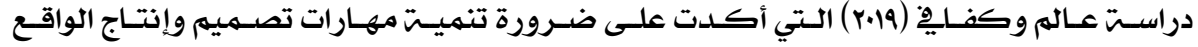

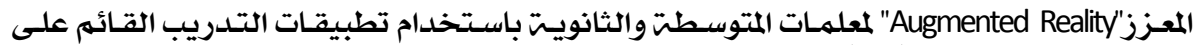

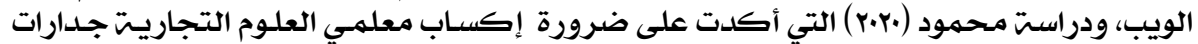

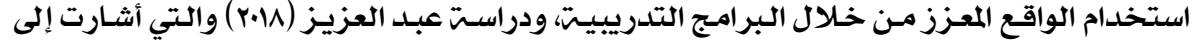

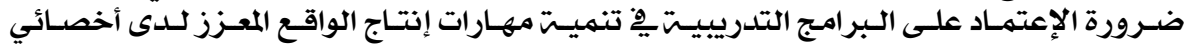

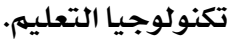




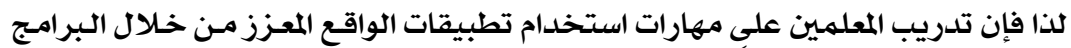

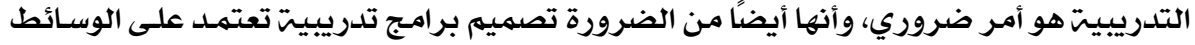

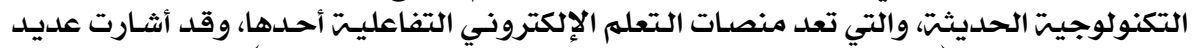

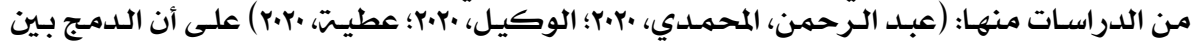

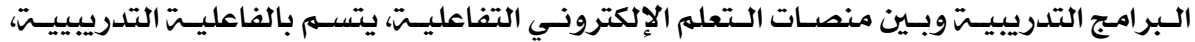

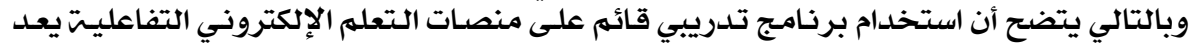

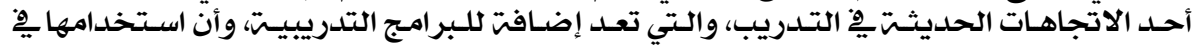

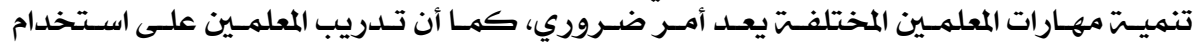
تطبيقات الواقع المعزز يعد حيوي ِِّ دعم عمليات التعلم والتعلم وتحقيق نواتج التعلم المستهدفته.

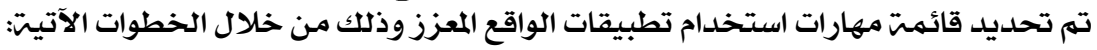

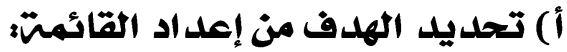

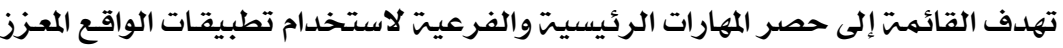

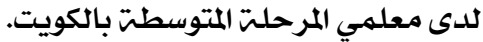
ب) تحديل محتوى القائمتر:

لتحديد المهارات الرئيسيت والفرية الميتيت لاستخدام تطبيقات الواقع المعزز التي تم تضمينها هِّ القائمتم، قام الباحث بما يلي:

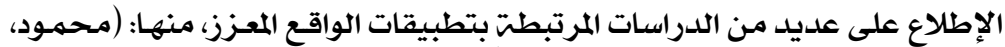

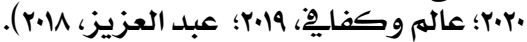

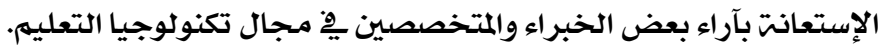

وبعد الحصول على المهارات تم تقسيمها إلى مهارات بعضرات أساسيتة، ويتبع كل مهارة أساسيتيت مجموعتة

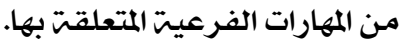

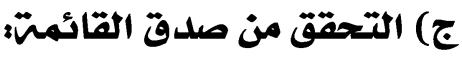

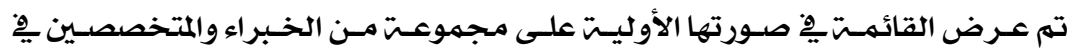

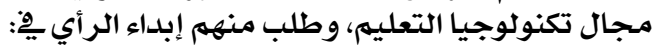

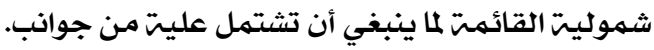

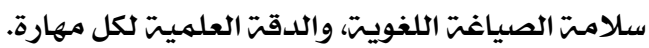

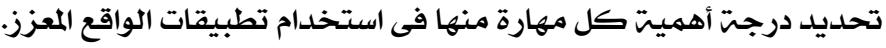

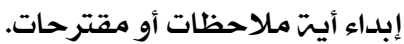

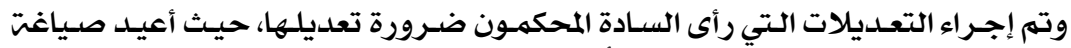

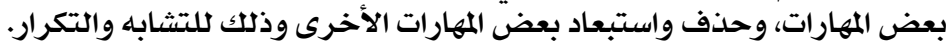

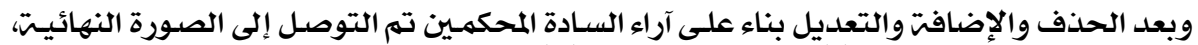
وبلغ عدد المهارات الرئيسيت (ه)، والمهارات الفيناء الفرعيت (.7). 


\section{ثانيـاً تحديـل معـايير تطـوير بربـامج تـلد ريبي قـائم على منصـات التتعلم} الإلكتروني التفاعليتاءت

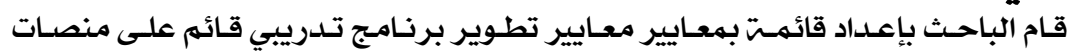

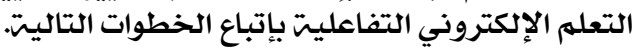

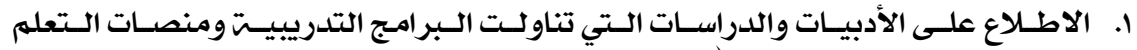

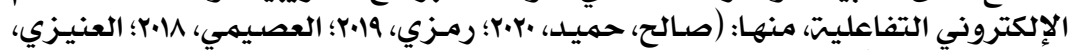

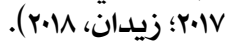

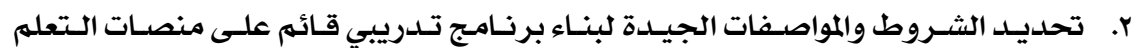
الإلكتروني التفاعليت.

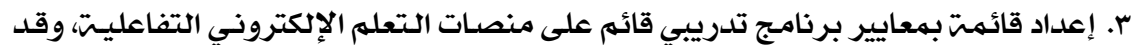

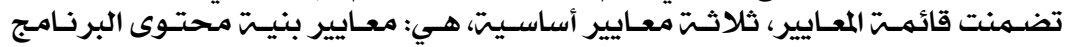

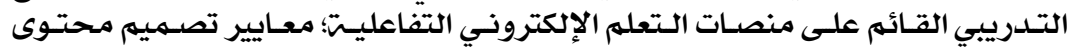

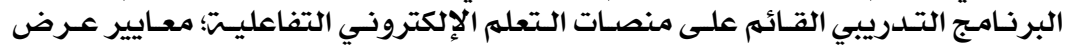

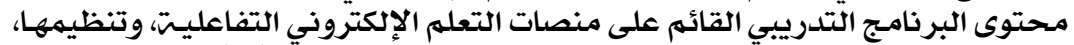

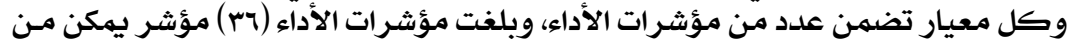

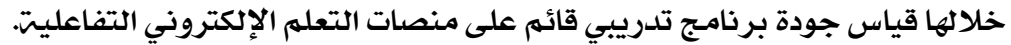

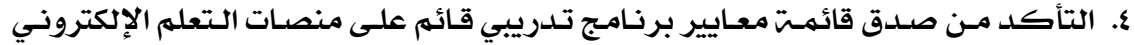

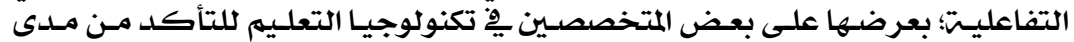

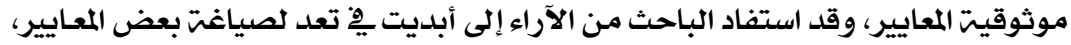

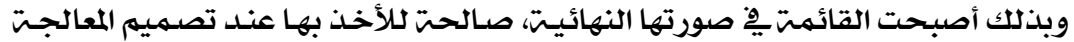

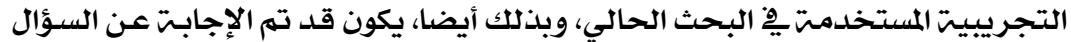

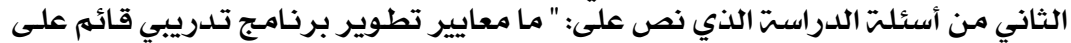

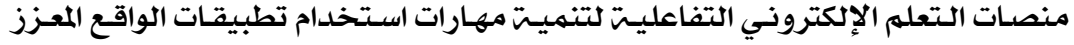

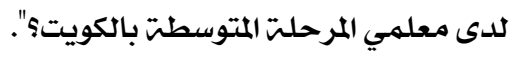

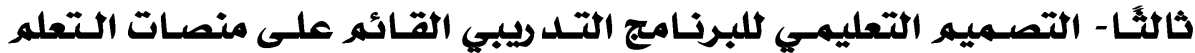 الإلكتروني التقاعليتئ}

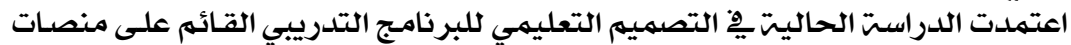

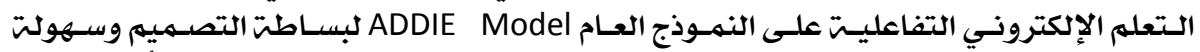

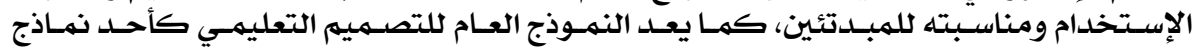

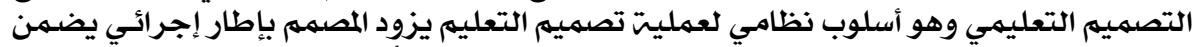

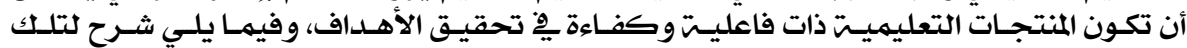

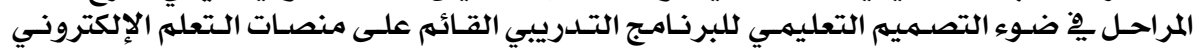

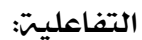

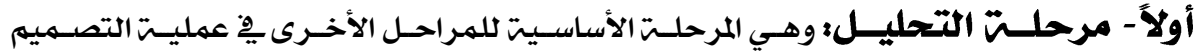

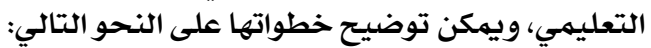

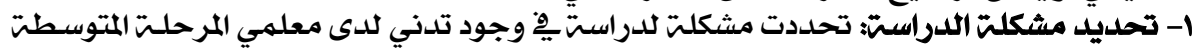

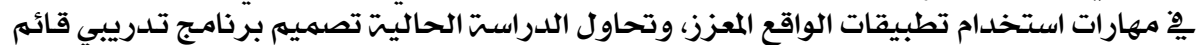
على منصات التعله الإلكتروني التفاعليت للتغلب على هلى هذات المشكلة. 


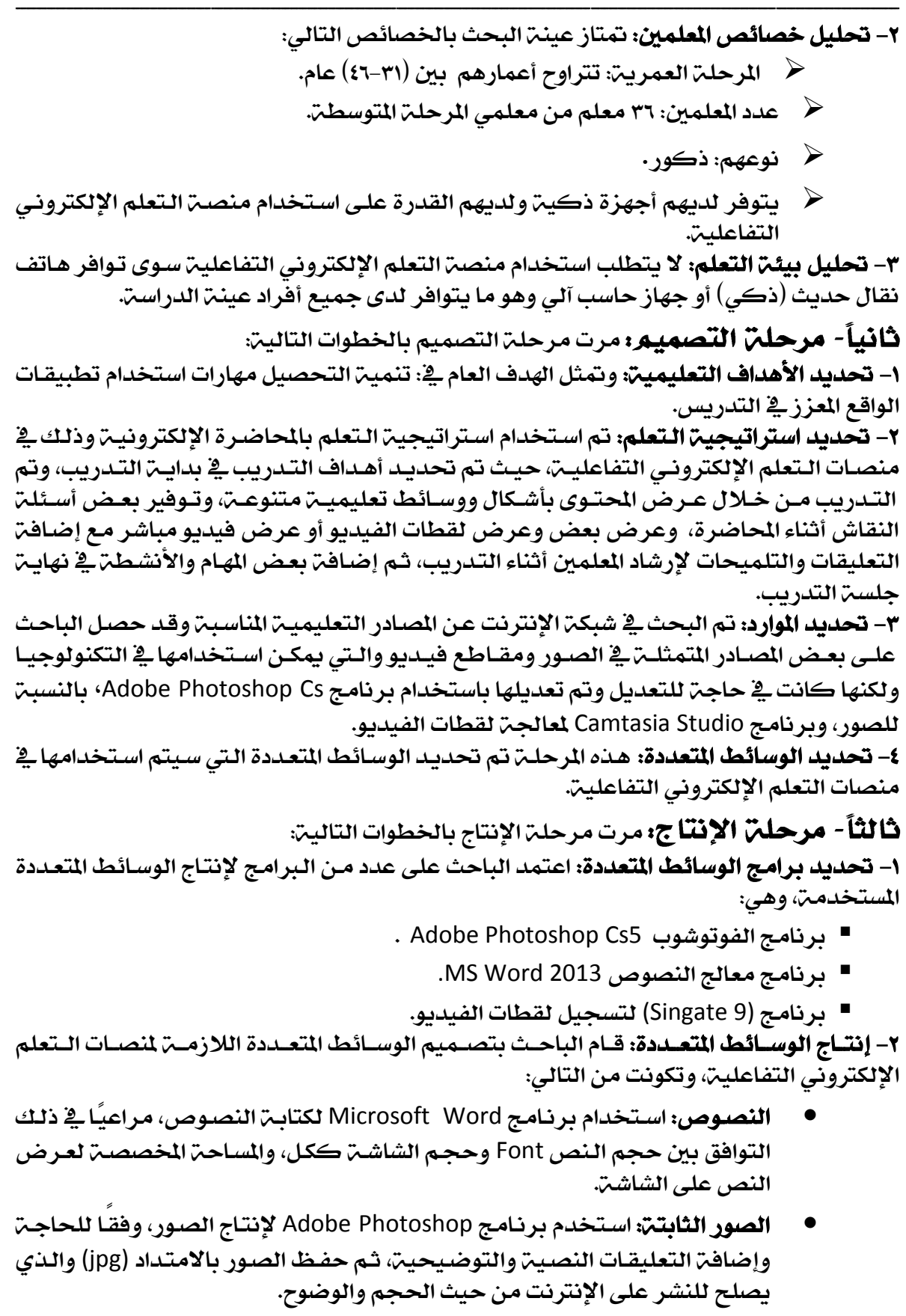




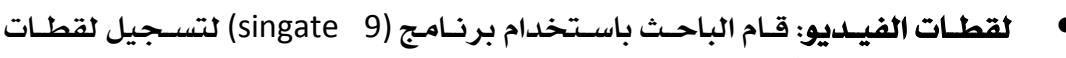

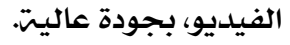

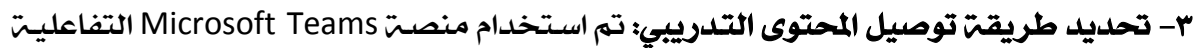

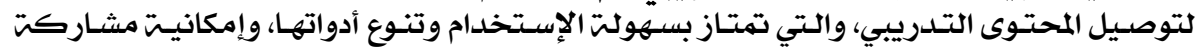

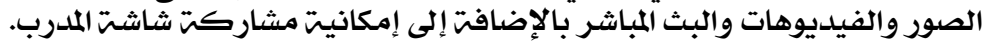

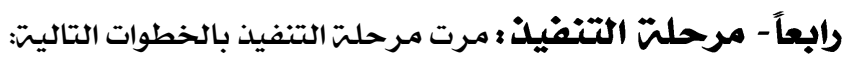

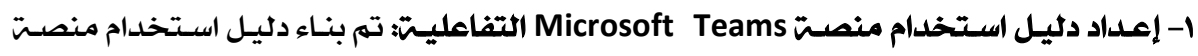

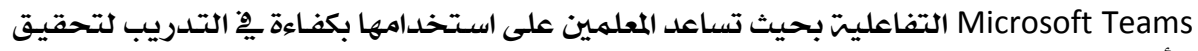

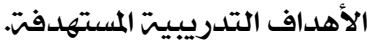

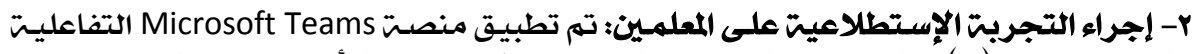

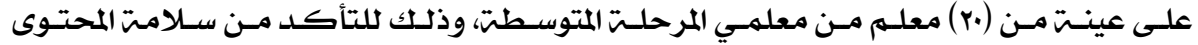

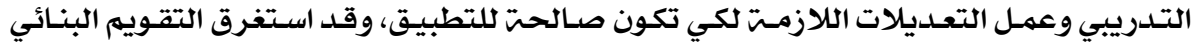
أسبوع.

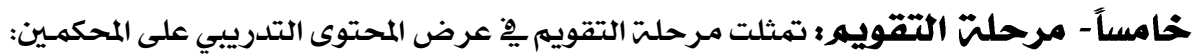

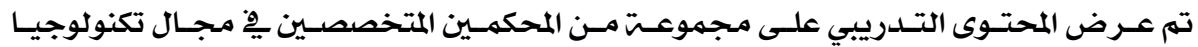

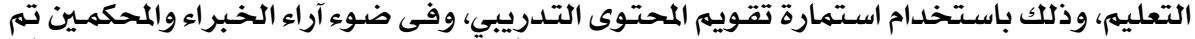

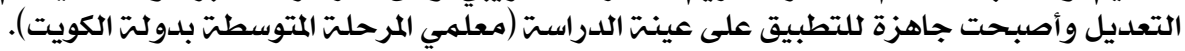

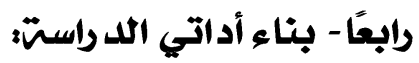
ا - الاختبار التحصيليلية اشتملت خطوات الاختبار التحصيلي على الخطوات التاليت:

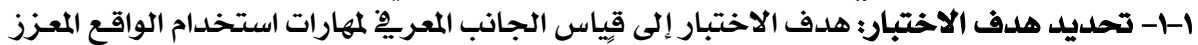

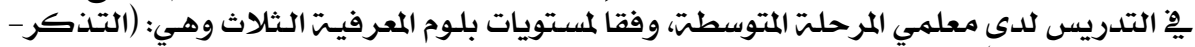

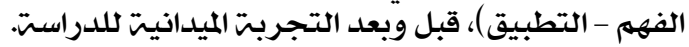

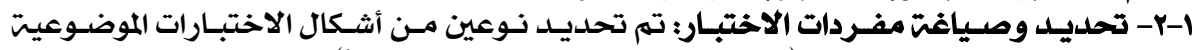

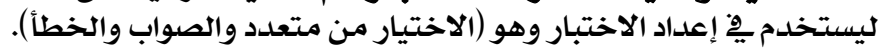

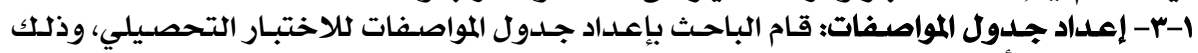

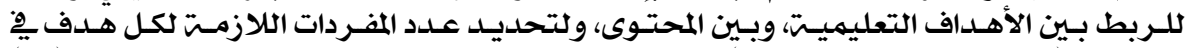

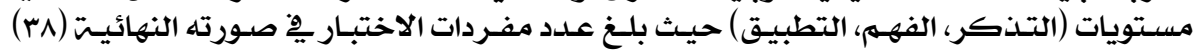
مفردة. ا-ع- وضـع تعليمـات الاختبـار: بعـد صـياغت مفـردات الاختبـار وضـع الباحـث تعليمـات الاختبـار التحصيلي.

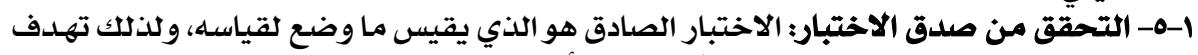

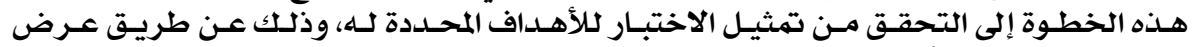

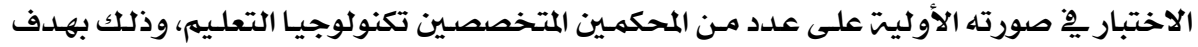

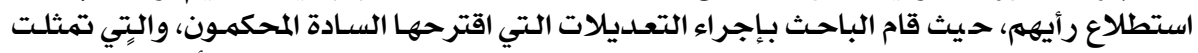

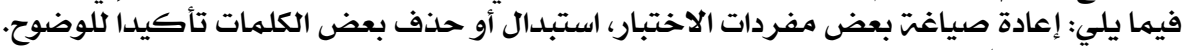

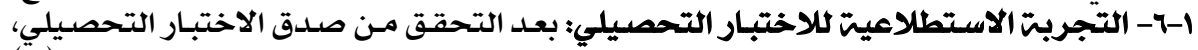

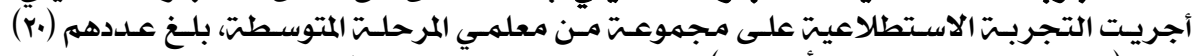

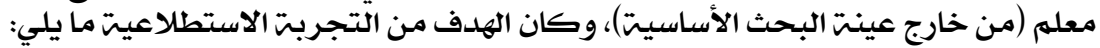




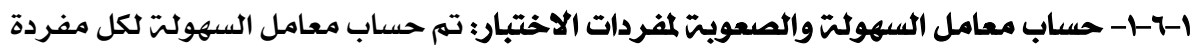

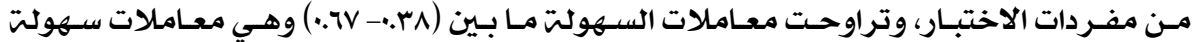

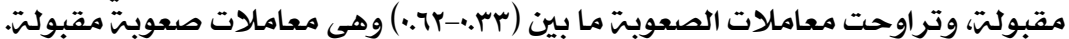

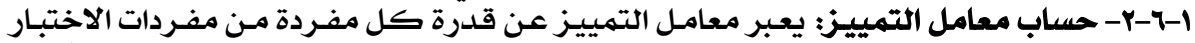

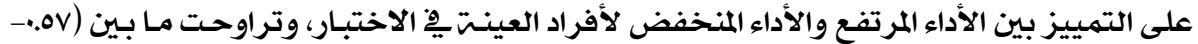

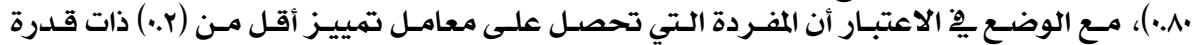

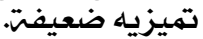

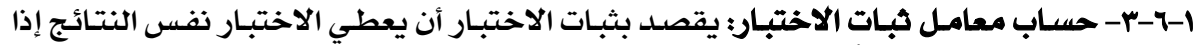

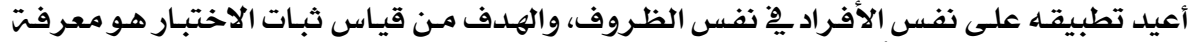

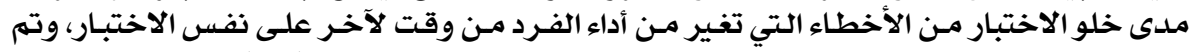

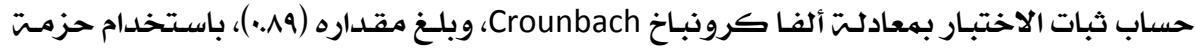

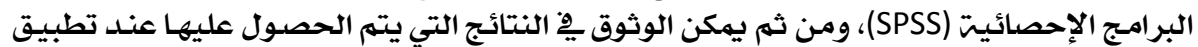

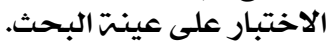

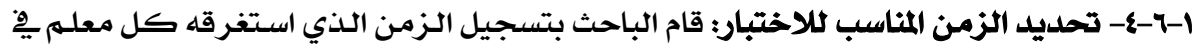

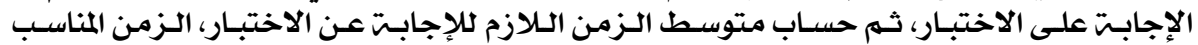

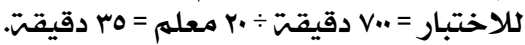

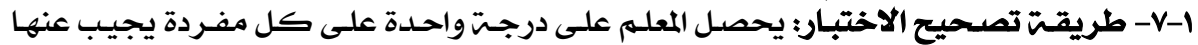

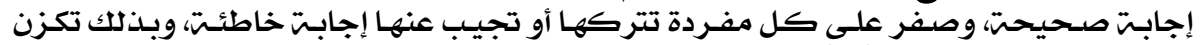

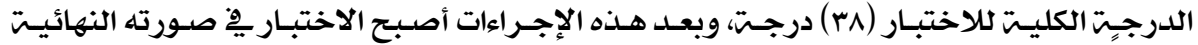

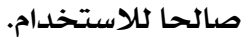

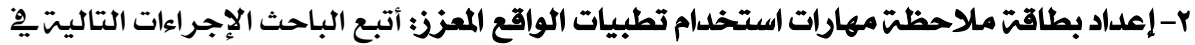

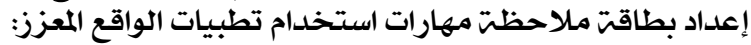

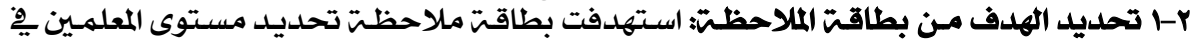

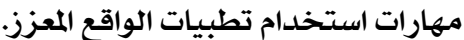

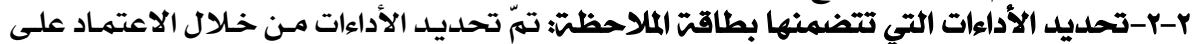

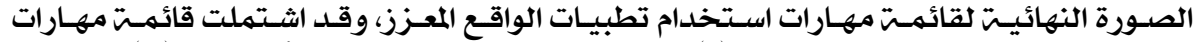

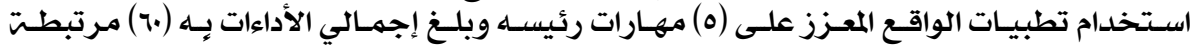

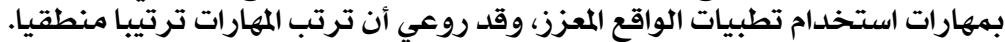

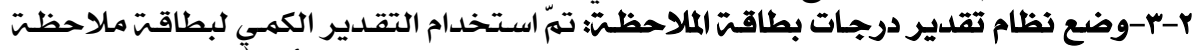

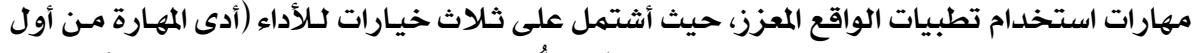

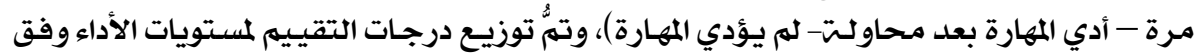
التقدير التالي: التهارة

$$
\begin{aligned}
& \text { • المستوي (أدى المهارة من أول مرة) (ץ) درجت. }
\end{aligned}
$$

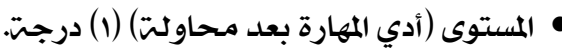

$$
\begin{aligned}
& \text { • المستوى (له يؤدي المهارة) (صفر) درجتّ. }
\end{aligned}
$$

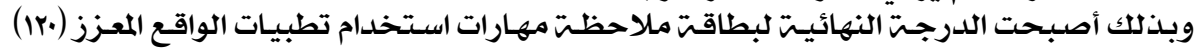

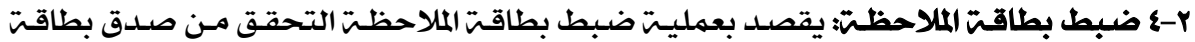

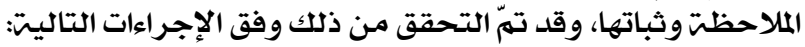

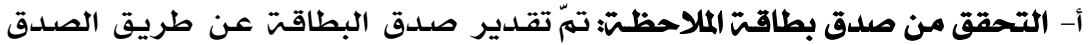

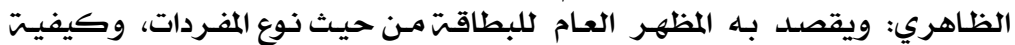




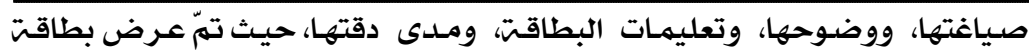

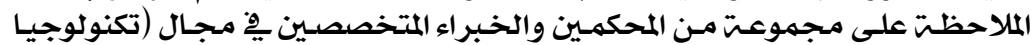

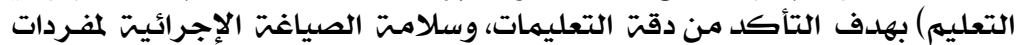
بطاقت الملاحظت ووضلافوحها، وإبداء أي تعديلات دئهات يرونها.

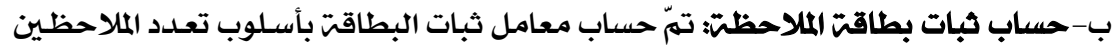

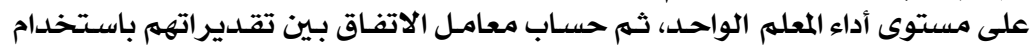

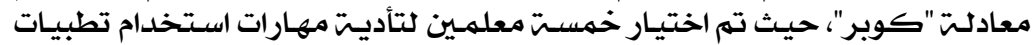

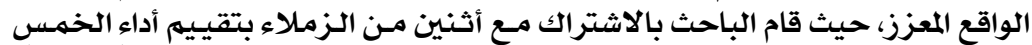

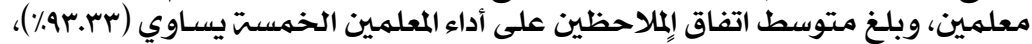

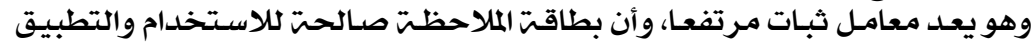

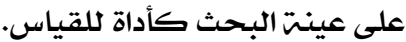

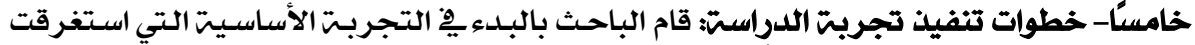

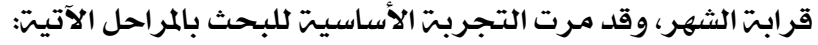

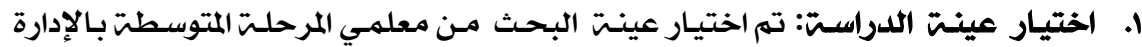

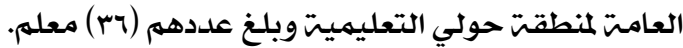

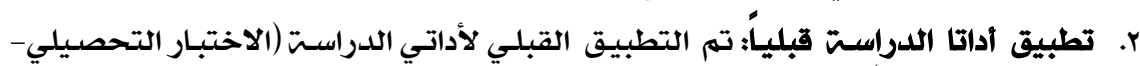

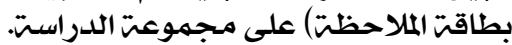

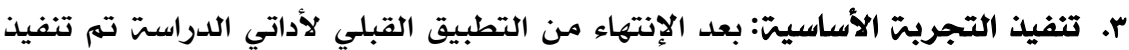

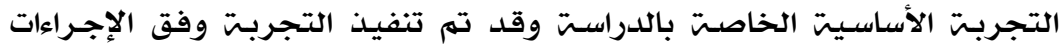

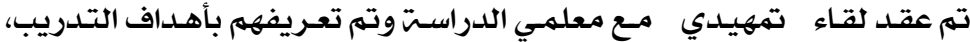

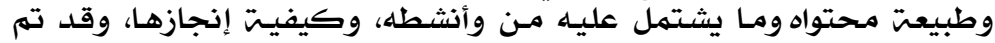

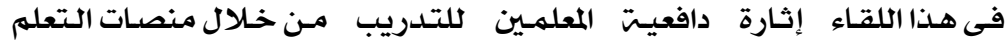
الإلكتروني التفاعليت.

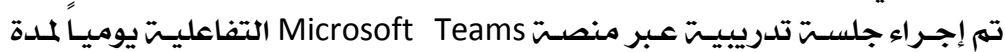

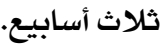

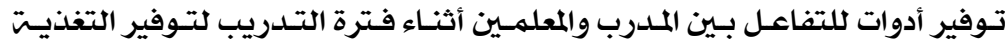
الراجعت اللازمت لهمه

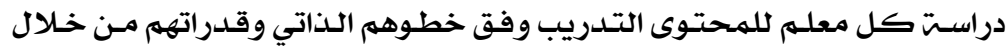

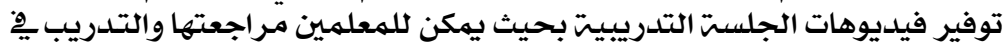
ضوفئها.

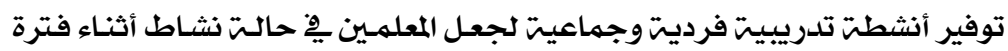

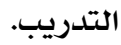

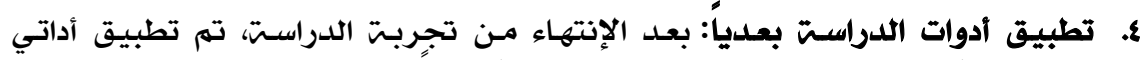

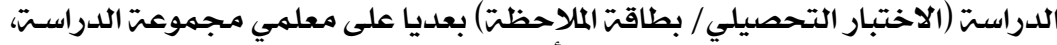
وتم تسجيل هذه النتائج ومعالجتها بالأساليب الإحصائيت المناسبتر. 


\section{نتائج الل راست وتفسيرها والتوصيات والمقترحات أولاً - اختبار فروض الد الد راستّا

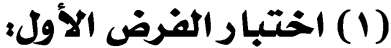

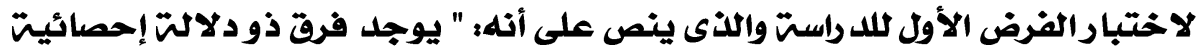

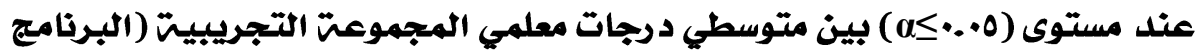

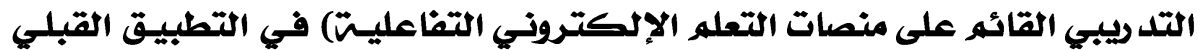

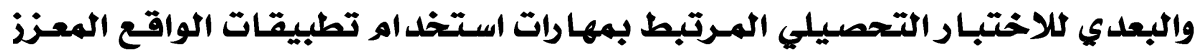

لصالح التطبيق البعدي".

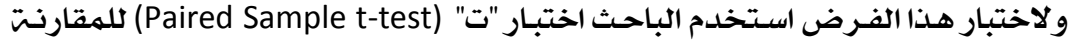

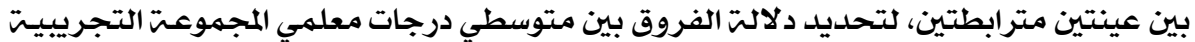

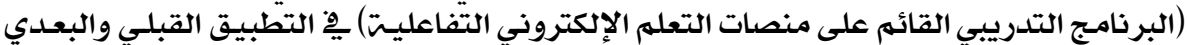

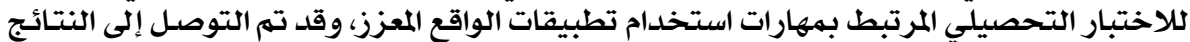

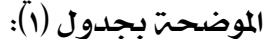

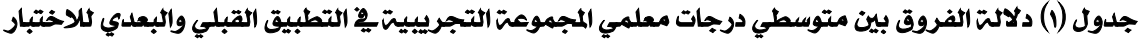

\begin{tabular}{|c|c|c|c|c|c|c|c|}
\hline مستوى الدلالة & & & & & & & \\
\hline مسلوى الدهلاس & Sig. & قيمنَ" & د.ح & المعيارى & المتوسط & ألعلد & التطبيق \\
\hline \multirow[t]{2}{*}{ دالت عند مستتوى } & \multirow[t]{2}{*}{$\because \cdots$} & & \multirow[t]{2}{*}{ ro } & 1.1790 & 1r.o. & \multirow[t]{2}{*}{ דו } & القبلي \\
\hline & & & & & & & \\
\hline
\end{tabular}

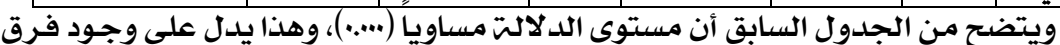

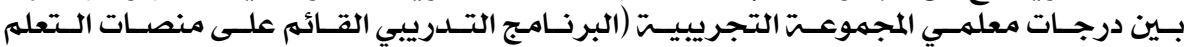

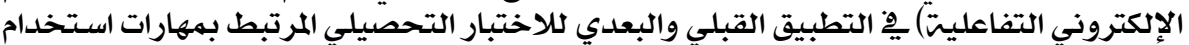

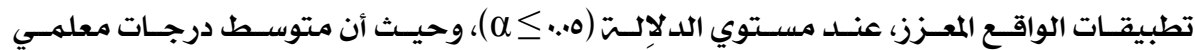

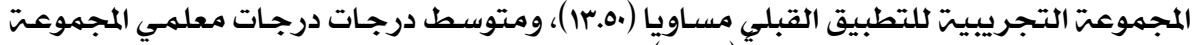

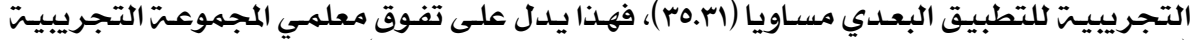

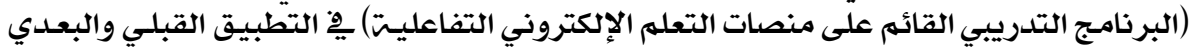

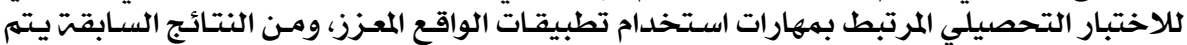

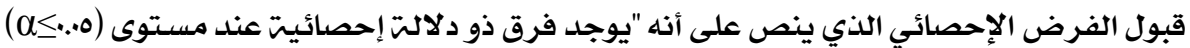

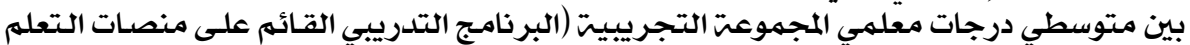

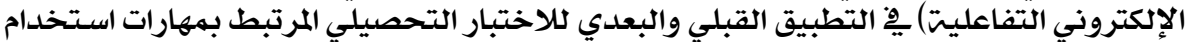
تطبيقات التواقع المعزز لصالح التطبيق التبيق البعدي". 


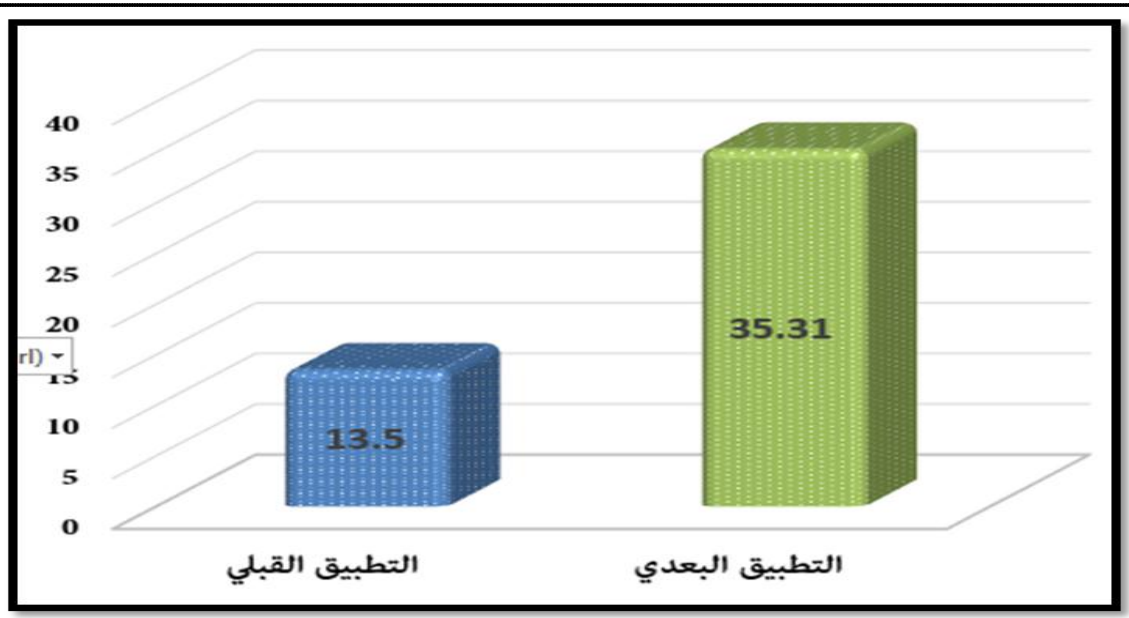

ثكل (1) متوسطي درجات معلمي المجمومت التجريبيتشيخ التطبيق القبلي والبعدي للاختبار التحصيلي المرتبط بمهارات استخدام تطبيقات الواقع المعزي

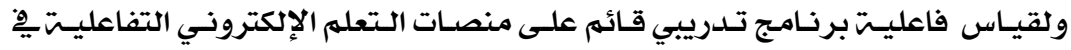

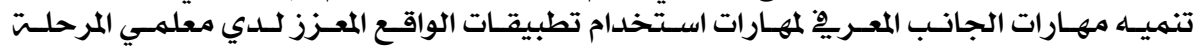

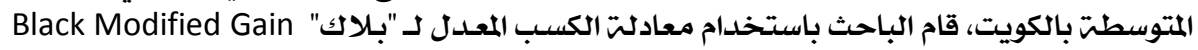

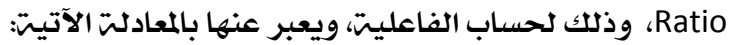

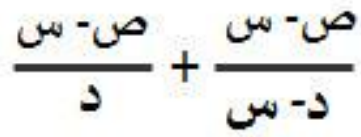

نسبت الكسب المعدل= حيث إن: تين:

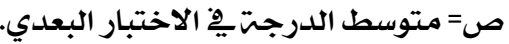

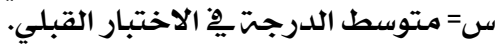

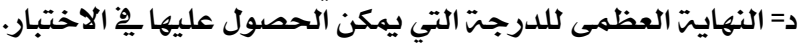

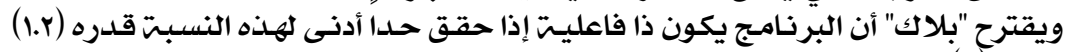

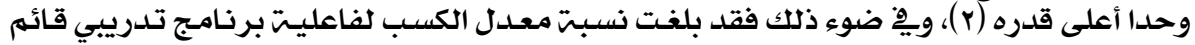

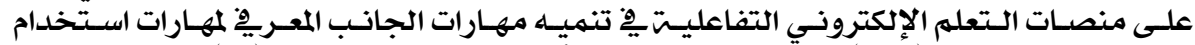

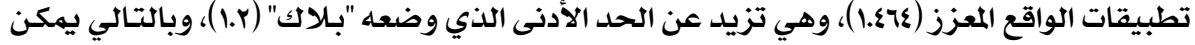

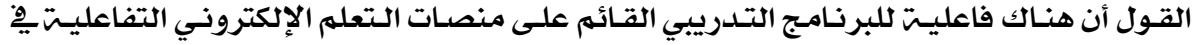

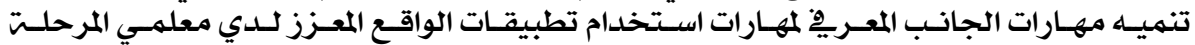
المتوسطت بالكويت. 
(r) اختبار الفرض الثاني؛

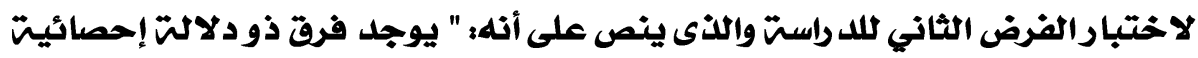

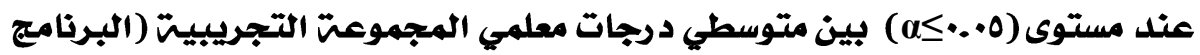

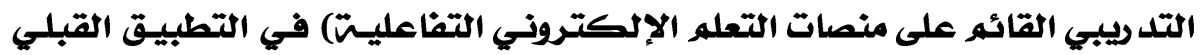

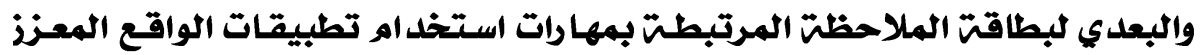
لصالح التطبيق البعدي".

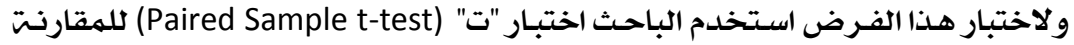

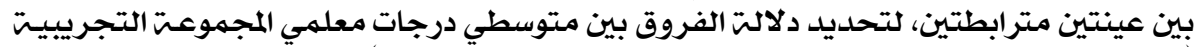

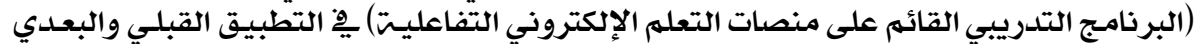

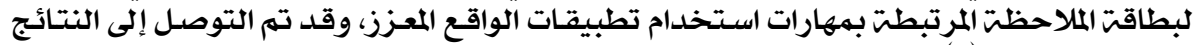

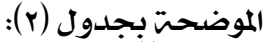

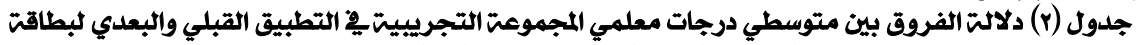

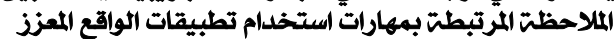

\begin{tabular}{|c|c|c|c|c|c|c|c|}
\hline مستوى الدلاكت & $\begin{array}{l}\text { الدلالة } \\
\text { Sig. }\end{array}$ & قيمت "ت" & د. & الانحصراف المعيارى & المتوسط & العدد & التطبيق \\
\hline \multirow{2}{*}{ دالت عند مستوى (0..) } & \multirow[t]{2}{*}{$\because \cdots$} & \multirow[t]{2}{*}{ v7.119 } & \multirow[t]{2}{*}{ ro } & $0 . Y_{1}$ & rV.YY & \multirow[t]{2}{*}{ ri } & القبلي \\
\hline & & & & $0.1 \cdot 1$ & IIr.rA & & البعلدي \\
\hline
\end{tabular}

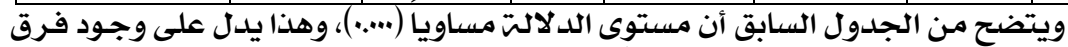

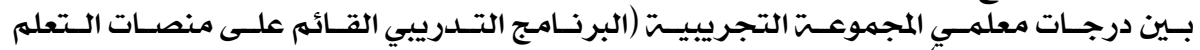

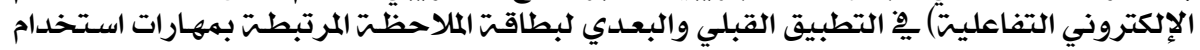

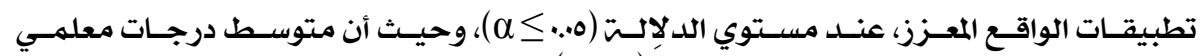

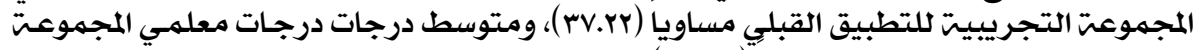

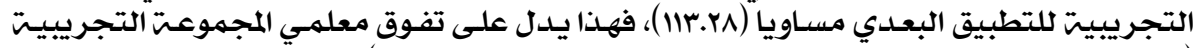

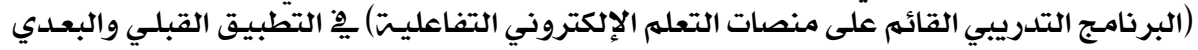

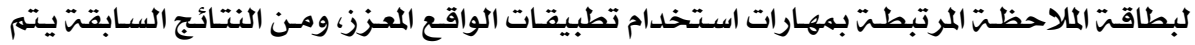

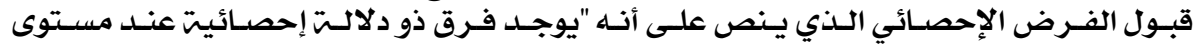

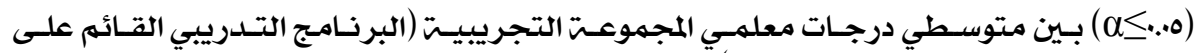

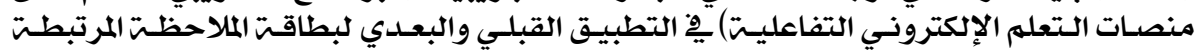

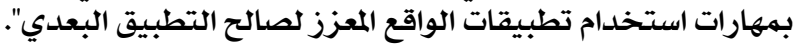




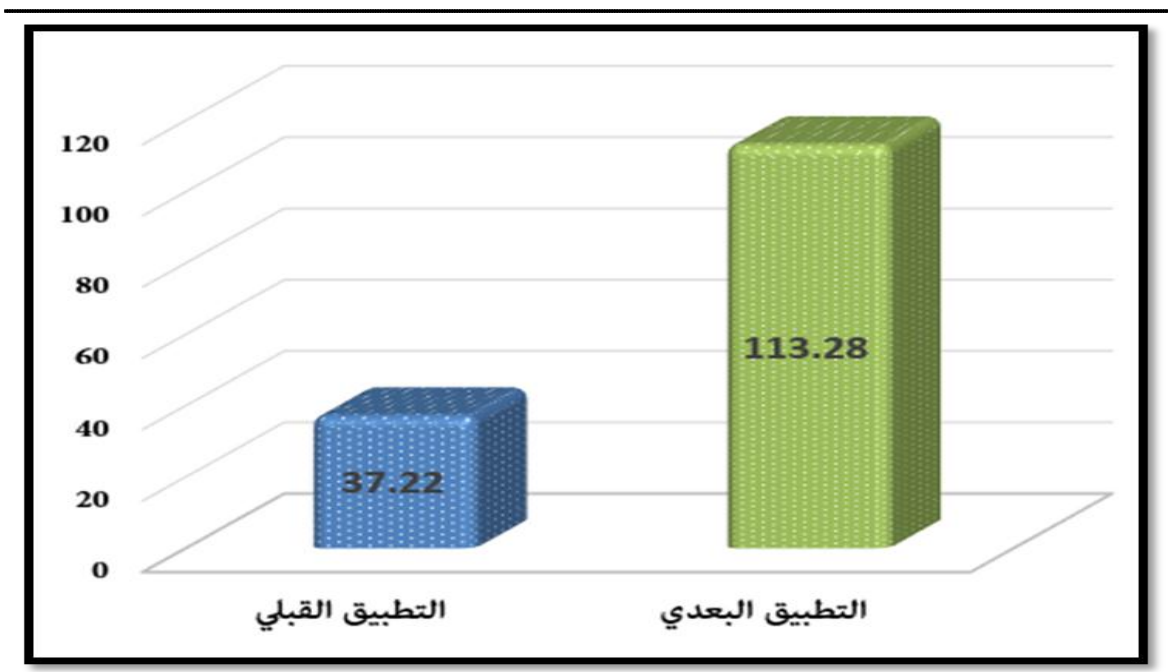

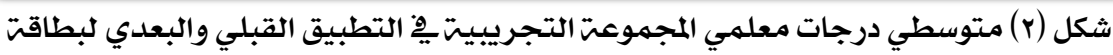

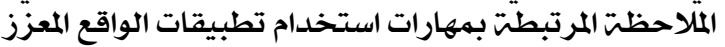

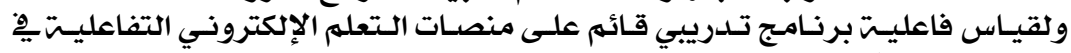

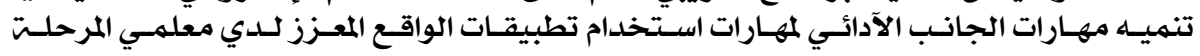

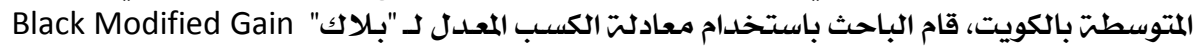

$$
\text { ص- ص- ص- }
$$

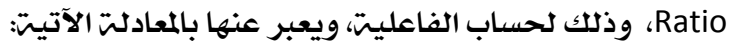
نسبت الكسب المعدل=

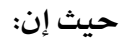
ص= متوسط الدرجت يِّ الاختبار البعدي.

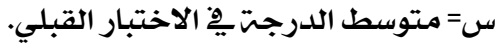

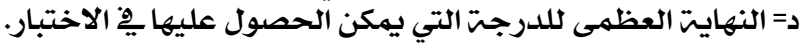

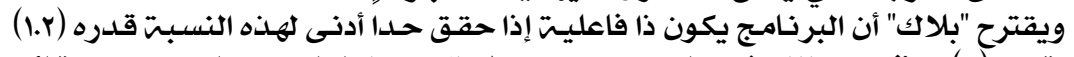

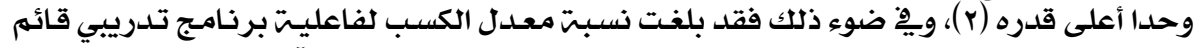

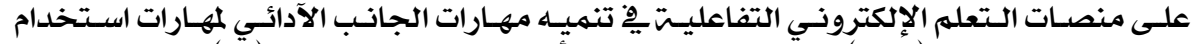

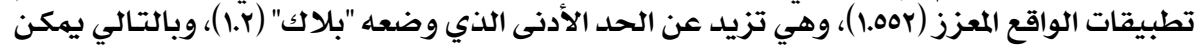

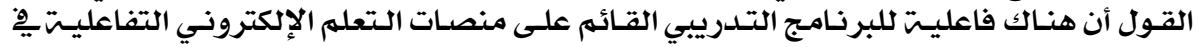

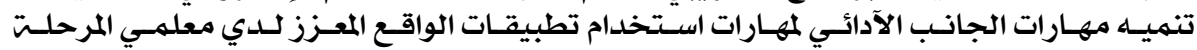
المتوسطت بالكويت.

\section{ثانياً - مناقشتّ وتمسير نتائج الد راستريت}

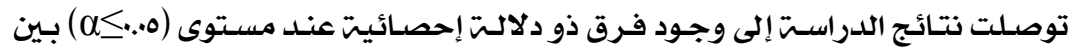

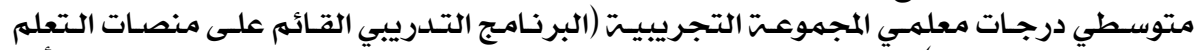

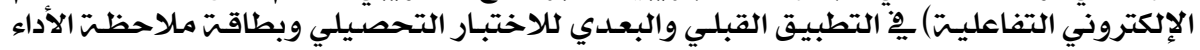

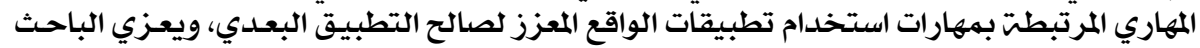

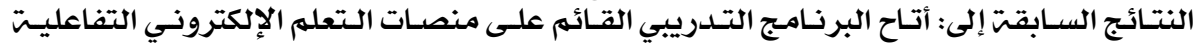

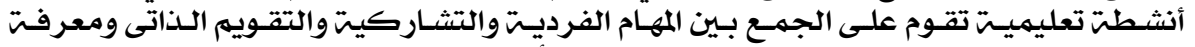

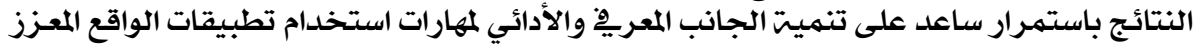




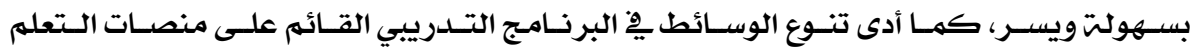

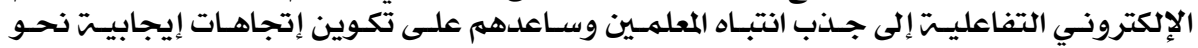

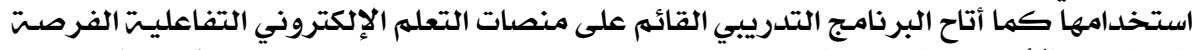

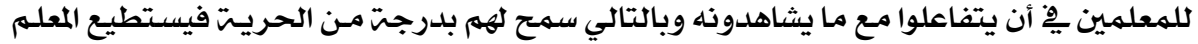

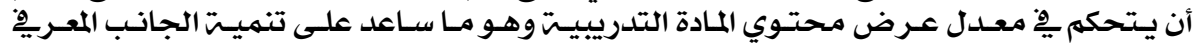

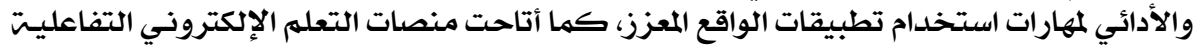

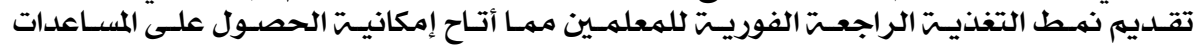

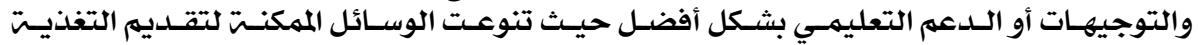

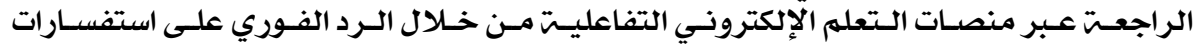

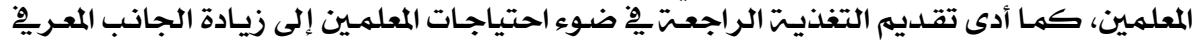

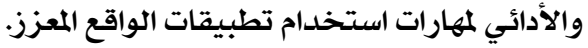

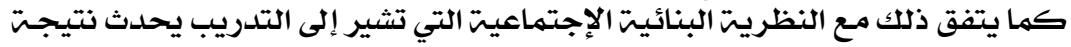

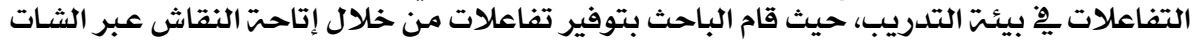

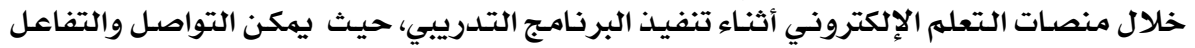

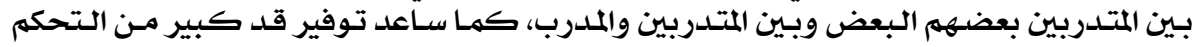

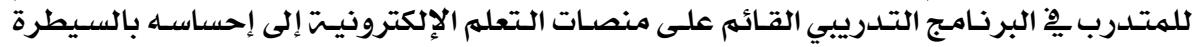

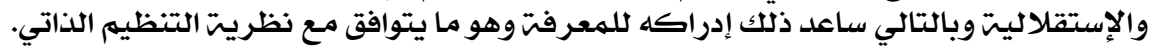

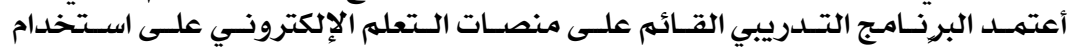

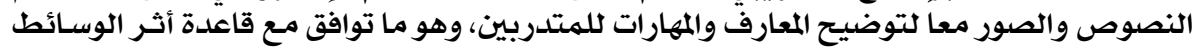

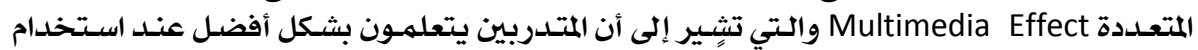

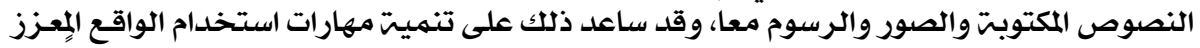

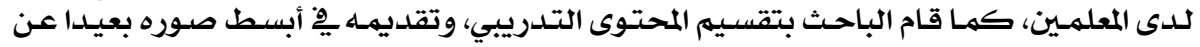

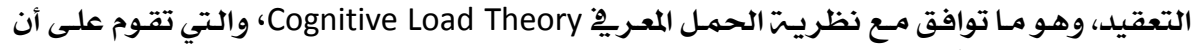

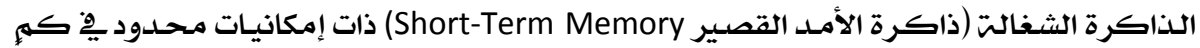

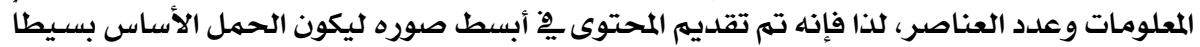

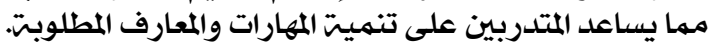

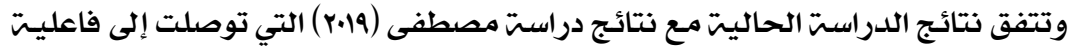

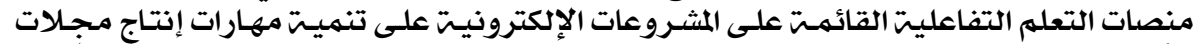

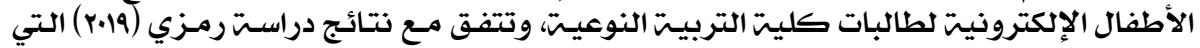

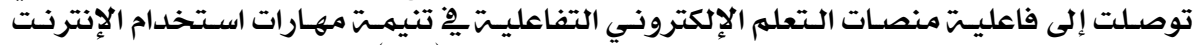

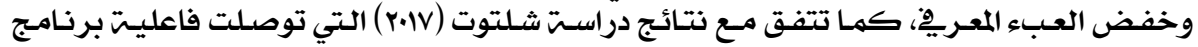

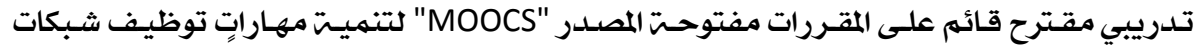

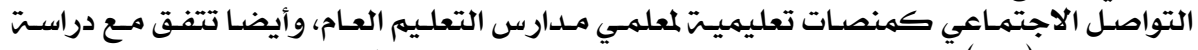

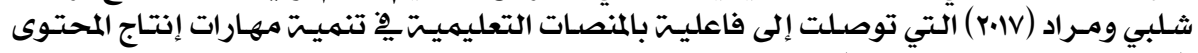

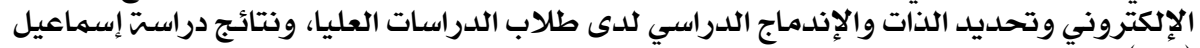

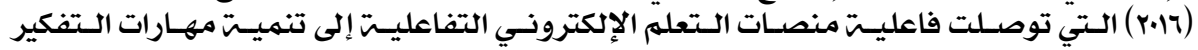

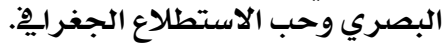


ثالثثاً توصيات الد راستّات

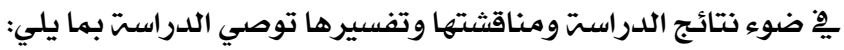

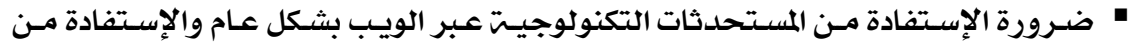

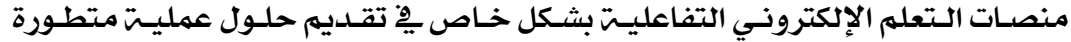

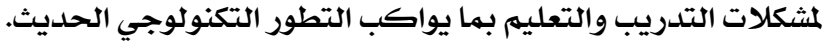

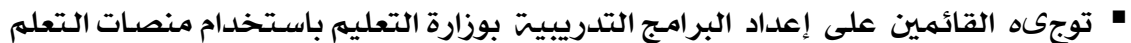

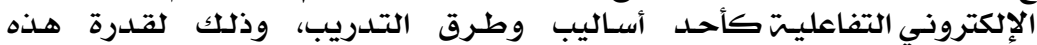

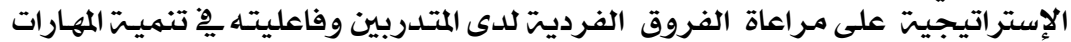

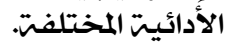

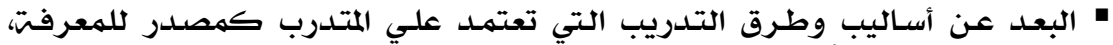

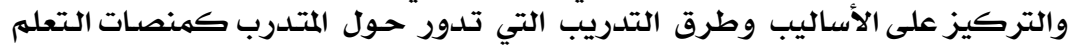

$$
\text { الإلكتروني التفاعليت. }
$$

رابعاً - مقترحات الد راستراء

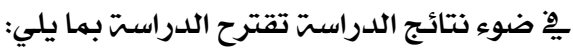

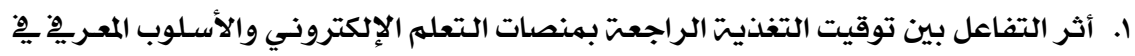

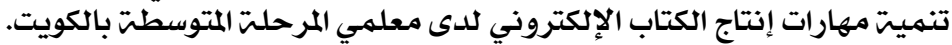

r. نهط التغذيـت الراجعت القائهـت على التحلـيلات التعليميـت بهنصـات التعلهم الإلكتروني

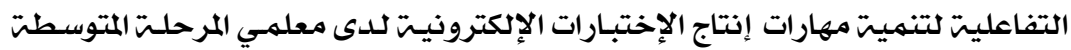

بالكويت.

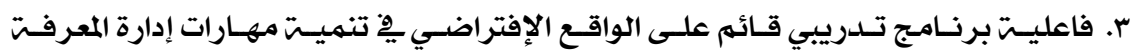

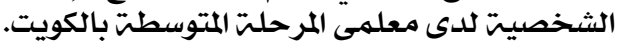




\section{المراجع}

\section{أولاً - المراجع العربيت:}

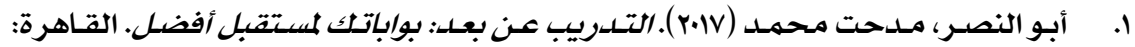

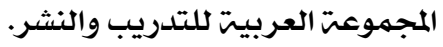

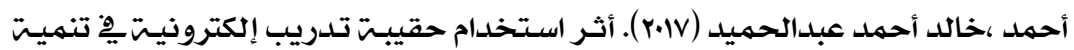

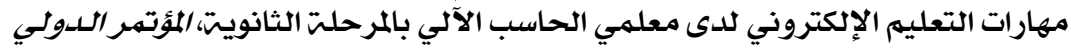

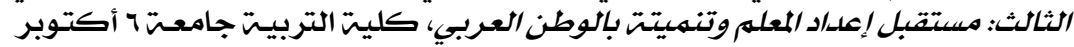

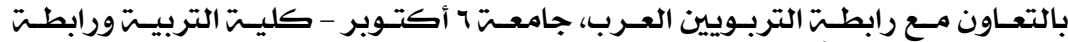

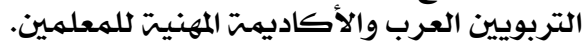

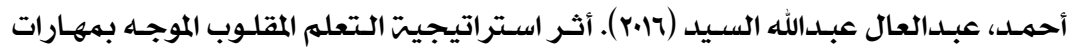

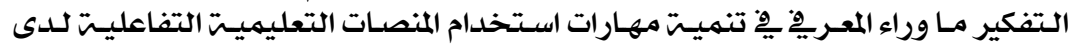

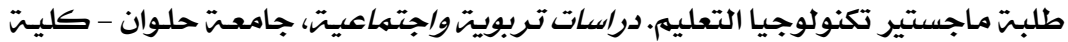

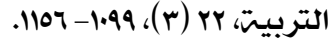

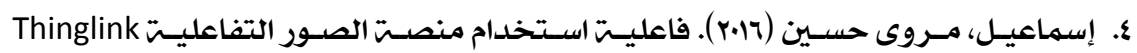

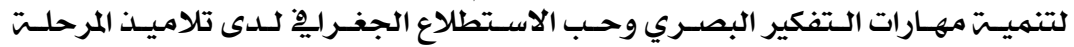

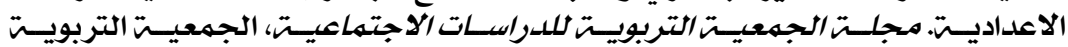

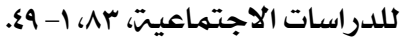

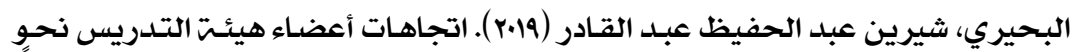

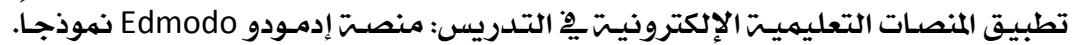

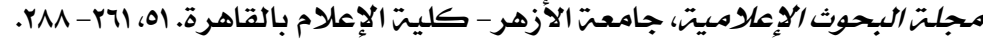

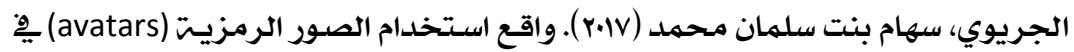

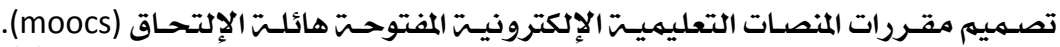

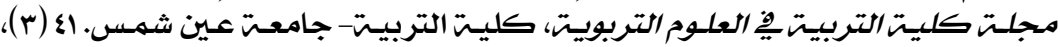
.TV $-1 \varepsilon$

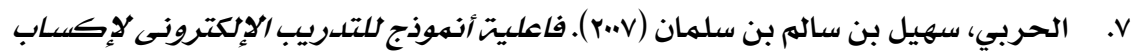

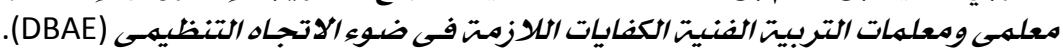

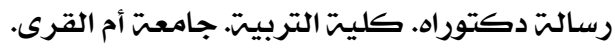

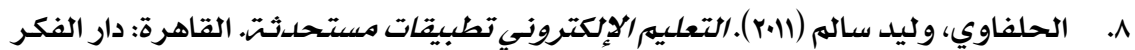
العربي.

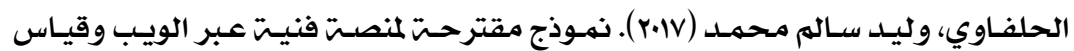

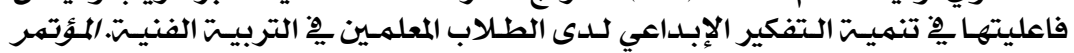

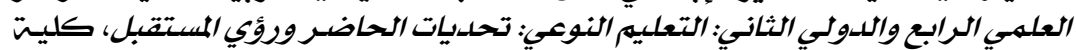

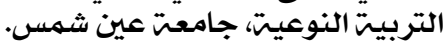

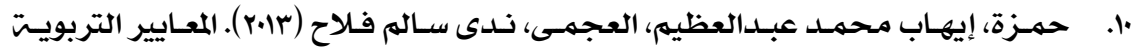

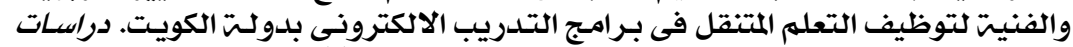

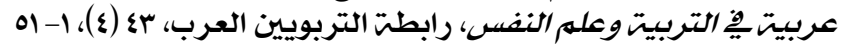




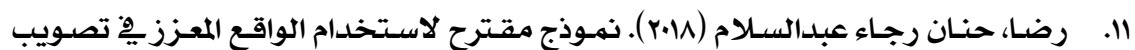

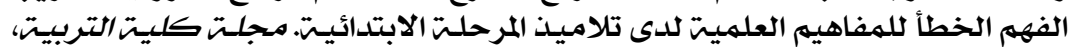

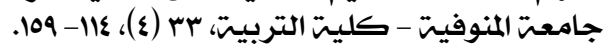

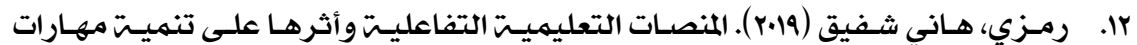

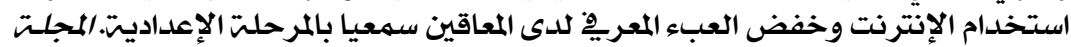

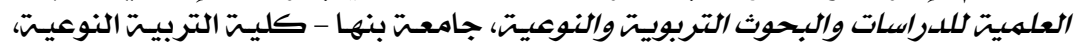
$.17 r-1.0 ،$

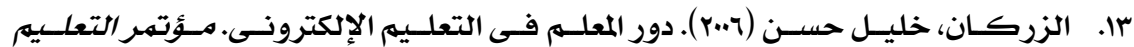
الاكلكتروني-جامعت البحرين.

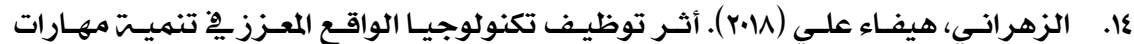

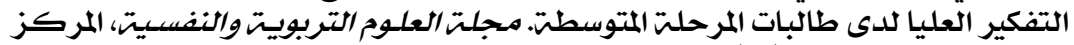

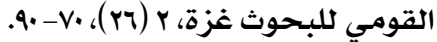

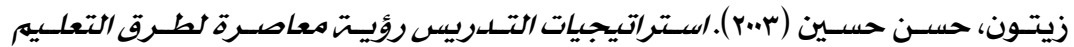

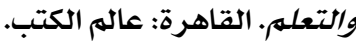

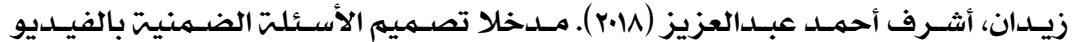

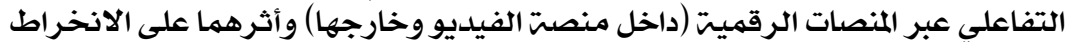

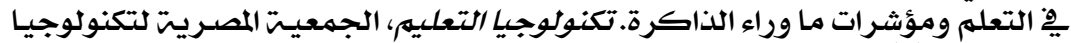

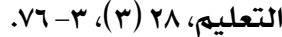

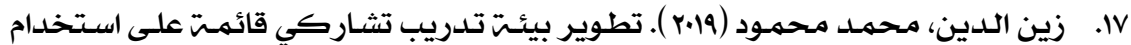

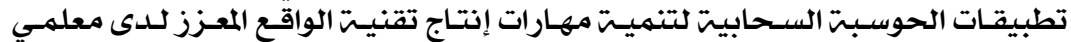

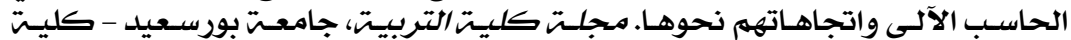

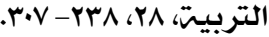

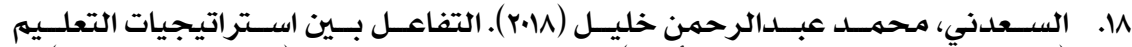

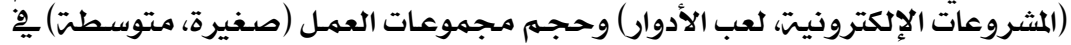

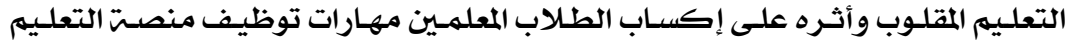

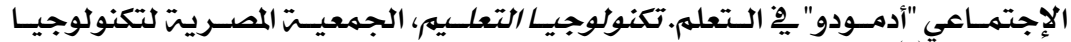

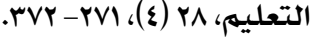

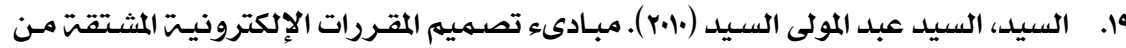

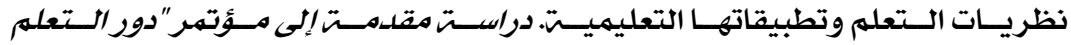

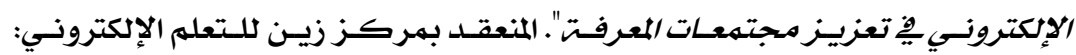
جامعت البحرين.

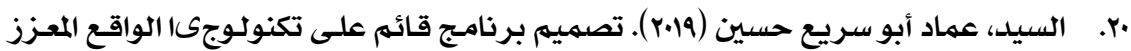

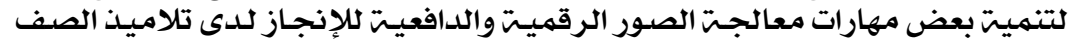

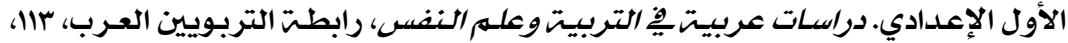




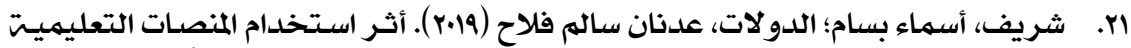

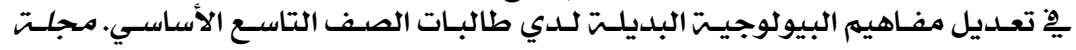

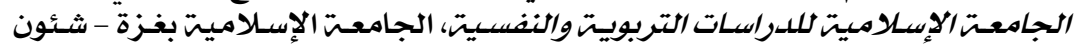

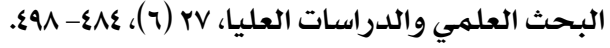

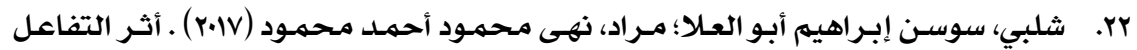

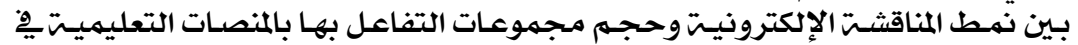

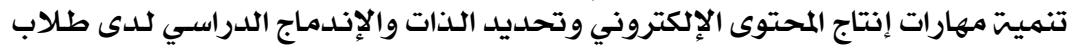

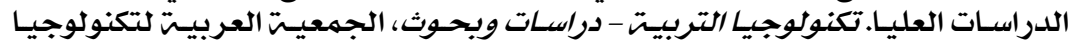

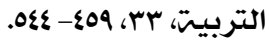

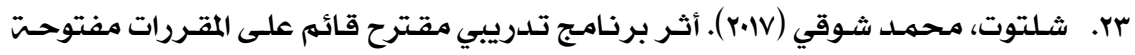

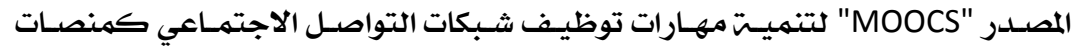

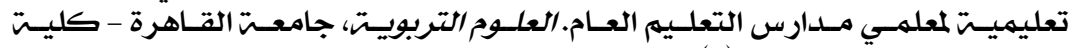

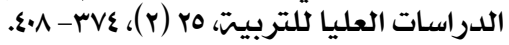

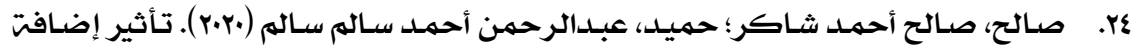

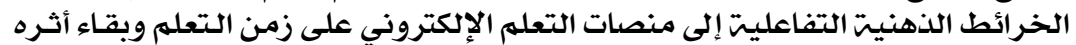

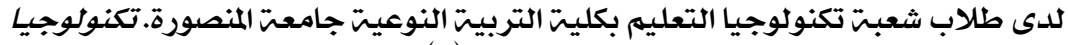

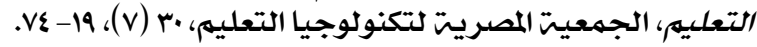

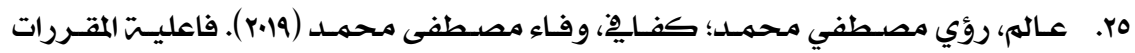

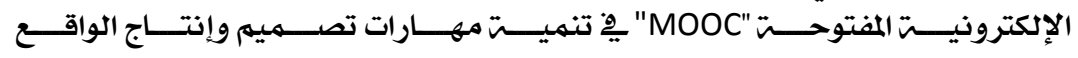

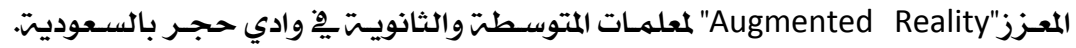

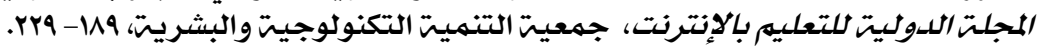

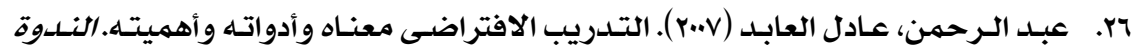

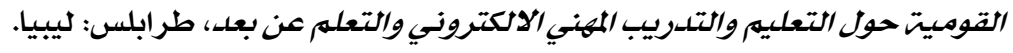

VV

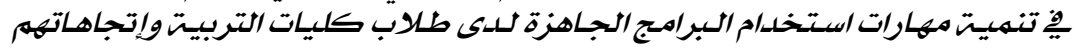

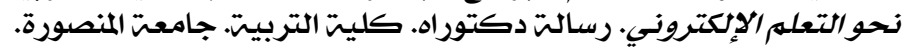

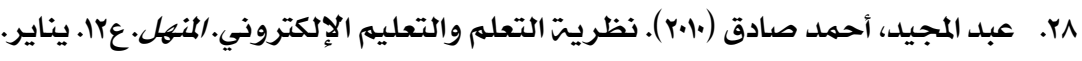

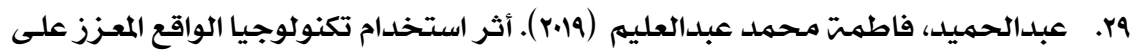

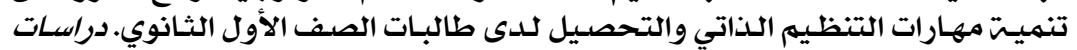

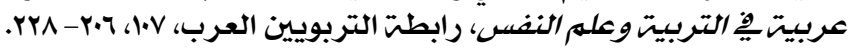

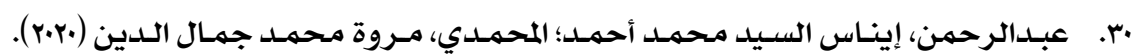

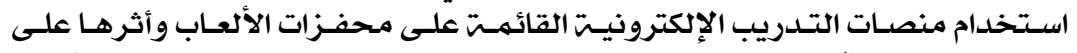

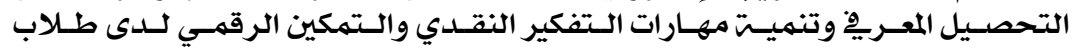

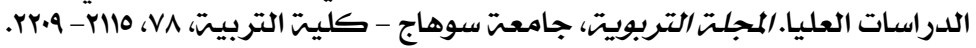

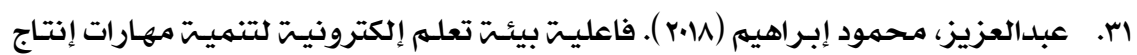

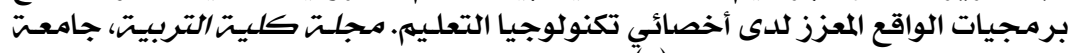

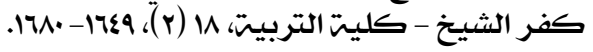




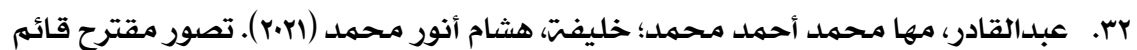

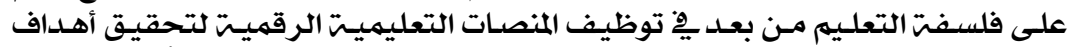

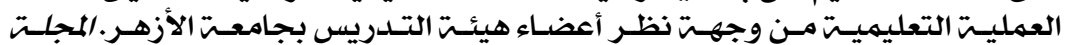

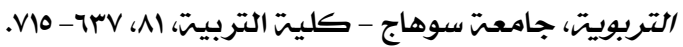

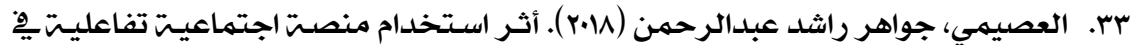

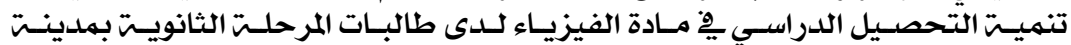

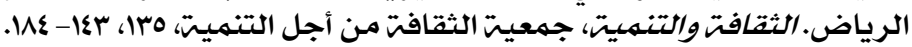

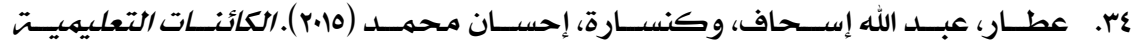
وتكنولوجيا النانو. الرياض: مكتبت الملكك فهد الوطنيت للنشر والتوزيع.

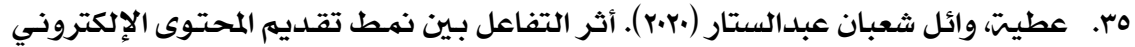

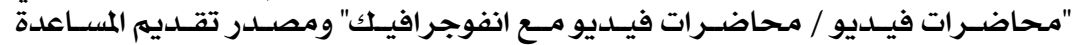

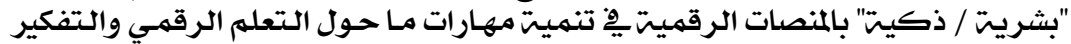

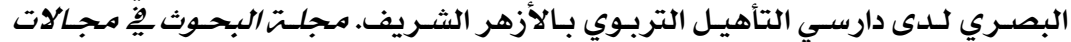

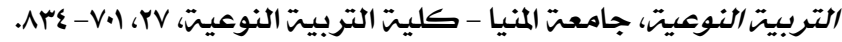

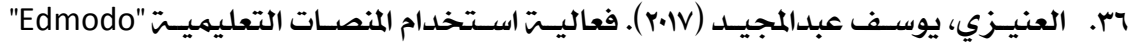

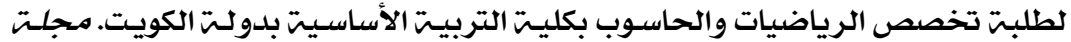

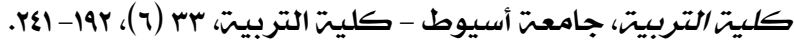

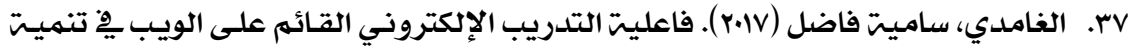

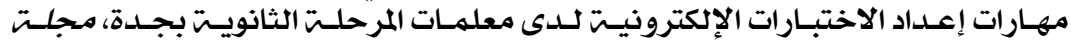

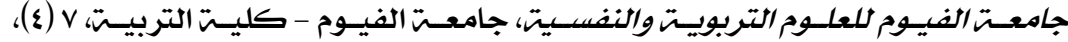

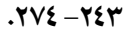

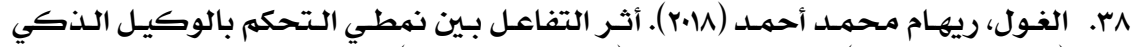

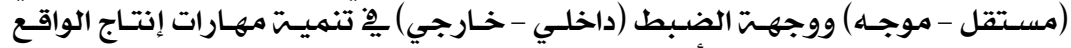

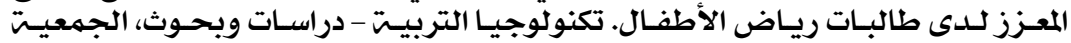

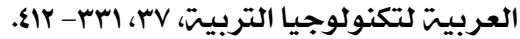

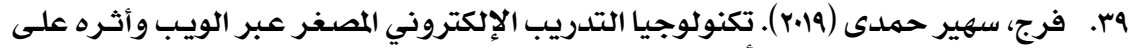

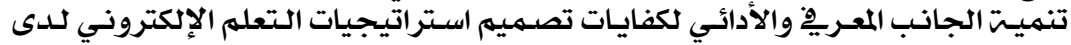

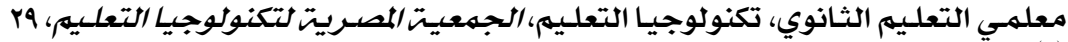

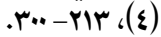

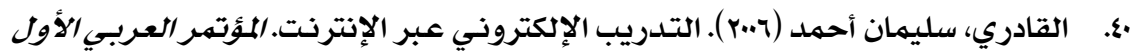

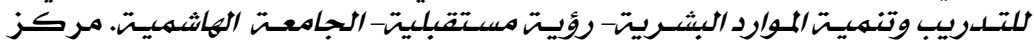

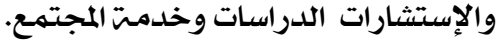

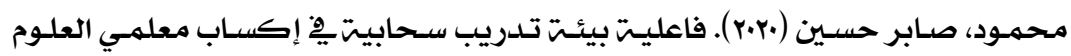
. 1

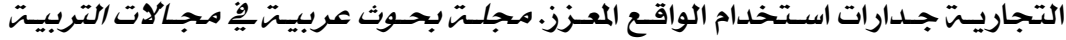

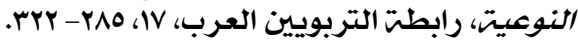




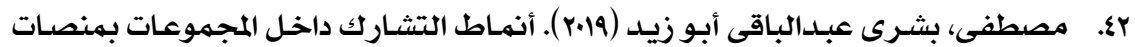

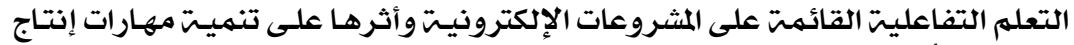

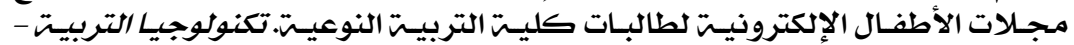

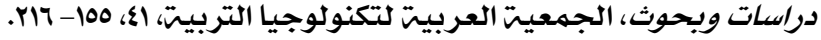

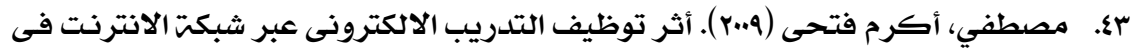

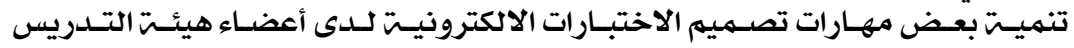

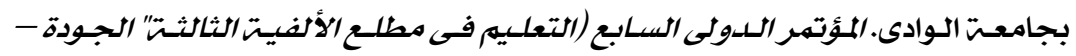

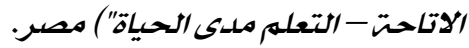

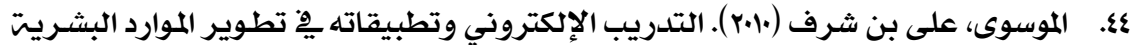

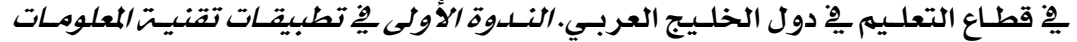

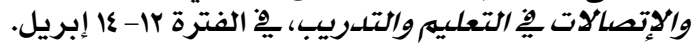

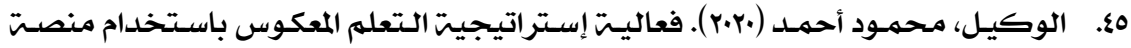

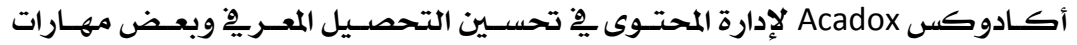

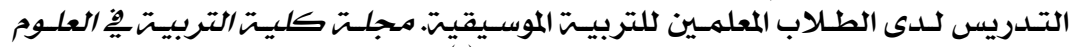
التربويتة، جامعت عين شمس المس - كليت التربيتة، ع؛ (1)، 79- 177.

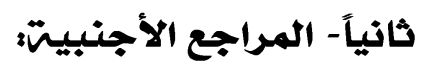

46. Abd Majid, N., Mohammed, H. \& Sulaiman, R. (2015). Students' perception of mobile augmented reality applications in learning computer organization. Procedia Social and Behavioral Sciences. 176. 111 - 116.

47. Adzobu, N. (2014). Design, Use and Evaluation of E-Learning Platforms: Experiences and Perspectives of a Practitioner from the Developing World Studying in the Developed World, Informatics, 1, 147-159.

48. Akçayır, M., Akçayır, G., Pektas, H. M., \& Ocak, M. A. (2016). Augmented Reality In Science Laboratories: The Effects Of Augmented Reality On University Students' Laboratory Skills And Attitudes Toward Science Laboratories. Computers In Human Behavior. 57 (88). 334-342.

49. Amandu, G., Muliira, J. \& Fronda, D. (2013). Using moodle elearning platform to foster student self-directed learning: Experiences with utilization of the software in undergraduate nursing courses in a Middle Eastern university. Procedia Social and Behavioral Sciences, 93, 677-683. 
50. Arkorful, V. (2017). Awareness and Use of Electronic Learning Platforms: A Case of a Developing Country. World Journal of Computer Application and Technology, 5(2), 13-23.

51. Carmigniani, J. \& Furht, B. (2011). Augmented Reality: An Overview. B. Furht (ed.), Handbook of Augmented Reality, Springer Science+Business Media.

52. Ch, S. \& Popuri, S. (2013).Impact of online education: A study on online learning platforms and edX, 2013 IEEE International Conference in MOOC, Innovation and Technology in Education (MITE), 366-370.

53. Chen, C. \& Tsai, Y. (2012). Interactive Augmented Reality System For Enhancing Library Instruction In Elementary Schools. Computers \& Education. 59 (22). 638-652.

54. Diaza, C., Hincapiéb, M. \& Morenoc, G. (2015). How The Type Of Content In Educative Augmented Reality Application Affects The Learning Experience. Procedia Computer Science .75. $205-212$.

55. Dunleavy, M. (2014). Design Principles For Augmented Reality Learning. Tec trends. 58 (1). 28-34.

56. Ghavifekr, S. \& Rosdy, W. (2015). Teaching and learning with technology: Effectiveness of ICT integration in schools. International Journal of Research in Education and Science (IJRES), 1(2), 175-191.

57. Homanova, Z. \& Prextova, T. (2017). Educational Networking Platforms Through the Eyes of Czech Primary School Students. Academic Conferences International Limited, European Conference on e-Learning; Kidmore End, 195-204.

58. Judith, B. (2002). An Assessment of the Effectiveness of ELearning in Corporate Training Programs. The International Review of Research in Open and Distance Learning. 3 (1).

59. Khan, I. (2016). Effectiveness of E-learning for the Teaching of English: A Study of Comparative Strategies, Advances in Language and Literary Studies, 7 (3). 
60. König, J., Jäger-Biela, D. \& Glutsch, N. (2020) Adapting to online teaching during COVID-19 school closure: teacher education and teacher competence effects among early career teachers in Germany, European Journal of Teacher Education, 43 (4), 608-622.

61. Mai, N. (2004). Cooperative Learning on the Web: A Group Based, Student Centered Learning Experience in the Malaysian Classroom. Australasian Journal of Educational Technology. 20 (2).

62. Matcha, W. \& Rambli, D. (2013). Exploratory study on collaborative interaction through the use of Augmented Reality in science learning. Procedia Computer Science. 25. $144-153$

63. Microsoft (2020). Microsoft Teams More ways to be a team, available in 22/12/2020, on: https://www.microsoft.com/en/microsoft-teams/group-chatsoftware

64. Oproiu, G. (2015). A Study about Using E-learning Platform (Moodle) in University Teaching Process. Procedia - Social and Behavioral Sciences, 180, $426-432$.

65. Parker, M. \& Martin, F. (2010). Using virtual classrooms: Student perceptions of features and characteristics in an online and a blended course, MERLOT Journal of Online Learning and Teaching, 6 (1).

66. Radu, I. (2014). Augmented Reality In Education: A MetaReview And Cross-Media Analysis. Personal And Ubiquitous Computing. 18(6). 1-11.

67. Roger, M. \& Dianne, S. (2006). Adding an Online Component to a Teacher Training Program Helps. Learning \& Leading with Technology. 33 (17). 32-35.

68. Salmi, H., Kaasinen, A., \& Kallunki, V. (2012). Towards an Open Learning Environment via Augmented Reality (AR): Visualising the Invisible in Science Centres and Schools for Teacher Education. Procedia - Social and Behavioral Sciences, 45(0), 284-295. 
69. Sandybayev. A. (2020).The Impact of E-Learning Technologies on Student's Motivation: Student Centered Interaction in Business Education. International Journal of Research in Tourism and Hospitality (IJRTH), 6 (1), 16-24.

70. Serio, A., Ibáñez, M. \& Kloos, C. (2013). Impact of an augmented reality system on students' motivation for a visual art course. Computers \& Education. 68. 586-596.

71. Stonebraker, I., Robertshaw, M. \& Moss, D. (2016). Student See versus Student Do: A Comparative Study of Two Online Tutorials. Linking Research and Practice to Improve Learning, 60 (2), 176-182.

72. Tsai, P. (2018) Business Chat Apps in 2018: Top Players and Adoption Plans 20 December. The Spice works Community. [Online]. Available from: https://community.spiceworks.com/blog/3157-business-chatapps-in-2018-topplayers-and-adoption-plans.

73. Tschida, C., Hodge, E., \& Schmidt, S. (2016). Learning to teach online: Negotiating issues of platform, pedagogy and professional development. In V. Wang (Ed.), Handbook of research on learning outcomes and opportunities in the digital age (pp. 664-684). Hershey, PA: Information Science Reference.

74. William, J. (2005). Transforming a Traditional Personnel Preparation Program in Orientation and Mobility into an Online Program At The University Of Arkansas At Little Rock. JVIB. 99 (11). 1-10.

75. Wu, H., Lee, S. W., Chang, H., \& Liang, J. (2013). Current Status, Opportunities, And Challenges Of Augmented Reality In Education. Computers and Education. 62 (13). 41-49.

76. Yuen, S., Yaoyuneyong, G. \& Johnson, E. (2011). Augmented Reality: An Overview And Five Directions For AR In Education. Journal of educational technology development and exchange .4. 119-140. 